Illinois State University

ISU ReD: Research and eData

Theses and Dissertations

7-24-2017

\title{
Elucidating The Molecular Parameters And Mechanism Of Homology Searching During Meiosis In Neurospora Crassa
}

Nicholas Adam Rhoades

Illinois State University, nrhoade@ilstu.edu

Follow this and additional works at: https://ir.library.illinoisstate.edu/etd

Part of the Genetics Commons, and the Molecular Biology Commons

\section{Recommended Citation}

Rhoades, Nicholas Adam, "Elucidating The Molecular Parameters And Mechanism Of Homology Searching During Meiosis In Neurospora Crassa" (2017). Theses and Dissertations. 813.

https://ir.library.illinoisstate.edu/etd/813

This Thesis is brought to you for free and open access by ISU ReD: Research and eData. It has been accepted for inclusion in Theses and Dissertations by an authorized administrator of ISU ReD: Research and eData. For more information, please contact ISUReD@ilstu.edu. 


\title{
ELUCIDATING THE MOLECULAR PARAMETERS AND MECHANISM OF HOMOLOGY \\ SEARCHING DURING MEIOSIS IN NEUROSPORA CRASSA
}

\author{
Nicholas A. Rhoades
}

\section{Pages}

Integration of foreign DNA into a host genome is often detrimental to the host organism, as the DNA is often of viral or transposon origin. Many organisms have established DNA surveillance and genome integrity mechanisms to defend against these harmful DNA insertions. Neurospora crassa, a filamentous fungus belonging to the Ascomycota group, has several DNA defense mechanisms to combat foreign DNA integration to its genome. One such mechanism is Meiotic Silencing of Unpaired DNA (MSUD). During meiosis, this remarkable system can detect unpaired genes on homologous chromosomes during sexual reproduction and silence their expression throughout meiosis. In order to detect this unpaired DNA (unDNA), the MSUD machinery must be able to, somehow, search through $N$. crassa's 40 million base-pair genome for homology and be able to pick out individual genes that lack pairing partners on their respective homologous chromosomes.

In the following studies, we present research to describe what parameters are sufficient and required for unDNA to be characterized as unpaired to the MSUD machinery. First, to shed light upon how unDNA is detected, we designed experiments to determine what physical properties of DNA affect MSUD. To do this, we introduced large unpaired regions of DNA surrounding an unpaired genetic marker into the $N$. crassa genome and measured the MSUD efficiency of these crosses by observing ascospore phenotype ratios. These large unpaired 
regions may form complex unpaired DNA structures that could affect how MSUD detects unDNA. We have found that as the length of unDNA increases, detection of unDNA by MSUD becomes less efficient, suggesting that these large, unpaired regions may be interfering with MSUD's ability to detect unpaired genes.

We have also designed experiments to observe how sequence homology plays a role in detection of unDNA. To achieve this, we designed several fragments of DNA that have patterns of interspersed homology to a common genetic marker. These interspersed homology fragments share similar levels of homology to the genetic marker, while the pattern of interspersed homology differs. We have found that certain patterns of interspersed homology are more efficient at being detected as unpaired than others, suggesting that sequence-level homology patterns may play a role in homology searching.

KEYWORDS: Meiosis; Transposable Elements; Homologous Chromosomes; Homology Searching; Genome Defense 


\title{
ELUCIDATING THE MOLECULAR PARAMETERS AND MECHANISM OF HOMOLOGY
}

SEARCHING DURING MEIOSIS IN NEUROSPORA CRASSA

\author{
NICHOLAS A. RHOADES
}

\author{
A Thesis Submitted in Partial \\ Fulfillment of the Requirements \\ for the Degree of

\section{MASTER OF SCIENCE} \\ School of Biological Sciences \\ ILLINOIS STATE UNIVERSITY
}


Copyright 2017 Nicholas A. Rhoades 


\title{
ELUCIDATING THE MOLECULAR PARAMETERS AND MECHANISM OF HOMOLOGY
}

SEARCHING DURING MEIOSIS IN NEUROSPORA CRASSA

\author{
NICHOLAS A. RHOADES
}

COMMITTEE MEMBERS:

Thomas M. Hammond, Chair

Alysia Vrailas-Mortimer

Nathan Mortimer 


\section{ACKNOWLEDGMENTS}

Thank you to my committee, current, and former Hammond lab members, without whom I would not have been able to complete the work presented in this thesis.

To Nate and Alysia, thank you for always having time to discuss my work and for listening to me complain about it when things do not work. I could not have chosen a better committee; you guys made grad school a lot less painful just by being around.

To all my grad school friends, thank you for all the nights of drinking that went a little too late and a little too hard sometimes.

Finally, to Tom, thank you for everything you have done for me in the last 4 years. It certainly does not feel like 4 years sometimes. Thank you for allowing me to work in your lab and giving me the opportunity to further my scientific career; I honestly do not know what I would be doing without this lab. Perhaps we will work together in the future.

Peace out, ISU.

N. A. R. 


\section{CONTENTS}

\section{Page}

ACKNOWLEDGMENTS

CONTENTS

TABLES $\quad$ iv

FIGURES

CHAPTER I: GENOME SURVEILENCE IN NEUROSPORA CRASSA 1

$\begin{array}{ll}\text { Abstract } & 1\end{array}$

Neurospora crassa: A Model Organism 2

MSUD: Literature Review $\quad 4$

$\begin{array}{ll}\text { References } & 19\end{array}$

CHAPTER II: UNPAIRED GENE DETECTION AND HOMOLOGY SEARCH

PARAMETERS IN MSUD 23

$\begin{array}{ll}\text { Abstract } & 23\end{array}$

$\begin{array}{ll}\text { Introduction } & 24\end{array}$

$\begin{array}{ll}\text { Materials And Methods } & 27\end{array}$

$\begin{array}{ll}\text { Strain And Culture Information } & 27\end{array}$

$\begin{array}{ll}\text { DNA Vector Construction } & 27\end{array}$

Transformation And Homokaryon Isolation Methods 28

Quantitative Sexual Crosses And Spore Collection 28

$\begin{array}{ll}\text { Results } & 29\end{array}$

The Region Between ncu09279 And ncu09430 Is Not Required For Spindle-shaped

$\begin{array}{ll}\text { Ascospores } & 30\end{array}$ 
MSUD Is Less Efficient At Detecting unDNA In The Presence Of Complex DNA

$\begin{array}{ll}\text { Structures } & 30\end{array}$

Sequence Homology Patterns Can Effect MSUD Efficiency 31

Insertion Of A Non-homologous Fragment Of DNA Reduces unDNA Detection 32

Some Sequence Homology Patterns Are Ignored By MSUD 33

$\begin{array}{ll}\text { Discussion } & 34\end{array}$

Complex DNA Affects unDNA Detection 34

Patterns Of Interspersed Homology Can Affect Silencing 37

$\begin{array}{ll}\text { References } & 68\end{array}$

$\begin{array}{ll}\text { APPENDIX: PRIMERS USED IN THIS STUDY } & 70\end{array}$ 


\section{TABLES}

Table

Page

1. MSUD Protein Descriptions

2. MSUD Protein Localization

3. Strains Used In This Study

4. Complex unDNA Cross Results

5. Complex unDNA Vector Descriptions

6. Interspersed Homology Fragment Crosses 


\section{FIGURES}

Figure

Page

1. MSUD molecular mechanism and localization

2. MSUD silencing complex interactions

3. Lifecycle and genome defense mechanisms of Neurospora crassa

4. Ascospore phenotypes.

5. Conditions of gene silencing in MSUD.

6. As unpaired distance increases, unDNA detection increases.

7. Unidirectional crossing method.

8. Deletion of hypothetical genes ncu09279-ncu094304 does not affect ascospore phenotype.

9. v50R-v73 deletion vector insertion sites.

10. Deletion of large regions of DNA to insert a genetic marker results in large unpaired structures.

11. MSUD efficiency decreases as unpaired distance increases.

12. $r^{e f-1370}$ marker construct and interspersed homology to microhomology fragments. $\quad 54$

13. Interspersed homology patterns affect the detection of unDNA. 55

14. The $\mathrm{r}^{e f-1370: 7 H 4 N}$ pattern of interspersed homology is not detected as unpaired. 56

15. Spacer Fragments paired with the $r^{e f-1370}$ marker balance homologous chromosomes. 57

16. Placing a non-homologous segment of DNA across from a genetic marker reduces unDNA detection efficiency.

17. $r^{e f-1370}$ Inversion spacer constructs.

18. Unpairing the $h p h$ marker does not affect $r s p$ silencing in $w t$ crosses. 
19. Unpairing the $h p h$ marker does not affect $r s p$ silencing in $r^{e f-1370}$ crosses. 61

20. The 7H4N pattern of interspersed homology is not recognized as unpaired. 62

21. Unpairing the $h p h$ marker increases silencing efficiency in $2 \mathrm{H} 1 \mathrm{~N}$ crosses. 63

22. Unpairing the $h p h$ marker increases silencing efficiency in $0 \mathrm{H}$ crosses. 64

23. Many patterns of interspersed homology do not trigger silencing. 65

24. Complex unDNA may dilute siRNA homology. 66

25. Further experimental conditions. $\quad 67$ 


\title{
CHAPTER I: GENOME SURVEILENCE IN NEUROSPORA CRASSA
}

\begin{abstract}
Meiosis is essential to sexual reproduction and maintaining genetic variability within a population. However, despite its importance, very little is known regarding the specifics of how it functions. Among the details of meiosis that are relatively obscure is the process of how homologous chromosomes recognize and pair with each other in order to undergo genetic recombination (Moore and Shaw 2009; Bhalla and Dernburg 2008). Not only must chromosomes find and pair with their homologs during meiosis, they must do so accurately in order to maintain genetic integrity. Many organisms have developed mechanisms that monitor the genome for inaccuracies that may be harmful to the organism (Crichton et al. 2014; Cloutier et al. 2016). Meiotic Silencing by Unpaired DNA (MSUD) is one such meiotic surveillance mechanism possessed by the filamentous fungus, Neurospora crassa. MSUD can be defined as a gene regulation pathway that is active during meiosis to prevent the expression of genes that lack a pairing partner on homologous chromosomes (Shiu et al. 2001). The mechanism of MSUD can be separated into two phases; the initial homology recognition phase and the downstream silencing phase. The silencing phase takes place outside of the nucleus, where many of the identified MSUD proteins localize to the perinuclear region (Shiu et al. 2006). This phase is thought to work via an RNAi pathway to silence expression of unpaired genes (Shiu et al. 2001). Conversely, the homology recognition phase must take place within the nucleus, where the MSUD machinery somehow efficiently examines the 40Mbp genome for any unpaired regions as small as $1.3 \mathrm{~kb}$. Considerable work has gone into the study of the MSUD mechanism, which has revealed eleven proteins that are required for MSUD activity (Figure 2; 3) (Table 1). Of these eleven proteins, seven are associated with the silencing phase, localizing outside of the nucleus
\end{abstract}


(Shiu et al. 2001; Shiu et al. 2006; Hammond et al.2013a; Hammond et al.2011; Hammond et al. 2013b; Samarajeewa et al. 2014; Decker et al. 2017; Cogoni and Macino 1997; Samarajeewa et al. 2017). Much less is known regarding what takes place during the homology recognition phase. It is therefore the goal of this study to shed light upon what parameters the MSUD machinery uses to detect homology.

\section{Neurospora crassa: A Model Organism}

Integration of foreign DNA into an organism's genome is often harmful to the organism, as transposable elements and retroviruses are frequently the source of this foreign DNA. To prevent these detrimental DNA insertions and minimize their potential damage, many organisms have developed complex DNA defense and genome surveillance mechanisms. One such organism that has several of these mechanisms, including MSUD, is Neurospora crassa.

Neurospora crassa is a filamentous fungus belonging to the phylum Ascomycota, the largest fungal phyla, which includes upwards of 64,000 different species (Deacon, 2005). N. crassa is an ideal model organism for genetics as it is easily cultivated in lab settings, has quick generational time, and has a fully annotated genome (Galagan et al. 2003). Another advantage of N. crassa as a genetic model organism is that it remains haploid for much of its lifecycle, allowing alleles to be traced through parental origin easily.

$N$. crassa remains haploid throughout its vegetative lifecycle, but is briefly diploid during sexual reproduction. At this time, $N$. crass $a$ will produce extended "sac-like" asci distinctive of Ascomycota, which will result in eight haploid sexual spores called ascospores (Webster and Weber 2007). $N$. crassa is a heterothallic organism consisting of two distinct and characterized mating types, mat $a$ and mat $A$, both of which are required for $N$. crass $a$ to undergo a successful mating event (Glass et al. 1988; Metzenberg and Glass 1990; Glass et al. 1992). In N. crassa, 
sexual reproduction is considered bi-directional. That is, either mating type can act as the "male" or "female" during a sexual cross. Here, we consider the male to be the strain that fertilizes the female protoperithecium.

Prior to sexual reproduction, the female strain produces a protoperithecium, which can best be described as an immature fruiting body (Raju 1980). Following protoperithecium formation, a mating structure called the trichogyne immerges from the protoperithecium and grows toward a conidium of opposite mating type using chemical pheromones to direct its growth (Kim and Borkovich 2006). The conidium then fertilizes the protoperithecium, which, at this point, becomes a matured fruiting body called the perithecium. Following fertilization, the perithecium sequesters a single nucleus from both mating types into a pre-meiotic structure called the crozier hook, where the two haploid nuclei then fuse inside a meiotic cell during a process called karyogamy to generate a single diploid nucleus. At this point during sexual reproduction, the organism is now diploid. This diploid zygotic nucleus then undergoes meiosis to produce four haploid products that then undergo a post-meiotic round of mitosis to produce eight haploid nuclei. These eight haploid products in turn give rise to the eight haploid ascospores (Figure 3).

During the brief diploid phase of the $N$. crassa lifecycle, homologous chromosomes, one from each haploid nucleus, must search for and pair with one another in order for meiotic recombination to take place. However, the mechanism by which these, and subsequently all, homologous chromosomes recognize each other is largely unknown. Examining the process of how MSUD detects non-homologous regions of DNA on homologous chromosomes may shed light on the process of homology searching. It is therefore the goal of this study to investigate the parameters employed by the MSUD machinery to detect homologous partners. 


\section{MSUD: Literature Review}

Neurospora crassa, like many Ascomycetes, is a coenocyte, meaning that multiple nuclei share the same cytoplasmic matrix. Because of this, N. crassa's genome is highly vulnerable to genetic invasion by retroviruses and transposable elements (Galagan and Selker 2004). Despite this susceptibility, the genome of $N$. crassa is comparatively small, containing approximately 40 Mbp and, remarkably, mostly devoid of repetitive DNA. Of the approximate 10,000 coding genes found in the $N$. crassa genome, less than $9 \%$ are repetitive. Compare this with the human genome, which is composed of approximately 50\% repetitive elements (Galagan 2003). These genomic properties have been attributed to $N$. crassa's stringent genome defense mechanisms; RIP, Quelling, and MSUD. While the focus of the study presented here is on MSUD, it is important to review all of $N$. crassa's genome defense pathways, as they may have overlapping activity and mechanism.

Repeat-induced Point Mutation (RIP), like MSUD, is active during the sexual cycle of $N$. crassa. Unlike MSUD, however, RIP occurs pre-karyogamy and functions to eliminate duplicated DNA, whereas MSUD occurs during and after karyogamy and functions to silence unpaired DNA (Figure 1). RIP was the first described example of a eukaryotic genome defense system (Galagan and Selker 2004). Prior to nuclear fusion (karyogamy), RIP machinery somehow detects the homology of repetitive sequences, as small as $400 \mathrm{bp}$ when linked or $1 \mathrm{~kb}$ when unlinked, which are then in turn subjected to numerous GC-to-AT mutations nondiscriminately. That is, if a gene duplication occurs, both the native and duplicated gene are subject to mutagenesis via RIP. It had previously been suggested that the homology search employed by RIP machinery could make use of homologous recombination (HR) in order to detect homology of DNA repeats, however the timing of HR does not coincide with RIP. It has 
also been shown that RIP is fully functional in the absence of MEI3, the only canonical RAD51/RecA homolog found in N. crassa (Gladyshev and Kleckner 2014; Gladyshev and Kleckner 2017a). Since MEI3 has been shown to mediate double-strand break (DSB) repair via HR strand invasion, this suggests that homology searching in RIP is uncoupled from HR in a double-strand break independent manner. In the same study, it was shown that RIP can efficiently recognize repetitive DNA segments that are only approximately $25 \%$ homologous, if the homology is interspersed as homologous triplets along an 11 or 12 bp periodicity. This, along with the uncoupling of RIP from HR, suggests that homologous, DSB-independent, dsDNAdsDNA interactions could facilitate the homology search employed by RIP.

The process of "ripping" also targets the mutated sequences for further epigenetic silencing via de novo methylation. It has been shown that RIP is reliant upon one of two DNA methyltransferases (DMT) found in the $N$. crassa genome. This DMT, named RID (rip deficient), is thought to be required for RIP activity, as shown by the lack of ripping events in a homozygous ridd cross (Frietag et al. 2002). Contrastingly, the other DMT found in N. crassa, DIM-2, is required for all cytosine methylation events, but is not required for RIP (Frietag et al. 2002; Kouzminova and Selker 2001). A recent study, however, shows that DIM-2 can mediate RIP in the absence of RID, in the presence of DIM-5, an H3K9 methyltransferase (Gladyshev and Kleckner 2017b). DIM-5 trimethylates histone 3 on a lysine residue (H3K9) that marks the chromatin region for methylation. This suggests that, since DIM-2 can also methylate nonrepetitive regions of the genome that RIP may require a two-step mechanism, possibly involving deamination of cytosine bases, of which is dependent upon the presence homologous DNA repeats (Belden et al. 2011). This, along with the results of HR-independent ripping and efficient ripping of DNA repeats with interspersed homology, suggest that the search for homology may 
be sequence-dependent. If the process of homology searching required HR, RIP would not function in the absence of MEI3. Likewise, if homology searching was not, at some level, sequence dependent, then patterns of homologous base pairs would be less important than percentage of homology. Gladyshev et at have shown this to not be the case. Knowing this, perhaps MSUD could utilize a similar dsDNA-dsDNA interaction as a substrate for detecting unpaired DNA.

The second genome defense mechanism that $N$. crassa possesses is Quelling. Unlike RIP and MSUD, Quelling takes place in somatic cells, during the vegetative phase of the $N$. crassa lifecycle (Figure 3). Quelling can be considered to be the vegetative counterpart to MSUD, as they both likely silence genes via an RNAi pathway. The two silencing mechanisms even share several proteins. (Table 1). Quelling was first discovered when attempts to overexpress the al-1 gene, responsible for the orange carotenoid pigments that give $N$. crassa its distinctive color, resulted in approximately 30\% pigmentless strains (Romano and Macino 1992). Following this observation, transcript levels of the al-1 gene in the overexpression mutant were measured. The mRNA transcription of the overexpression mutant was found to be at similar levels to wild type, suggesting that the silencing of the al-1 product did not occur before transcription. Indeed, later studies showed that transgenic strains carrying ectopic copies of the al-1 gene produced a sense RNA product complimentary to the al- 1 gene that was not present in the wild type strains (Cogoni et al. 1996). This suggested that quelling worked via a posttranscriptional gene silencing (PTGS) mechanism, similar to that discovered in plants. Because N. crassa is coenocytic, transformants can remain in a heterokaryotic state, where a common cytoplasm can contain both wild type nuclei as well as transformed nuclei. As al-1 seemed to be completely silenced, even in a heterokaryotic state, it further suggests that this silencing works via an RNAi pathway, where 
the silencing RNA can freely sequester any complementary transcript, regardless of source. There are seven proteins associated with quelling, two of which are shared with the MSUD pathway; QIP and DCL-1 (Chang et al. 2012). These proteins and their functions will be described in more detail in the following section.

The final genome defense mechanism to be described here, meiotic silencing by unpaired DNA (MSUD), will be the focus of the studies presented. MSUD, as the name implies, functions solely during meiosis to silence unpaired genes on homologous chromosomes (Shiu et al. 2001; Hammond et al. 2013b; Aramayo and Metzenberg 1996). The MSUD mechanism can be categorized into two phases, comprising of a homology recognition phase and a silencing phase. The silencing phase is thought to work via an RNAi pathway that uses an aberrant RNA (aRNA) molecule produced from an unpaired region on homologous chromosomes during the recognition phase to target the unpaired gene for silencing (Lee et al. 2004). RNAi is a posttranscriptional gene regulation mechanism that was first characterized in the model nematode C. elegans (Tabara et al. 1998). Shortly after the characterization of RNAi, it was found that this gene silencing mechanism was conserved in many higher eukaryotic systems (Shabalina and Koonin 2008). The general mechanism of RNAi begins with the synthesis of a double-stranded RNA molecule (dsRNA), typically via an RNA-dependent RNA polymerase (RdRP). These dsRNA molecules are then bound by a Dicer protein, a member of the RNase-III family, which cleaves the dsRNA into small interfering RNAs (siRNA) of about 20-25 nucleotides in length. Following dsRNA cleavage by Dicer, the RNA-induced silencing complex (RISC), a complex of proteins involved in the RNAi pathway, then binds the siRNA. The Argonaut protein, a member of RISC, then removes the anti-sense, "passenger" strand from the siRNA while retaining the "guide" strand for use in targeted silencing in an ATP-independent manner (Höck and Meister 2008). 
RISC then uses this siRNA molecule to target complementary mRNAs to regulate their translation, either via binding of the mRNA to prevent translation or via degradation of the mRNA molecule (Agrawal et al. 2003; Wilson and Doudna 2013).

The first indication that MSUD silences unDNA via an RNAi-like pathway was the discovery that MSUD's activity was dependent upon a protein called SAD-1(ㅁuppressor of ascus dominance), which has homology to known RNA-dependent RNA polymerases (RdRP) (Shiu et al. 2001). As mentioned earlier, MSUD works to silence any genes that lack a pairing partner during meiosis. Indeed, MSUD was initially discovered in studies involving the asm-1 gene, a gene responsible for ascospore maturation (Aramayo and Metzenberg 1996). Full expression of asm-1 results in the black pigment of ascospores, while crosses involving a single knockout of asm-1 (wt $\mathrm{x}$ asm-1 $1 \Delta$ ) result in nonviable, white ascospores. This is because MSUD silences the expression of the unpaired asm- 1 gene during meiosis. Additionally, the $r$ gene, or $r s p$ (roundspore) gene is a gene that, when unpaired, produces round-shaped ascospores. When $r s p$ is paired throughout meiosis, natural spindle-shaped ascospores are produced (Figure 4).

SAD-1 was discovered during an MSUD suppression assay, in which randomly UVmutated strains were screened for their ability to suppress MSUD activity (Shiu et al. 2001). This was done by crossing the UV-mutants to a female strain whose asm- 1 gene was knocked out $\left(w t^{U V} \times\right.$ asm-14). Traditionally, every cross should result in $100 \%$ white ascospores unless a critical component of MSUD has been mutated (Shiu et al. 2001; Hammond et al. 2013b). In the presence of a single mutated or absent SAD-1 allele, MSUD activity is suppressed. In the presence of a homozygous SAD-1 knockout cross, where both parents lack a functional SAD-1 allele, sexual reproduction stalls and aborts. This suggests that SAD-1 is required for sexual development progression in $N$. crassa. SAD-1 is thought to be an RdRP, as it shows homology to 
other RdRPs found throughout the eukaryotic kingdom, including those used by C. elegans in its RNAi pathway. Additionally, SAD-1 shows homology to QDE-1, a known RdRP in N. crassa that functions in quelling, another RNAi-mediated gene silencing pathway (Shiu et al. 2001; Cogoni and Macino 1999; Smardon et al. 2000). Following the discovery of SAD-1, random UV mutagenesis and MSUD suppression assays of the $N$. crassa knockout library were used to identify additional proteins that may be involved in the MSUD pathway. These suppression assays identify possible MSUD-related genes by crossing knockout strains with a female that lacked either $a s m-1$ or $r s p$. The expected phenotype of these crosses would be either white ascospores or round ascospores respectively. However, if the gene that was knocked out is critical for MSUD activity, the ascospore phenotype should revert, partially, to a wild type phenotype (Colot et al. 2006). Additionally, since MSUD is thought to silence unDNA through an RNAi-like pathway, RNAi proteins in the N. crassa genome were also studied. Through either mutagenesis or MSUD suppression assays, eleven MSUD proteins have been characterized that, when knocked out, suppress MSUD activity (Table 1). These proteins are SAD-1, SAD-2, SAD-3, SAD-4, SAD-5, SAD-6, SAD-7, SMS-2, QIP, CBC, and DCL-1 (Shiu et al. 2001; Shiu et al. 2006; Hammond et al.2013a; Hammond et al.2011; Hammond et al. 2013b; Samarajeewa et al. 2014; Decker et al. 2017; Cogoni and Macino 1997; Samarajeewa et al. 2017).

SAD-2, similar to SAD-1, was discovered during a screen of a UV-mutant that suppressed MSUD activity. SAD-2 was found to be required for SAD-1 localization during meiosis; however, its exact function is unclear (Shiu et al. 2006). Moreover, it has been shown that all other perinuclear MSUD proteins are dependent upon SAD-2 for localization to the perinuclear region. This suggests a possible recruitment and scaffolding role for SAD-2 (Decker 
2015). SAD-3 contains a helicase domain and localizes to the perinuclear region (Hammond $e t$ al. 2013a). SMS-2 (suppressor of meiotic silencing-2) was discovered to be a paralog of QDE-2, the Argonaute protein used by quelling (Cogoni and Macino 1997). The DCL-1 (dicer-like) protein was initially discovered to be utilized by quelling, alongside DCL-2, as dicer proteins (Alexander et al. 2008; Xiao et al. 2010). Because these proteins were implicated in RNAi pathways, their roll in MSUD was examined. Both DCL-1 and DCL-2 show sequence homology to Drosophila melanogaster DICER-1 protein (Catalanotto et al. 2000, Lee et al. 2003). It was shown that $d c l-1 \Delta$ mutants suppressed MSUD activity, however $d c l-2 \Delta$ mutants did not. QIP (QDE-2 Interacting Protein) was first discovered in studies characterizing QDE-2 in Quelling; however, it was later shown that in the absence of QIP, MSUD was suppressed (Maiti et al. 2007; Xiao et al. 2010). QIP contains an exonuclease domain that is thought to aid in passenger strand removal from RISC (Maiti et al. 2007). All proteins mentioned thus far have been shown to be necessary for sexual development, as homozygous knockout crosses produce sterile perithecia. In order to study the ability of a protein to suppress MSUD, a knockout mutant must be used in a heterozygous cross. This indicates that many MSUD proteins are required for the sexual cycle, as well as for MSUD activity. Unlike the previously described proteins, SAD-4 and SAD-5 are not required for the sexual cycle, allowing for homozygous knockout studies to be performed (Table 2). SAD-4, like all previously mentioned MSUD proteins, localizes to the perinucular region in the presence of SAD-2 (Hammond, 2013b). SAD-4 contains no previously characterized domains, making its role in MSUD difficult to interpret, however sad-4A $x$ sad-4A crosses were shown to decrease the levels of MSUD-associated small-interfering RNAs (masiRNAs), suggesting that SAD-4's activity occurs prior to the formation of masiRNAs (Hammond et al. 2013b). Thus far, all proteins described have localized to the perinuclear 
region, implicating their function in the silencing phase of MSUD (Table 2). SAD-5, however, was shown to localize to the nucleus during meiosis, excitingly suggesting that it may play a role in the homology recognition phase. Similar to SAD-4, sad-5 $x$ sad-5 4 crosses are reduced in their masiRNA production, suggesting its function may be related to the production of masiRNAs. However, despite localizing to the nucleus and its apparent involvement in masiRNA production, SAD-5 lacks homology to any characterized motif, consequentially leaving its exact role in MSUD difficult to predict (Hammond et al. 2013b). A recently characterized MSUD protein, SAD-6, was the second MSUD protein to localize within the nucleus. Similar to SAD-4 and SAD-5, SAD-6 is not required for meiosis, so sad-64 $x$ sad-64 crosses can be analyzed. Surprisingly, homozygous SAD-6 knockout crosses still show a low level of silencing, suggesting that SAD-6's function in MSUD is either redundant with another protein or that its activity is non-essential (Samarajeewa et al. 2014). SAD-6 contains a helicase domain that is highly conserved with the $S$. cerevisiae Rad54. In yeast, Rad54 is involved in double-strand break repair during recombination using homologous sequences as a template to accurately repair damaged DNA. $N$. crassa possesses a second Rad54-like protein in MUS-25 (Handa et al. 2000). Comparisons of mus-25 and sad-6 mRNA levels show similar levels of transcription in both vegetative and sexual tissue, suggesting that SAD-6 may have activity independent from MSUD as well (Samarajeewa et al. 2014). The most recently described MSUD protein, SAD-7, contains an RNA-recognition motif (RRM). Like many MSUD proteins, at least one copy of sad7 must be present in order for meiosis to progress. Unlike any MSUD protein, however, SAD-7 localizes to the nucleus, perinuclear region, and cytoplasmic matrix of meiotic cells. This unique localization may suggest that SAD-7 could be involved in coordination of nuclear and perinuclear silencing events. 
Recently, the cap-binding complex (CBC) has also been shown to play a role in gene silencing via MSUD. The CBC is made up of the cap-binding proteins CBP20 and CBP80, and associates with the 5' cap of mRNA molecules in eukaryotes. The CBP is a significant component for RNA export and nonsense-mediated decay of mRNA (NMD), among others (Gonatopoulos-Pournatizis and Cowling 2014). The loss of CBC results in a decrease of MSUD activity, suggesting that $\mathrm{CBC}$ may play a critical role in the silencing pathway (Decker et al. 2017). The CBC is primarily located within the nucleus; however, it has been shown that the $\mathrm{CBC}$ can also travel outside the nucleus to facilitate transport of RNA molecules. Bi-molecular fluorescence complementation analysis suggests that the CBC interacts with SMS-2, which would indicate interaction between the CBC and the MSUD silencing complex (MSC).

The proposed MSUD mechanism initiates by the detection of unpaired DNA (unDNA) via an unknown homology search mechanism. Detection of unDNA then may signal for the synthesis of an aberrant RNA (aRNA) molecule from the unpaired region, perhaps mediated by SAD-5 and SAD-6, in the nucleus. This aRNA may then be transported to the perinuclear region, perhaps coordinated by SAD-7, where many of the characterized MSUD proteins localize. At the perinuclear region, the aRNA is delivered to the MSUD silencing complex (MSC), where it is further processed into dsRNA by SAD-1 and SAD-3. The dsRNA molecule is then processed into siRNA molecules via DCL-1 activity. The siRNA passenger strands are removed while the guide strand is used by the RISC proteins, QIP and SMS-2, to target complementary mRNAs for degradation. The CBC may enhance the ability of the MSC to detect mRNAs leaving the nucleus by binding to the 5 ' end of exported mRNAs. The CBC may then transport this mRNA molecule to the proximity of the MSC via the interaction between the CBC and SMS-2, allowing the mRNA to be silenced efficiently (Figure 2; 3). 
The experiments presented in this study will attempt to shed light on how unDNA is detected during meiosis and targeted for silencing by the MSUD machinery. Similar to the process used to reveal the features of how RIP machinery detects homologous DNA, this study will use fragments of DNA containing interspersed sequence homology to the rsp gene to determine what characteristics allows unDNA to be detected by the MSUD machinery. 


\section{Table 1}

MSUD Protein Descriptions

\begin{tabular}{|l|l|l|}
\hline Protein & \multicolumn{1}{|c|}{ Function } & \multicolumn{1}{c|}{ Proposed Activity } \\
\hline SAD-1 & RNA-directed RNA polymerase & Converts aRNA into dsRNA \\
\hline SAD-2 & MSUD Scaffolding Protein & $\begin{array}{l}\text { Recruits and Scaffolds MSUD } \\
\text { proteins at the perinuclear region }\end{array}$ \\
\hline SAD-3 & Helicase & Assists SAD-1 in dsRNA formation \\
\hline SAD-4 & No known motif & $\begin{array}{l}\text { Assist in masiRNA transport; } \\
\text { Argonaute protein assistance }\end{array}$ \\
\hline SAD-5 & No known motif & $\begin{array}{l}\text { Localizes to nucleus; may function } \\
\text { to produce masiRNAs }\end{array}$ \\
\hline SAD-6 & Rad-54 paralog/SNF2-family protein & Assist in detection of unDNA \\
\hline SAD-7 & RNA Recognition Motif & Transport of aRNA \\
\hline DCL-1 & Dicer Protein & Cleaves dsRNA into siRNA \\
\hline QIP & Exonuclease & $\begin{array}{l}\text { Processes siRNA into single } \\
\text { stranded siRNAs }\end{array}$ \\
\hline SMS-2 & Argonaute protein & $\begin{array}{l}\text { Uses siRNA to target mRNA for } \\
\text { silencing }\end{array}$ \\
\hline CBP-20 & Member of Cap Binding Complex & Transports mRNA to MSC \\
\hline CBP-80 & Member of Cap Binding Complex & $\begin{array}{l}\text { Interacts with SMS-2; Transports } \\
\text { mRNA to MSC }\end{array}$ \\
\hline
\end{tabular}


Table 2

MSUD Protein Localization

\begin{tabular}{|l|l|l|}
\hline Protein & Localization & Required for Meiosis \\
\hline SAD-1 & Perinuclear region & Yes \\
\hline SAD-2 & Perinuclear region & Yes \\
\hline SAD-3 & Perinuclear region & Yes \\
\hline SAD-4 & Perinuclear region & No \\
\hline SAD-5 & Nucleus & No \\
\hline SAD-6 & Nucleus & No \\
\hline SAD-7 & Nucleus; Perinuclear region & Yes \\
\hline DCL-1 & Perinuclear region & Yes \\
\hline QIP & Perinuclear region & Yes \\
\hline SMS-2 & Perinuclear region & Yes \\
\hline CBP-20 & Nucleus; Perinuclear region & Yes \\
\hline
\end{tabular}




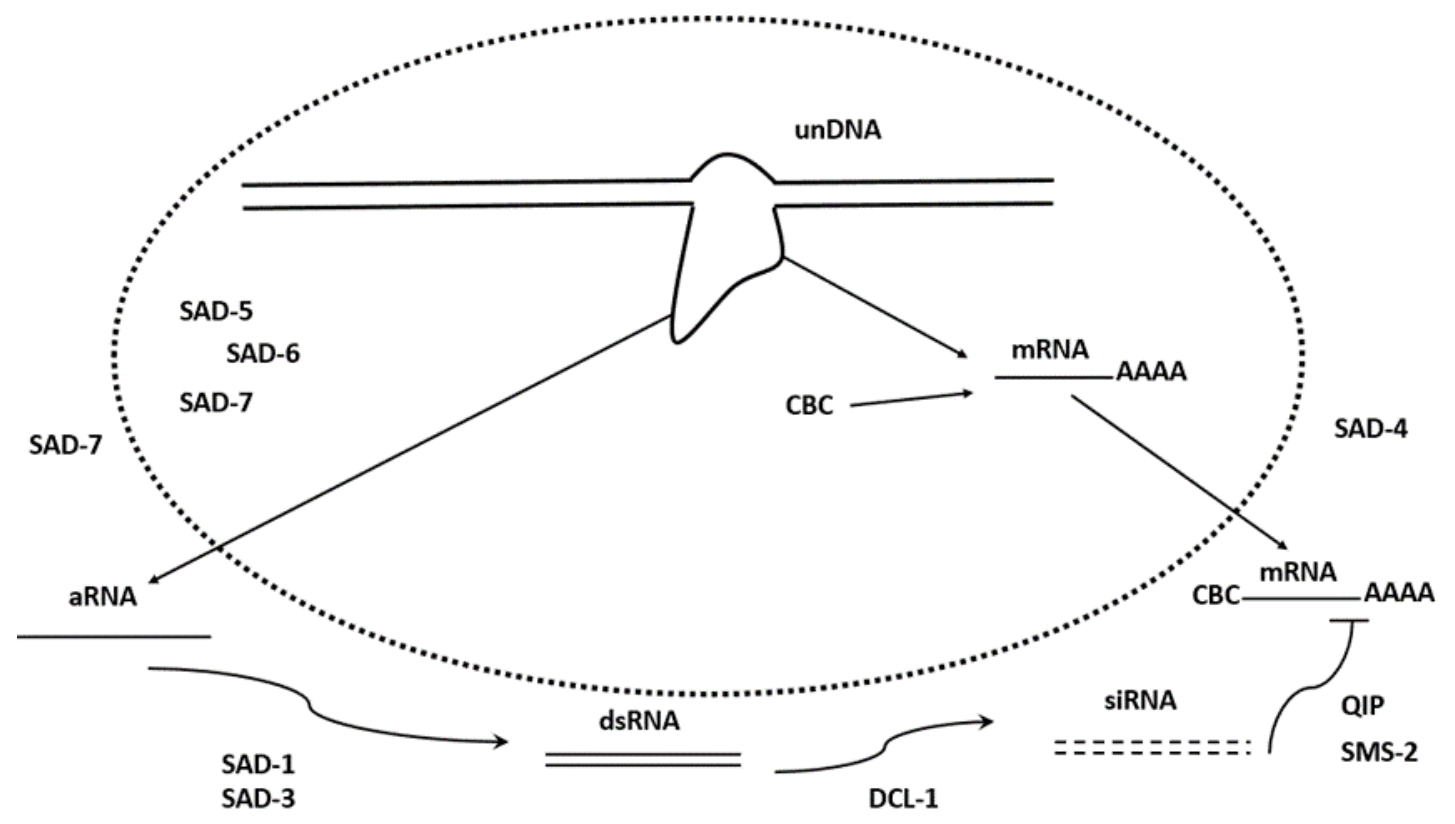

Figure 1: MSUD molecular mechanism and localization

Figure 1 describes the proposed mechanism of MSUD. Here, an aRNA molecule is produced from unDNA on homologous chromosomes. This aRNA is transported to the perinuclear region where the meiotic silencing complex (MSC) uses the aRNA to create siRNAs via an RNAi-like mechanism. Adapted from: Hammond et al. 2011 


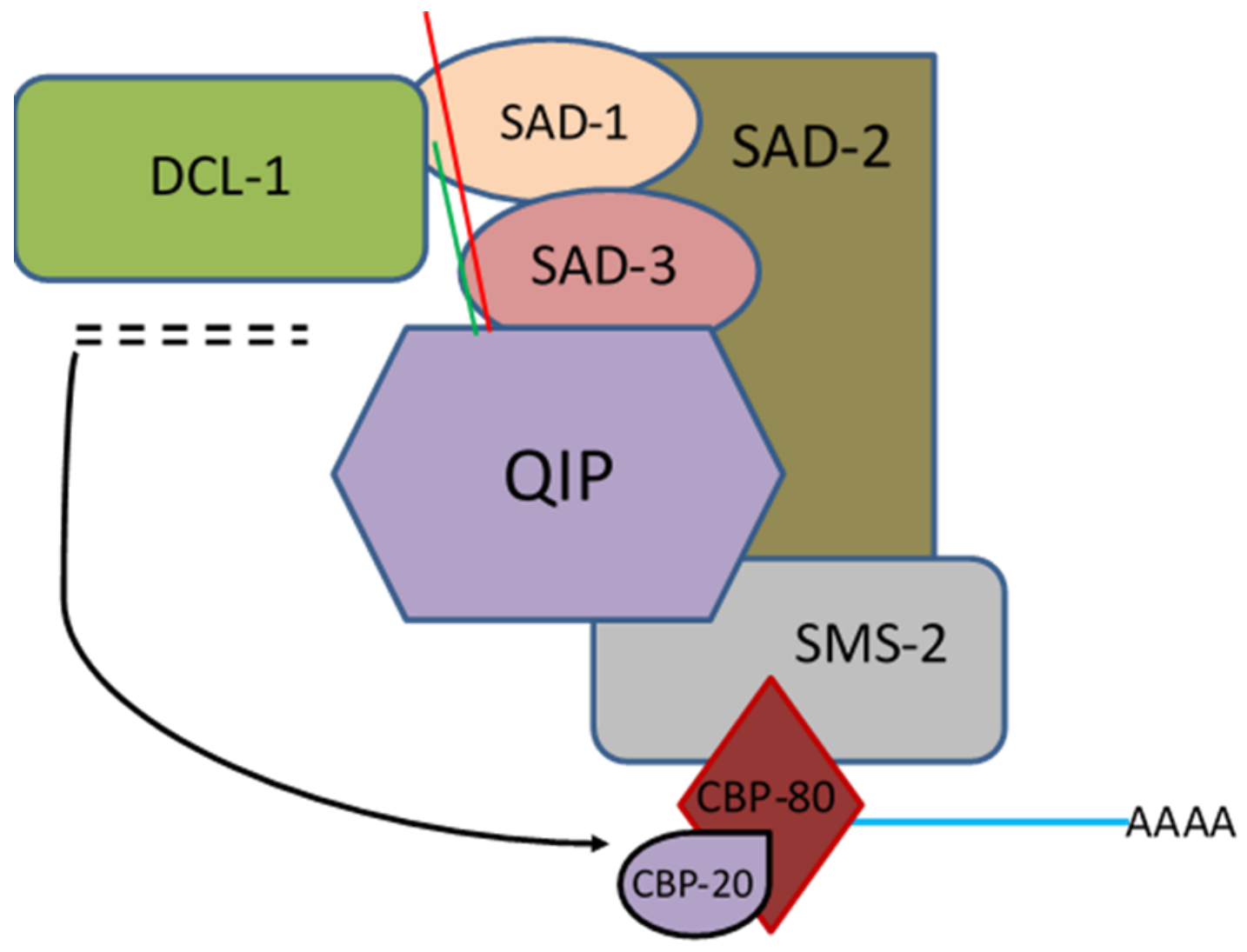

Figure 2: MSUD silencing complex interactions

The meiotic silencing complex (MSC) is located in the perinuclear region and is thought to silence unpaired genes via an RNAi like mechanism. Protein interactions are represented by overlapping regions in the figure. Interactions were determined using BiFC. Adapted from: Hammond et al. 2011 with permission from the author. 


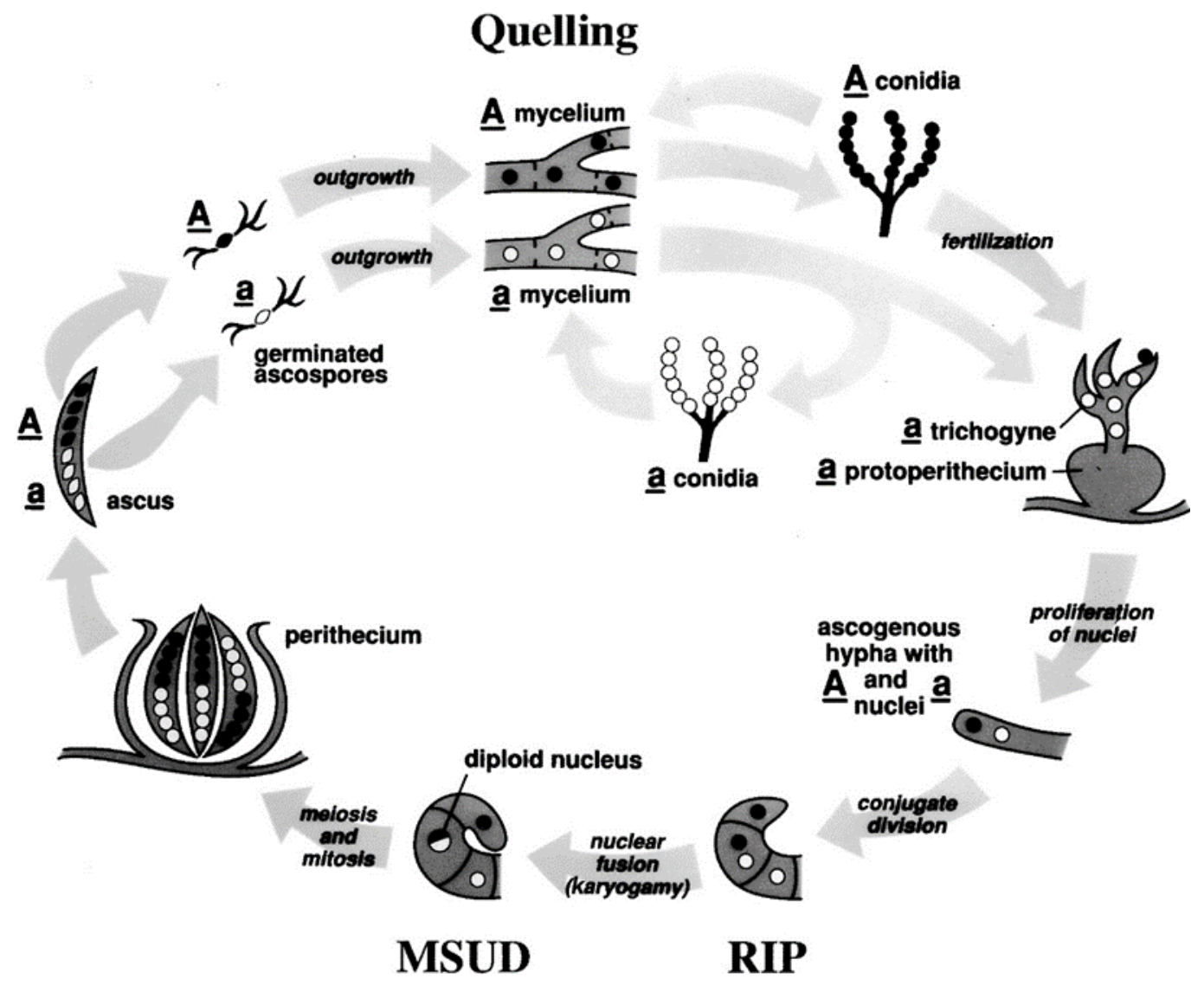

Figure 3: Lifecycle and genome defense mechanisms of Neurospora crassa.

The lifecycle of N. crassa is similar to that of most Ascomycetes. Asexual spores, conidia, can produce genetic copies of themselves to reproduce. A conidium can also fertilize a protoperithicium to begin sexual reproduction, usually triggered by environmental stress.

Source: Shiu PK, Raju NB, Zickler D \& Metzenberg RL (2001) Meiotic silencing by unpaired DNA. Cell 107: 905-916. Reprinted with permission from Elsevier Limited: Cell. Copyright 2001. 


\section{References}

Alexander WG, Raju NB, Xiao H, Hammond TM, Perdue TD, Metzenberg RL, Pukkila PJ \& Shiu PKT (2008) DCL-1 colocalizes with other components of the MSUD machinery and is required for silencing. Fungal Genet. Biol. 45: 719-727

Aramayo R \& Metzenberg RL (1996) Meiotic transvection in fungi. Cell 86: 103-113

Belden WJ, Lewis ZA, Selker EU, Loros JJ \& Dunlap JC (2011) CHD1 Remodels Chromatin and Influences Transient DNA Methylation at the Clock Gene frequency. PLoS Genet 7: Available at: http://www.ncbi.nlm.nih.gov/pmc/articles/PMC3140994/ [Accessed August 22, 2017]

Bhalla N \& Dernburg AF (2008) Prelude to a Division. Annual Review of Cell and Developmental Biology 24: 397-424

Catalanotto C, Azzalin G, Macino G \& Cogoni C (2000) Gene silencing in worms and fungi. Nature 404: 245

Catalanotto C, Azzalin G, Macino G \& Cogoni C (2002) Involvement of small RNAs and role of the qde genes in the gene silencing pathway in Neurospora. Genes Dev 16: 790-795

Chang S-S, Zhang Z \& Liu Y (2012) RNA Interference Pathways in Fungi: Mechanisms and Functions. Annual Review of Microbiology 66: 305-323

Cloutier JM, Mahadevaiah SK, ElInati E, Tóth A \& Turner J (2016) Mammalian meiotic silencing exhibits sexually dimorphic features. Chromosoma 125: 215-226

Cogoni C, Irelan JT, Schumacher M, Schmidhauser TJ, Selker EU \& Macino G (1996) Transgene silencing of the al- 1 gene in vegetative cells of Neurospora is mediated by a cytoplasmic effector and does not depend on DNA-DNA interactions or DNA methylation. EMBO J. 15: 3153-3163

Cogoni C \& Macino G (1997) Isolation of quelling-defective (qde) mutants impaired in posttranscriptional transgene-induced gene silencing in Neurospora crassa. Proc Natl Acad Sci U S A 94: 10233-10238

Colot HV, Park G, Turner GE, Ringelberg C, Crew CM, Litvinkova L, Weiss RL, Borkovich KA \& Dunlap JC (2006) A high-throughput gene knockout procedure for Neurospora reveals functions for multiple transcription factors. Proc. Natl. Acad. Sci. U.S.A. 103: $10352-$ 10357

Crichton JH, Dunican DS, MacLennan M, Meehan RR \& Adams IR (2014) Defending the genome from the enemy within: mechanisms of retrotransposon suppression in the mouse germline. Cell Mol Life Sci 71: 1581-1605 
Deacon J \& Deacon J (2005) The Diversity of Fungi and Fungus-Like Organisms. In Fungal Biology pp 16-47. Blackwell Publishing Ltd. Available at: http://onlinelibrary.wiley.com/doi/10.1002/9781118685068.ch2/summary [Accessed August 22, 2017]

Decker LM, Boone EC, Xiao H, Shanker BS, Boone SF, Kingston SL, Lee SA, Hammond TM $\&$ Shiu PKT (2015) Complex formation of RNA silencing proteins in the perinuclear region of Neurospora crassa. Genetics 199: 1017-1021

Decker LM, Xiao H, Boone EC, Vierling MM, Shanker BS, Kingston SL, Boone SF, Haynes JB \& Shiu PKT (2017) The Nuclear Cap-Binding Complex Mediates Meiotic Silencing by Unpaired DNA. G3 (Bethesda) 7: 1149-1155

Freitag M, Williams RL, Kothe GO \& Selker EU (2002) A cytosine methyltransferase homologue is essential for repeat-induced point mutation in Neurospora crassa. PNAS 99: 8802-8807

Galagan JE, Calvo SE, Borkovich KA, Selker EU, Read ND, Jaffe D, FitzHugh W, Ma L-J, Smirnov S, Purcell S, Rehman B, Elkins T, Engels R, Wang S, Nielsen CB, Butler J, Endrizzi M, Qui D, Ianakiev P, Bell-Pedersen D, et al. (2003) The genome sequence of the filamentous fungus Neurospora crassa. Nature 422: 859-868

Galagan JE \& Selker EU (2004) RIP: the evolutionary cost of genome defense. Trends Genet. 20: $417-423$

Gladyshev E \& Kleckner N (2014) Direct recognition of homology between double helices of DNA in Neurospora crassa. 5: 3509

Gladyshev E \& Kleckner N (2017a) DNA sequence homology induces cytosine-to-thymine mutation by a heterochromatin-related pathway in Neurospora. Nat Genet 49: 887-894

Gladyshev E \& Kleckner N (2017b) Recombination-independent recognition of DNA homology for repeat-induced point mutation. Curr. Genet. 63: 389-400

Glass NL \& Lee L (1992) Isolation of Neurospora crassa A mating type mutants by repeat induced point (RIP) mutation. Genetics 132: 125-133

Glass NL, Vollmer SJ, Staben C, Grotelueschen J, Metzenberg RL \& Yanofsky C (1988) DNAs of the two mating-type alleles of Neurospora crassa are highly dissimilar. Science 241: $570-573$

Gonatopoulos-Pournatzis T \& Cowling VH (2014) Cap-binding complex (CBC). Biochem. J. 457: $231-242$

Hammond TM, Spollen WG, Decker LM, Blake SM, Springer GK \& Shiu PKT (2013a) Identification of small RNAs associated with meiotic silencing by unpaired DNA. Genetics 194: 279-284 
Hammond TM, Xiao H, Boone EC, Decker LM, Lee SA, Perdue TD, Pukkila PJ \& Shiu PKT (2013b) Novel proteins required for meiotic silencing by unpaired DNA and siRNA generation in Neurospora crassa. Genetics 194: 91-100

Hammond TM, Xiao H, Boone EC, Perdue TD, Pukkila PJ \& Shiu PKT (2011) SAD-3, a Putative Helicase Required for Meiotic Silencing by Unpaired DNA, Interacts with Other Components of the Silencing Machinery. G3 (Bethesda) 1: 369-376

Handa N, Noguchi Y, Sakuraba Y, Ballario P, Macino G, Fujimoto N, Ishii C \& Inoue H (2000) Characterization of the Neurospora crassa mus-25 mutant: the gene encodes a protein which is homologous to the Saccharomyces cerevisiae Rad54 protein. Mol. Gen. Genet. 264: $154-163$

Höck J \& Meister G (2008) The Argonaute protein family. Genome Biol. 9: 210

Kim H \& Borkovich KA (2006) Pheromones are essential for male fertility and sufficient to direct chemotropic polarized growth of trichogynes during mating in Neurospora crassa. Eukaryotic Cell 5: 544-554

Kouzminova E \& Selker EU (2001) dim-2 encodes a DNA methyltransferase responsible for all known cytosine methylation in Neurospora. EMBO J 20: 4309-4323

Lee DW, Pratt RJ, McLaughlin M \& Aramayo R (2003) An argonaute-like protein is required for meiotic silencing. Genetics 164: 821-828

Lee DW, Seong K-Y, Pratt RJ, Baker K \& Aramayo R (2004) Properties of unpaired DNA required for efficient silencing in Neurospora crassa. Genetics 167: 131-150

Maiti M, Lee H-C \& Liu Y (2007) QIP, a putative exonuclease, interacts with the Neurospora Argonaute protein and facilitates conversion of duplex siRNA into single strands. Genes Dev. 21: 590-600

Metzenberg RL \& Glass NL (1990) Mating type and mating strategies in Neurospora. Bioessays 12: $53-59$

Moore G \& Shaw P (2009) Improving the chances of finding the right partner. Current Opinion in Genetics \& Development 19: $99-104$

Raju NB (1980) Meiosis and ascospore genesis in Neurospora. Eur. J. Cell Biol. 23: 208-223

Romano N \& Macino G (1992) Quelling: transient inactivation of gene expression in Neurospora crassa by transformation with homologous sequences. Mol. Microbiol. 6: 3343-3353

Samarajeewa DA, Manitchotpisit P, Henderson M, Xiao H, Rehard DG, Edwards KA, Shiu PKT \& Hammond TM (2017) An RNA Recognition Motif-Containing Protein Functions in Meiotic Silencing by Unpaired DNA. G3 (Bethesda) 7: 2871-2882 
Samarajeewa DA, Sauls PA, Sharp KJ, Smith ZJ, Xiao H, Groskreutz KM, Malone TL, Boone EC, Edwards KA, Shiu PKT, Larson ED \& Hammond TM (2014) Efficient detection of unpaired DNA requires a member of the rad54-like family of homologous recombination proteins. Genetics 198: 895-904

Shabalina SA \& Koonin EV (2008) Origins and evolution of eukaryotic RNA interference. Trends Ecol Evol 23: 578-587

Shiu PK, Raju NB, Zickler D \& Metzenberg RL (2001) Meiotic silencing by unpaired DNA. Cell 107: 905-916

Shiu PKT, Zickler D, Raju NB, Ruprich-Robert G \& Metzenberg RL (2006a) SAD-2 is required for meiotic silencing by unpaired DNA and perinuclear localization of SAD-1 RNAdirected RNA polymerase. Proc. Natl. Acad. Sci. U.S.A. 103: 2243-2248

Shiu PKT, Zickler D, Raju NB, Ruprich-Robert G \& Metzenberg RL (2006b) SAD-2 is required for meiotic silencing by unpaired DNA and perinuclear localization of SAD-1 RNAdirected RNA polymerase. Proc. Natl. Acad. Sci. U.S.A. 103: 2243-2248

Smardon A, Spoerke JM, Stacey SC, Klein ME, Mackin N \& Maine EM (2000) EGO-1 is related to RNA-directed RNA polymerase and functions in germ-line development and RNA interference in C. elegans. Current Biology 10: 169-178

Tabara H, Grishok A \& Mello CC (1998) RNAi in C. elegans: soaking in the genome sequence. Science 282: $430-431$

Wilson RC \& Doudna JA (2013) Molecular Mechanisms of RNA Interference. Annual Review of Biophysics 42: 217-239

Xiao H, Alexander WG, Hammond TM, Boone EC, Perdue TD, Pukkila PJ \& Shiu PKT (2010) QIP, a protein that converts duplex siRNA into single strands, is required for meiotic silencing by unpaired DNA. Genetics 186: 119-126 


\title{
CHAPTER II: UNPAIRED GENE DETECTION AND HOMOLOGY SEARCH
}

\section{PARAMETERS IN MSUD}

\begin{abstract}
Neurospora crassa fails to form complete septum walls between individual cells, leaving multiple nuclei to occupy the same cytoplasmic matrix. Because of this coenocytic nature, the $N$. crassa genome is particularly vulnerable to incorporation of foreign DNA such as viral or transposable elements. Like most eukaryotes, $N$. crassa is able to undergo sexual reproduction in order to maintain genetic variability within a population. This allows genetic recombination of homologous chromosomes during meiosis to safeguard its advantageous alleles and select against genetic disease. However, during meiosis, $N$. crassa is especially susceptible to transmission of genome invaders, such as transposable elements. In response, $N$. crassa has developed several genome surveillance mechanisms in order to maintain genetic integrity. One particular mechanism, meiotic silencing by unpaired DNA (MSUD), functions during meiosis to silence the expression of unpaired DNA (unDNA) on homologous chromosomes. It has been shown that MSUD uses an RNAi-like pathway to perform the silencing of mRNAs produced from unDNA; however, despite our increasing knowledge regarding how MSUD silences unpaired genes, very little is known about how these unpaired regions are detected. In this study, we have used custom-designed gene fragments that share precise interspersed homology patterns to the $r s p$ gene to determine whether sequence homology plays a role in the homology searching process. We also present data that suggests that complex DNA structures surrounding unDNA decrease the efficiency of MSUD activity.
\end{abstract}




\section{Introduction}

During meiosis, homologous chromosomes must find and pair with one another in order to undergo genetic recombination. Through this pairing, chromosomes make several physical connections with their homologous partner to form the synaptonemal complex (SC) (Zickler 2006; Ding et al. 2010; Bishop et al. 1992). Following the formation of the SC, a physical exchange of DNA between homologous chromosomes occurs which is mediated by controlled double-stranded DNA (dsDNA) breaks (Stahl 1996; Stacey et al. 2006; Lisby et al. 2001). Intensive studies have revealed mechanisms by which synaptonemal complex formation and genetic recombination occur (Ding et al. 2010). The process by which chromosomes recognize their homologs, and subsequently reject their heterologs, however, remains largely unsolved (Renkawitz et al. 2013; Samarajeewa et al. 2014).

Meiotic silencing by unpaired DNA (MSUD) is a genome defense mechanism in $N$. crassa that provides a unique opportunity to investigate the mechanism of homology searching during meiosis. MSUD has the remarkable ability to detect unpaired genes on homologous chromosomes and target these genes for silencing (Shiu et al. 2001). For example, the $r s p$ gene is responsible for the spindle-shaped phenotype of $N$. crassa ascospores (Figure 4A). When $r s p$ lacks a pairing partner on a homologous chromosome during meiosis however, MSUD silences the expression of $r s p$ resulting in round-shaped ascospores (Figure 4B). It is important to clarify that gene expression in $N$. crassa is not dependent upon gene pairing; rather it is dependent upon lack of unpaired genes. In example, when $r s p$ is paired at its native location on LG I, yet unpaired at an ectopic location within the genome, expression of $r s p$ is completely silenced (Figure 5). Due to this universal silencing of unpaired genes, it has been proposed that MSUD utilizes a post-transcriptional RNAi mechanism to regulate gene expression. 
The mechanism of MSUD can be broken down into two phases, a homology recognition phase and a silencing phase. The silencing phase, as mentioned previously, is proposed to work via an RNAi-like mechanism by which an aberrant RNA molecule (aRNA) is produced from an unpaired DNA (unDNA) region on homologous chromosomes (Figure 2). This aRNA molecule is then somehow exported to the perinuclear region, where the meiotic silencing complex (MSC) is located (Figure 2; Figure 3). The MSC converts the aRNA into siRNAs that are then used to target commentary mRNAs for silencing. In order for an aRNA molecule to be produced, unDNA regions must first be detected during the homology recognition phase, a mechanism that has been largely unsolved (Shiu et al. 2001; Shiu et al. 2006; Hammond et al.2013a; Hammond et al.2011; Hammond et al. 2013b; Samarajeewa et al. 2014; Decker et al. 2017; Cogoni and Macino 1997; Samarajeewa et al. 2017).

A previous study shows that the search for homology is spatially constrained within the nucleus (Samarajeewa et al. 2014). In this study, genetic markers were placed at differing locations on homologous chromosomes to see how MSUD would detect this slight unpairing. When the $r s p$ gene is separated by only $4.1 \mathrm{~kb}$, an MSUD response is only about $5 \%$ efficient, even though the two alleles are at different physical locations. When the distance of unpaired $r s p$ genes is increased to $18.0 \mathrm{~kb}$, MSUD efficiency increases to $42 \%$. MSUD efficiency continues to increase as unpaired distance increases, with a distance of $1.2 \mathrm{Mbp}$ eliciting a full MSUD response of $99.05 \%$ detection (Figure $6 \mathrm{~A}-\mathrm{C}$ ). This data shows that as the distance between unpaired genes increases, the less likely the genes are detected as paired, resulting in a higher level of silencing as distance increases. Because chromatin loops are tethered to the synaptonemal complex in fixed positions, this could suggest that chromatin loop interactions are required for MSUD activity. As genes get further apart, the less likely that they will be contained 
in the same chromatin loop. Likewise, as distance between unpaired genes increases, the less likely that their respective chromatin loops will interact with each other, which may lead to an increase in silencing. The interactions of these chromatin loops may be random, suggested by the gradual increase of MSUD silencing as unpaired gene distance increases. If these chromatin loop interactions were not random, in respect to MSUD activity, then we would expect to see no silencing when genes were located close to each other and full silencing when a certain distance constraint was reached. Since gradual increases in MSUD activity were observed, this suggests that interactions may have been getting less and less frequent as unpaired distance increased.

The $r s p$ gene, as well as any gene that produces an abnormal phenotype when unpaired during meiosis, can be used to measure the efficiency of an MSUD response. For example, in a $w t \mathrm{x} r s p \Delta$ cross, we can expect to see $90-100 \%$ round-shaped ascospores. This is due to $r s p$ being detected as unpaired and subsequently silenced. We can infer from this that MSUD is fully functional in this scenario. However, in a cross between $w t$ x $r s p \Delta$; sad-2A, only $5 \%$ roundshaped ascospores are produced (Samarajeewa et al. 2014). This is due to the sad-2 deletion, a critical component of MSUD (Table 1). We can infer that in this cross, MSUD only detected 5\% of $r s p$ genes as unpaired, and therefore MSUD efficiency is measured at $5 \%$.

In this study, we report the use of custom-designed oligonucleotide fragments that share interspersed homology to the $r s p$ gene to observe how sequence-level homology may play a role in homology searching. We also report findings that complex DNA structures can inhibit MSUD's ability to detect unDNA. 


\section{Materials And Methods}

\section{Strain And Culture Information}

Key strains used in this study are listed with their genotypes in Table 1. All strains were cultured using Vogel's minimal medium (VMM) with or without supplements $(0.5 \mathrm{~g} / \mathrm{mL})$ as needed (Vogel 1956). Sexual crosses were performed using synthetic crossing medium (SCM) with or without supplements $(0.5 \mathrm{~g} / \mathrm{mL})$ as needed (Westergaard and Mitchel 1947). Strains were cultured on VMM slants at $32^{\circ} \mathrm{C}$ before moving to room temperature. All sexual crosses were performed at room temperature.

\section{DNA Vector Construction}

All microhomology fragments described were cloned into the NotI::EcoRI cloning site of pTH 256.1, a his-3 targeting vector, using standard T4 ligase cloning protocol (ThermoFisher \#EL0014). Ligation reactions were transformed into ig5a chemical competent cells per manufacture instruction (Intact Genomics Cat. \#1232). Exceptions to this protocol involve a scaled down reaction of $2.5 \mathrm{uL}$ of ligation reaction to $12.5 \mathrm{uL}$ of competent cells. Competent cells were rescued in $235 \mathrm{uL}$ of Recovery Media for one hour prior to plating on selectable media (Intact Genomics Cat. \#1711). All plasmids were linearized via restriction digest using SspI restriction endonuclease in a standard $25 \mathrm{uL}$ digestion reaction. Purification of digested plasmid was done using IBI Scientific's Gel/PCR DNA Fragment Extraction Kit.

All large deletion vectors were constructed using via double-joint PCR (Yu et al. 2004). PCR was performed using Thermo Scientific Phusion High Fidelity DNA Polymerase. Following fusion and amplification, the final amplified double-joint PCR product was gel purified using an IBI Scientific Gel/PCR DNA Fragment Extraction Kit. 


\section{Transformation And Homokaryon Isolation Methods}

Purified linearized plasmids or double-joint vectors were transformed into freshly collected N. crassa asexual spores (conidial cells) via electroporation (Margolin et al. 1997). Alterations to this protocol include separation of the asexual spores from vegetative tissue (mycelia) using a 100 $\mu$ m nylon filter (Steriflip; Milipore, Billerica, MA) prior to pelleting. Homokaryon strains were isolated by backcrossing transformant strains to wild type strain RTH 1005.2. After 21 days post-fertilization (DPF), ascospores produced from this sexual cross were collected into $500 \mu \mathrm{L}$ of $\mathrm{H}_{2} \mathrm{O}$ and soaked overnight at $4^{\circ} \mathrm{C}$. Following overnight soaking, a 1:10 dilution of ascospores was heat shocked at $55^{\circ} \mathrm{C}$ for 30 minutes. Heat-shocked spores were then spread onto a plate of VMM + Hygromycin $(200 \mu \mathrm{g} / \mathrm{mL})$ for selection and incubated at room temperature overnight. Germinating ascospores were picked 18 hours following spreading onto $\mathrm{VMM}+$ Hygromycin $(200 \mathrm{ug} / \mathrm{mL})$ slants and grown at $32^{\circ} \mathrm{C}$ for $2-3$ days.

\section{Quantitative Sexual Crosses And Spore Collection}

Unidirectional sexual crosses were performed at room temperature on SCM. All male strains used in sexual crosses were inoculated to new VMM slants + supplements and grown at $32^{\circ} \mathrm{C}$ for three days and at room temperature for three days prior to crossing to ensure consistent age of tissue. On the same day as new male strains were started, $60 \mathrm{~mm} \mathrm{SCM} \mathrm{plates} \mathrm{were}$ inoculated with selected female strains. Following six days of growth, conidial suspensions were made of all male strains by inoculating a small amount of conidial cells into $500 \mu \mathrm{L}$ of sterile water. Conidial suspensions were quantified using a hemocytometer and diluted to 1000 conidia $/ \mu \mathrm{L}$. Sexual crosses were performed by inoculating $33 \mu \mathrm{L}$ of diluted conidial suspension to three zones of the 6-day-old female strain for a total $99 \mu \mathrm{L}$ of cells per plate. Each experimental cross was performed in four replicates and lasted 21 days post-fertilization 
(21DPF), during which ascospores were shot to the lid of the crossing plates. Figure 7 describes the process of unidirectional quantitative crossing (Hammond et al 2013b).

Ascospores were collected from the lid of crossing plates on 21DPF into $1 \mathrm{~mL}$ of sterile $\mathrm{H}_{2} \mathrm{O}$. This is done by washing the lid of the crossing plate three times with $333 \mu \mathrm{L}$ of $\mathrm{H}_{2} \mathrm{O}$. On the same day of collections, $10 \mu \mathrm{L}$ of ascospore suspension was loaded onto a hemocytometer to image ascospore phenotypes for counting. For each replicate, at minimum of one hundred ascospores were counted. Ascospores were imaged the same day of collection to prevent any swelling of ascospores that could conceivably interfere with the ability to differentiate round vs. spindle-shaped ascospores.

\section{Results}

A sexual cross between wild type (wt) strains of $N$. crassa will typically result in the production of spindle-shaped ascospores (Shiu et al. 2001). This spindle-shaped phenotype is produced by the expression of the $r s p$ gene during meiosis. However, if $r s p$ is detected as unpaired and subsequently silenced, the cross ( $w t$ x $r s p \Delta)$ will produce round-shaped ascospores (Figure II-1). Due to this phenotype difference, we are able to use percentage comparisons of round vs spindle-shaped ascospores to infer MSUD efficiency. For example in a $w t \mathrm{x} r s p \Delta$ cross we expect to see $90-100 \%$ round-shaped ascospores. We can infer from this that MSUD is fully functional in this scenario. However if a cross between $w t \mathrm{x} r s p \Delta$; sad-2 2 produces only $5 \%$ round-shaped spores, we can infer that MSUD was only approximately $5 \%$ as efficient (Samarajeewa et al 2017). 


\section{The Region Between ncu09279 And ncu09430 Is Not Required For Spindle-shaped}

\section{Ascospores}

Nine hypothetical coding genes between ncu09279 and ncu09430 on chromosome VII were not necessary for the production of spindle-shaped ascospores. This was determined by replacing the entire $45 \mathrm{~kb}$ region with the $h p h$ marker, a gene conferring resistance to the antibiotic hygromycin (Figure 8A). A cross between $n c u 09279-n c u 094304:: h p h \mathrm{x} w t$ results in spindle-shaped ascospores similar to a $w t \times$ wt cross, implicating that deletion of this $45 \mathrm{~kb}$ region does not affect spindle-shaped ascospore production (Figure 8B).

\section{MSUD Is Less Efficient At Detecting unDNA In The Presence Of Complex DNA Structures}

In order to investigate the effect of complex DNA structures in proximity to unDNA on MSUD's ability to detect unDNA, we placed vectors containing $r^{e f}$ within a $45 \mathrm{~kb}$ region on LGVII between hypothetical genes $n c u 09279$ and $n c u 09430$ (Figure 9). The $r^{e f}$ marker is a 2.6kb fragment of the $r s p$ gene that, when unpaired during meiosis, can trigger silencing of the $r s p$ gene. This $2.6 \mathrm{~kb}$ fragment is fused to the $h p h$ marker. The $r^{e f}$ marker replaced increasingly large regions of DNA, resulting in large, unpaired "loops" in a $w t \mathrm{x} r^{e f}$ cross (Figure 10A-C). As we increase the number of base pairs deleted in order to insert our $r^{e f}$ marker, the ability of MSUD to detect $r^{e f}$ as unpaired decreases. Deletion of approximately 50kb of DNA results in MSUD detecting $r^{e f}$ as unpaired with $36 \%$ efficiency. Deletions of approximately $200 \mathrm{bp}$, however, result in MSUD detecting $r^{e f}$ as unpaired with 98\% efficiency (Figure 11). Table 2 describes the results of all crosses performed in this experiment. Table 3 describes deletion sizes of each deletion vector. The results shown in Figure 11 imply that that larger the unpaired region of DNA surrounding an unpaired gene, the less efficient MSUD is at silencing said unpaired gene. The implications of these findings are discussed later. 


\section{Sequence Homology Patterns Can Effect MSUD Efficiency}

In the process of Repeat-Induced Point Mutation (RIP), duplicated genes are identified and targeted for mutation. This process, alongside MSUD, functions to keep N. crassa's genome free of transposable elements. The homology search mechanism used by RIP, like MSUD, is currently unknown; however, it has been recently shown that overall sequence homology is less important than the pattern of homology within the sequence in detection of duplicated genes (Gladyshev and Kleckner 2016; Gladyshev and Kleckner 2017).

To identify whether periodicity of homology, or “microhomology” effect MSUD’s ability to detect unDNA, we constructed a genetic marker, called $r^{e f-1370}$ and inserted this marker into the N. crassa genome at the his-3 locus (Figure 12A). The $r^{e f-1370}$ fragment is a 1370bp fragment of the $r s p$ gene fused with the $h p h$ marker that, when unpaired in a sexual cross $\left(w t \mathrm{x} r^{e f-1370}\right)$, produces approximately 70-75\% round-shaped ascospores (Figure II-1). Custom gene blocks were designed to have differing patterns of sequence microhomology to the $r^{e f-1370}$ marker (Figure 12B). One such microhomology fragment, $r^{e f-1370: 7 H 4 N}$, features seven homologous basepairs followed by four non-homologous base-pairs, with $64 \%$ overall homology to $r^{e f-1370}$. A second microhomology fragment, $r^{e f-1370: 2 H I N}$, features two homologous base-pairs followed by a single, non-homologous base-pair, with $67 \%$ overall homology to $r^{e f-1370}$ (Figure 12B). Both microhomology fragments were kept within $1 \%$ of overall GC content to $r^{e f-1370}$ and were inserted into the $N$. crassa genome at the his-3 locus. Sexual crosses performed in this study are listed in Table 6. Crosses of $r^{e f-1370: 744 N} \times r^{e f-1370}$ produce majority spindle-shaped ascospores, similar to $w t \mathrm{x} w t$ crosses. Crosses of $r^{e f-1370: 2 H I N} \mathrm{x} r^{e f-1370}$ produce approximately $50 \%$ roundshaped ascospores, suggesting that this periodicity of homology is able to be detected as unpaired by MSUD (Figure 13). The implications of these findings are discussed below. 
The $r^{e f-1370: 7 H 4 N}$ marker produced $100 \%$ spindle-shaped ascospores despite having only $67 \%$ overall homology. To determine if this was due to the pattern of interspersed homology and not because of an exact sequence pattern, two additional $r^{e f-1370: 7 H 4 N}$ fragments were designed. These two microhomology fragments, named $r^{e f-1370: 7 H 4 N O f f 2}$ and $r^{\text {ef-1370:7H4NOff4 }}$, retained the same 7H4N sequence homology pattern, but were offset by two base-pairs and four base-pairs respectively (Figure 14A). The results of the crossing offset $7 \mathrm{H} 4 \mathrm{~N}$ fragments showed similar results to the original $r^{e f-1370: 7 H 4 N}$ marker, indicating that this particular pattern of homology is detected as paired by MSUD (Figure 14B).

\section{Insertion Of A Non-homologous Fragment Of DNA Reduces unDNA Detection}

Unpaired DNA detection efficiency decreases as unpaired distance increases, as seen in Figure 11. In crosses between $w t \times r^{e f-1370}$, the $r^{e f-1370}$ marker is physically and spatially unpaired from the $w t$ chromosome location. To examine whether this physical unpairing of an allele plays a role in how MSUD detects unDNA, a spacer fragment was designed with zero homologous base-pairs but similar GC content to the $r^{e f-1370}$ marker. This fragment, named $r^{e f-1370: 0 H}$, places a physical fragment of DNA at the same location that $r^{e f-1370}$ is inserted (Figure 15). By doing this, we have balanced the homologous chromosomes at the insertion locus. Strangely, sexual crosses of $r^{e f-1370: 0 H} \times r^{e f-1370}$ produce only $20 \%$ round-shaped ascospores. We would expect to see a high level of silencing, since the $r^{e f-1370}$ marker is completely unpaired at a sequence level. These results may suggest that there could be a physical property of chromosomes that assist in homology searching.

To confirm these results, several distinct spacer fragments were amplified from the $H$. sapiens and E. coli genomes that shared similar GC content, yet also shared zero sequence homology, to $r^{e f-1370}$. These fragments were inserted at the his-3 locus. Similar to the $r^{e f-1370: 0 H}$, all 
$H$. sapiens and E. coli spacers showed production of 20\%-30\% round-shaped ascospores (Figure 16).

In an attempt to identify a condition where a non-homologous fragment of DNA placed at the same location as the $r^{e f-1370}$ marker on homologous chromosomes produces a majority roundshaped ascospores, several inversion vectors were constructed (Figure 17). These inversion vectors simply orient either the $r^{e f-1370}$ fragment, $h p h$ marker, or both opposite of their original orientation in the $r^{e f-1370}$ construct. These vectors were named $r^{e f-1370}:: h p h i n v$ for the inverted hph marker and $r^{e f-1370}$ inv : hphinv respectively. The hph marker was replaced by a portion of the $E$. coli genome to determine whether unpairing of the selectable marker would have any affect upon unDNA detection. This vector was named $r^{e f-1370}:: E C S$ (E. coli. Spacer).

When these homology spacer strains are crossed to $w t, r^{e f-1370}$, or $r^{e f-1370: 7 H 4 N}$ strains, there is little observed difference from the original $r^{e f-1370}$ crosses shown in Figure 13 (Figure 18; Figure 19; Figure 20). When crossed to the $r^{e f-1370: 0 H}$ and $r^{e f-1370: 2 H 1 N}$ strains, however, we observe a significant increase in silencing the $r s p$ gene over the original $r^{e f-1370}$ crosses. The $r^{e f-1370}:: E C S$ crosses showed the highest level of silencing of the $r^{e f-1370: 0 H}$ fragment, with silencing observed in $51.2 \%$ of ascospore pheonotypes. Compared to the original cross, $r^{e f-1370} \times r^{e f-1370: 0 H}$, which only showed approximately $20 \%$ silencing (Figure 21; Figure 22).

\section{Some Sequence Homology Patterns Are Ignored By MSUD}

Custom oligonucleotides with differing interspersed homology patterns from those described previously were designed to further examine which sequence homology patterns MSUD could detect as unDNA. These custom oligos retained the 11 base-pair periodicity, however their pattern of homology (ie 2H1N vs 7H4N) was altered. See Table 1 strains T511.1, 
T512.1, T513.1, T514.1, T516.1, and T517.1 for descriptions of specific patterns of interspersed homology.

When each of these strains were crossed to $r^{e f-1370}$, the result was similar to the $r^{e f-1370: 7 H 4 N}$ fragment, in that there was little to no silencing of $r s p$ observed (Figure 23). The exception to this was the $r^{e f-1370: 3 H 8 N}$ fragment, which resulted in $r s p$ silencing in $28.5 \%$ of ascospore phenotypes. This is similar to results seen in non-homologous spacer crosses (Figure 16).

\section{Discussion}

\section{Complex DNA Affects unDNA Detection}

The biological mechanism by which MSUD detects and silences unpaired genes throughout meiosis remains poorly understood. Recent work has suggested the silencing pathway involves a silencing complex that localizes to the perinuclear region, utilizing an RNAi-like mechanism to post-transcriptionally silence unpaired genes. Despite our increasing knowledge regarding what transpires outside of the nucleus during the silencing phase, the mechanism by which MSUD is able to efficiently compare seven homolog pairs during meiosis for unpaired regions within the nucleus remains unresolved.

This study presents evidence that unDNA detection may be affected by the presence of complex unpaired regions of DNA surrounding an unpaired gene. Figure 11 suggests that as the distance of the unpaired region surrounding the unpaired genetic marker increases, the ability of MSUD to detect this genetic marker as unpaired decreases. These findings do not paint a clear picture of how the homology search process used in MSUD works, however several hypotheses can be formulated based upon them.

Results from the study represented in Figure II-3 suggest that detection of unDNA is dependent upon gene proximity and is spatially constrained within the nucleus (Samarajeewa $e t$ 
al. 2014). This proposes that the search mechanism may not scan the entire genome for sequence-level homology, but rather uses a semi-random probing of homologs to detect unDNA. This is more plausible than a mechanism that would have to scan a $40 \mathrm{Mbp}$ genome base-by-base. Building off this hypothesis, if the search for homology involves probed sampling of the genome, then these large, complex, unpaired regions of the genome surrounding a single unpaired gene may be able to mask the presence of this particular unpaired gene by a variety of mechansims.

A possibility stemming from this idea of unDNA masking, is that these complex unpairings could present a physical roadblock to MSUD homology searching machinery. Even if MSUD does not employ a homology scanning mechanism that slides along the genome looking for unDNA, it is likely that a physical binding to unpaired regions is required to produce the aRNA molecule used by MSC (Figure I-2). Perhaps these complex unpaired structures do not allow efficient binding of the unDNA, resulting in lower levels of aRNA molecules produced. A second hypothesis proposes that these large unpaired regions dilute the number of MSUD proteins available to perform silencing. That is, perhaps one or more MUSD proteins is limiting in the search for homology and in the presence of large regions of unpaired DNA, there simply is not enough MSDU machinery to perform a full silencing response. To test this, $\mathrm{v} 0050 \mathrm{H}$ and $\mathrm{v} 0051 \mathrm{H}$, the vectors that replaced a large region of LGVII with the $h p h$ marker could be crossed to a $r s p 4$ MSUD tester strain. In this $r s p 4 \mathrm{x} v 0050 H / v 0051 H$ cross, we would expect to see a full silencing response to the unpaired $r s p$ gene at its native location on the genome. However, if we observe a decrease in $r s p$ silencing, we can hypothesize that the large region of unpaired DNA on LGVII is taking MSUD resources away from the unpaired $r s p$ gene. 
Future experiments could make use of overexpression vectors to determine which, if any, current MSUD protein is limiting.

A third possibility is that these complex unpairings do not actually interfere with unDNA detection, but rather dilute the production of homologous aRNA molecules to the unpaired gene. In this situation, we must assume that every unDNA detection elicits a similar silencing response. In our experiments, we have unpaired the $r s p$ gene to measure MSUD activity. Recall that in the proposed MSUD mechanism, an aRNA molecule is produced from an unpaired region of DNA (Figure I-2). This aRNA molecule should be complementary in sequence to mRNAs transcribed from this region in order to target the mRNA for silencing via RNAi. That is, if $r s p$ is unpaired, aRNA molecules produced from this unDNA should be complementary to the $r s p$ mRNA. If we speculate that similar levels of aRNA molecules are produced from every unDNA detection event, then it is plausible that these complex unpaired regions simply dilute the level of homologous aRNAs available for silencing of $r s p$. For example, we will assume that there is one aRNA molecule produced from any such unpaired region in the genome and that this aRNA molecule is processed into ten siRNA molecules. When $r s p$ is inserted ectopically at a location in the genome that does not produce a complex unpairing of DNA (Figure 10A), aRNA molecules produced from this unpaired event will be mostly complementary to $r s p$ mRNAs which will lead to ten siRNA molecules that are able to silence rsp (Figure 20A). However, in the presence of these large deletions, perhaps the aRNA molecule produced is simply representative of a larger unpaired region that surrounds $r s p$. In this situation, possibly only one or two of the siRNA molecules produced from the aRNA are able to target $r s p$ mRNAs for silencing (Figure 20B). In this situation, we must also assume that an aRNA molecule is produced from each unpaired region on either parental homolog. 
The aRNA molecule has yet to be detected, leaving many of these hypotheses difficult to examine. However, there are several experiments that could be performed to further investigate these possibilities. The first experiment would involve insertion of the $r s p$ gene within the complex DNA structure to determine whether MSUD could detect $r s p$ as paired spatially (Figure 25D). The second experiment would involve insertion of the asm- 1 marker at the same locus as the $r s p$ marker. This cross, $r^{e f} \mathrm{x} a s m-1^{e f}$, may provide insight as to what regions of unDNA produce aRNAs. Increasing complex unpairing surrounding either of these genetic markers may allow us to have a better idea of how these complex regions of DNA affect MSUD. Figure 21 A$\mathrm{C}$ describes an overview of this experiment. One pitfall to this experiment may be that using two genetic markers that affect ascospore phenotype may produce unexpected phenotypes that do not accurately represent levels of silencing.

Another, more expensive experiment, would involve sequencing of total RNA molecules produced in a $r^{e f} \mathrm{X} w t$ cross, a $w t x w t$ cross, and a cross in which $r s p$ is surrounded by complex DNA. By searching for homology to the $r s p$ gene in the RNA molecules, we may be able to determine whether total sequence reads differ between the crossing conditions. An obvious pitfall to this experiment is the cost required for such sequencing, which may or may not result in any useful information.

\section{Patterns Of Interspersed Homology Can Affect Silencing}

Researchers looking into the mechanism by which RIP machinery searches for homology within the $N$. crassa genome discovered that homologous segments of DNA that shared only three base-pairs of sequence homology for every 11-12 base interval were able to be efficiently detected (Gladyshev and Kleckner 2014). This study presents evidence that patterns of interspersed homology to the $r^{e f-1370}$ marker influence the level of silencing of the $r s p$ gene by 
MSUD (Figure 13). The first two patterns investigated were the $r^{e f-1370: 7 H 4 N}$ and $r^{e f-1370: 2 H 1 N}$ fragments. Both of these patterns use an $11 \mathrm{bp}$ interval due to investigate whether major and minor groove interactions of homologous dsDNA is used in MSUD homology searching. The $2 \mathrm{H} 1 \mathrm{~N}$ pattern of homology was chosen to investigate whether identical triplets, similar to what has been observed in RIP, are critical for homology searching. Excitingly, in $r^{e f-1370: 2 H 1 N} \times r^{e f-1370}$ crosses, $r s p$ silencing is observed in approximately $45 \%$ of ascospore phenotypes (Figure 13). This suggests that losing sequence homology at every third base-pair position is somehow allowing MSUD to detect this pattern of homology as unpaired, at least partially. While this 2H1N pattern does not elicit a full MSUD silencing response (i.e. does not produce $80-100 \%$ round-shaped ascospores) as seen in $w t \times r^{e f-1370}$ crosses (Figure 13), it is more efficient at being detected than many other patterns of homology which will be discussed below.

The $7 \mathrm{H} 4 \mathrm{~N}$ pattern of homology was chosen to investigate the interactions of major and minor grooves of dsDNA. Recall that a single turn of a dsDNA helix is approximately $10.4 \mathrm{bp}$ in length. When $r^{e f-1370: 7 H 4 N} \times r^{e f-1370}$ crosses are performed, we do not observe any silencing of $r s p$ (Figure 13), suggesting that this pattern of sequence homology is not flagged as unpaired by the MSUD machinery. This could suggest that interactions between the major grooves of homologous dsDNA is sufficient to signal pairing. To confirm these results, two additional 7H4N fragments were constructed. Each of these fragments retained the same pattern and periodicity of homology, while the sequence position was offset by either two or four bases (Figure 14A). When $r^{\text {ef-1370:7H4NOff2 }} \mathrm{x} r^{e f-1370}$ and $r^{e f-1370: 7 H 4 N O f f 4} \mathrm{x} r^{e f-1370}$ crosses are performed, we still do not observe any silencing of $r s p$ (Figure 14B). This lends evidence to the hypothesis that it is the 7H4N pattern of homology, and not specific sequence homology, that is detected as paired by MSUD. This could further suggest that the search for homology is spatially 
constrained within the nucleus. If chromatin loops that are tethered to the synaptonemal complex are able to "slide" along each other, perhaps homologous base-pairs can flip and briefly interact, signaling a pairing partner. If MSUD does use a sampling method to detect unpaired regions in the genome, contacts made between the seven homologous base pairs in the $7 \mathrm{H} 4 \mathrm{~N}$ pattern may be sufficiently stable to resemble a homologous region within the genome.

Figure 23 outlines results of crosses investigating several patterns of interspersed homology. In nearly all crosses examined, little to no silencing of rsp is observed. These results are similar to the $7 \mathrm{H} 4 \mathrm{~N}$ pattern, suggesting that, if unDNA detection does indeed involve a sequence-level homology search, the search parameters are quite strict. It seems as though MSUD does not use overall levels of homology to detect unDNA. This is most obvious when comparing the results of the $r^{e f-1370: 11 H 22 N} \times r^{e f-1370}$ cross and the $r^{e f-1370: 2 H 1 N} \times r^{e f-1370}$ cross. In $r^{e f-}$ ${ }^{1370: 11 H 22 N} \mathrm{x} r^{e f-1370}$ crosses, overall homology shared between the two $r^{e f}$ markers is only at 33\%, however silencing of the $r s p$ gene is only observed in about $5 \%$ of ascospore phenotypes. Contrastingly, in $r^{e f-1370: 2 H 1 N} \times r^{e f-1370}$ crosses, silencing of the $r s p$ gene is observed in nearly $50 \%$ of ascospore phenotypes, even though total sequence homology shared between the $r^{e f}$ markers is $67 \%$. This suggests that the homology search mechanism used by MSUD may search for homologous triplets during meiosis.

To test this hypothesis further, a six base-pair periodicity fragment could be constructed with the sequence homology pattern of $3 \mathrm{H} 3 \mathrm{~N}$. The results of this cross are difficult to predict, as there are both homologous and non-homologous triplets. This cross could allow us to determine whether it is the presence of non-homologous triplets that trigger silencing or if it is the presence of homologous triplets that suppress silencing. A second experimental fragment with the sequence homology pattern of $1 \mathrm{H} 2 \mathrm{~N}$ could also shed light on how triplets are used by MSUD. In 
this situation, we would expect to see the level of $r s p$ silencing to increase from the $2 \mathrm{H} 1 \mathrm{~N}$ crosses.

Surprisingly, when a non-homologous spacer fragment is inserted at the same location as our $r^{e f-1370}$ marker, detection efficiency of $r^{e f-1370}$ as unpaired is reduced to approximately $25 \%$ of ascospore phenotypes (Figure 16). We would expect these crosses to show a high level of silencing due to the $r^{e f-1370}$ marker being completely unpaired. Additionally, when other unique sequences that shared no homology to the $r^{e f-1370}$ marker were inserted and crossed, a similar result was observed (Figure 14). This may suggest that the absence of a physical piece of DNA to balance homologous chromosomes somehow hinders MSUD's ability to detect unDNA efficiently.

To determine whether the hph marker that is fused to the interspersed homology fragments was interfering with $r s p$ silencing, several inversion and spacer constructs were assembled (Figure 17). By either inverting the $h p h$ marker or replacing it with a portion of the $E$. coli genome, we were able to observed a higher level of silencing when crossed to the nonhomologous spacer fragment $r^{e f-1370: 0 H}$ (Figure 22). This may suggest that paired genes in direct proximity to unpaired genes may affect how MSUD either detects or silences unDNA. Conversely, having unpaired DNA in direct proximity to paired genes does not seem to affect the paired gene's "paired" designation (Figure 19). In the cross of $r^{e f-1370} \times r^{e f-1370}: E C S$, the $r^{e f-1370}$ fragment is paired while the $h p h$ marker is unpaired in direct proximity. Even though there is unpaired DNA fused to the $r^{e f-1370}$ fragment, they are not detected as unpaired. This data is consistent with findings that insertion of the $h p h$ marker next to a meiotic drive element, Spore Killer-2 (sk-2), in N. crassa allows it to be detected as unpaired and therefore silenced throughout meiosis (unpublished data). In the absence of the hph marker, sk-2 elements are able 
to be expressed during meiosis even when unpaired (Harvey et al. 2014), however when the $h p h$ marker is inserted next to an sk-2 element, expression of this element is dependent upon the absence of MSUD.

We have only begun to understand the workings of MSUD, however the last few years of research has uncovered clues as to how this amazing mechanism silences unpaired genes. We still have very little knowledge about how these unDNA regions are detected during meiosis, but the results presented here may provide a starting point for investigating the exact parameters of homology searching. 
Table 3

Strains Used In This Study

\begin{tabular}{|c|c|}
\hline Strain & Genotype \\
\hline P8-43 & rid; his-3; mat $A ;$ mus-52A::bar \\
\hline RTPS 7.2.1 & rid; his-3; mus-52A::bar; LGVII::ref1-hph; mat $A$ \\
\hline RNR 3.6.4 & rid; his-3; mus-52A ::bar; v0069::hph; mat A \\
\hline RNR 4.4.4 & rid; his-3; mus-524 ::bar; v0070::hph; mat $A$ \\
\hline RNR 5.6.1 & rid; his-3; mus-524 ::bar; v0071::hph; mat $A$ \\
\hline RNR 6.2.1 & rid; his-3; mus-52A ::bar; v0072::hph; mat $A$ \\
\hline RNR 7.6.3 & rid; his-3; mus-52A ::bar; v0073::hph; mat A \\
\hline HDS 21.3.1 & rid; his-3; mus-52A ::bar; v0050R::hph; mat $A$ \\
\hline HDS 22.1.4 & rid; his-3; mus-52A ::bar; v0051R::hph; mat $A$ \\
\hline HPM 18.11.1 & rid; his-3; mus-52A ::bar; v0064::hph; mat $A$ \\
\hline HPM 19.12.6 & rid; his-3; mus-52A ::bar; v0065::hph; mat $A$ \\
\hline HPM 20.7.13 & rid; his-3; mus-52A ::bar; v0066::hph; mat $A$ \\
\hline HPM 21.1.3 & rid; his-3; mus-52A ::bar; v0067::hph; mat $A$ \\
\hline HPM 22.7.1 & rid; his-3; mus-52A ::bar; v0050H::hph; mat $A$ \\
\hline HPM 23.4.6 & rid; his-3; mus-52A ::bar; v0051H::hph; mat $A$ \\
\hline $\mathrm{RAB} 10.47$ & rid; his-3::ref-1370::hph; mat a; fl \\
\hline RTH 1005.2 & rid; mat a; $f l$ \\
\hline RNR 1.1 & rid; his-3::ref-1370::hph; mat $A$ \\
\hline RNR 2.3 & rid; his-3::ref-1370:0H::hph; mat $A$ \\
\hline RNR 3.2 & rid; his-3::ref-1370:7H4N::hph; mat A \\
\hline RNR 4.1 & rid; his-3::ref-1370:2H1N::hph; mat A \\
\hline RNR 5.1 & rid; mat $A$ \\
\hline HNR 57.1 & rid; his-3::ref-1370 7H4NOff $2:$ hph; mat $A$ \\
\hline HNR 58.2 & rid; his-3::ref-1370 7H4NOff4::hph; mat $A$ \\
\hline HNR 61.1 & rid; his-3::E.coli $R 2::$ hph; mat $A$ \\
\hline HNR 62.1 & rid; his-3::E.coli R3::hph; mat A \\
\hline HNR 63.1 & rid; his-3::H. sapiens Rl::hph; mat $A$ \\
\hline HNR 64.1 & rid; his- $3:: H$. sapiens $R 2: \because$ hph; mat $A$ \\
\hline T511.1 & rid; his-3::ref-1370:3H8N::hph; mat $A$ \\
\hline T512.1 & rid; his-3::ref-1370:3H8NOff $4::$ hph; mat $A$ \\
\hline T513.1 & rid; his-3::ref-1370:4H7N::hph; mat $A$ \\
\hline T514.1 & rid; his-3::ref-1370:5H6N::hph; mat A \\
\hline T515.1 & rid; his-3::ref-1370:6H5N::hph; mat A \\
\hline T516.1 & rid; his-3::ref-1370:11H11N::hph; mat $A$ \\
\hline T517.1 & rid; his-3::ref-1370:11H22N::hph; mat $A$ \\
\hline RNR 94.1.6 & rid; mat a; ref::hph invert::his-3; fl- \\
\hline RNR 95.10.3 & rid; mat a; ref::E. coli spacer $A: \because$ his- 3 ; fl- \\
\hline RNR 98.1.8 & rid; mat a; ref invert::hph invert::his-3; fl- \\
\hline
\end{tabular}




\section{Table 4}

Complex unDNA Cross Results.

\begin{tabular}{|l|l|l|}
\hline Cross \# & Strain Name & \% Round spores \\
\hline 1 & $1005.2 \times$ RNR 3.6 .4 & $80.25 \%+/-1.7 \%$ \\
\hline 2 & $1005.2 \times$ RNR 4.4 .4 & $73.00 \%+/-1.4 \%$ \\
\hline 3 & $1005.2 \times$ RNR 5.6 .1 & $86.50 \%+/-2.3 \%$ \\
\hline 4 & $1005.2 \times$ RNR 6.2 .1 & $83.00 \%+/-5.1 \%$ \\
\hline 5 & $1005.2 \times$ RNR 7.6 .3 & $64.50 \%+/-2.6 \%$ \\
\hline 6 & $1005.2 \times$ HDS 21.3 .1 & $36.25 \%+/-4.7 \%$ \\
\hline 7 & $1005.2 \times$ HDS 22.1 .4 & $45.75 \%+/-3.6 \%$ \\
\hline 8 & $1005.2 \times$ HPM 18.11 .1 & $89.00 \%+/-6.0 \%$ \\
\hline 9 & $1005.2 \times$ HPM 19.12 .6 & $69.25 \%+/-2.6 \%$ \\
\hline 10 & $1005.2 \times$ HPM 20.7 .13 & $70.75 \%+/-6.3 \%$ \\
\hline 11 & $1005.2 \times$ HPM 21.1 .3 & $97.25 \%+/-1.7 \%$ \\
\hline 12 & $1005.2 \times$ HPM 22.7 .1 & $0 \%+/-0.0 \%$ \\
\hline 13 & $1005.2 \times$ HPM 23.4 .6 & $0 \%+/-0.0 \%$ \\
\hline 14 & $1005.2 \times$ RTPS 7.2 .1 & $99.25 \%+/-0.5 \%$ \\
\hline 15 & $1005.2 \times$ P8-43 & $0 \%+/-0.0 \%$ \\
\hline
\end{tabular}




\section{Table 5}

Complex unDNA Vector Descriptions

\begin{tabular}{|l|l|l|}
\hline Vector & Deletion Size (bp) & \% $\boldsymbol{r s p}$ Silenced \\
\hline v67 & 26 & $98.5 \%$ \\
\hline v64 & 86 & $95.7 \%$ \\
\hline v69 & 5764 & $83.0 \%$ \\
\hline v70 & 9627 & $82.75 \%$ \\
\hline v65 & 10925 & $91.5 \%$ \\
\hline v71 & 11568 & $82.75 \%$ \\
\hline v72 & 13216 & $97.75 \%$ \\
\hline v66 & 19125 & $83.88 \%$ \\
\hline v73 & 20248 & $68.5 \%$ \\
\hline v51R & 30657 & $45.0 \%$ \\
\hline v50R & 48642 & $36.0 \%$ \\
\hline
\end{tabular}




\section{Table 6}

Interspersed Homology Fragment Crosses

\begin{tabular}{|c|c|c|}
\hline Cross \# & Strain Name & $\%$ Round spores \\
\hline 1 & $1005.2 \times \mathrm{RNR} 1.1$ & $66.4 \%+/-1.4 \%$ \\
\hline 2 & $1005.2 \times \mathrm{RNR} 2.3$ & $0 \%+/-0.0 \%$ \\
\hline 3 & $1005.2 \times \mathrm{RNR} 3.2$ & $0 \%+/-0.0 \%$ \\
\hline 4 & $1005.2 \times \mathrm{RNR} 4.1$ & $0 \%+/-0.0 \%$ \\
\hline 5 & $1005.2 \times$ RNR 5.1 & $0 \%+/-0.0 \%$ \\
\hline 6 & $1005.2 \times$ HNR 57.1 & $0 \%+/-0.0 \%$ \\
\hline 7 & $1005.2 \times$ HNR 58.2 & $0 \%+/-0.0 \%$ \\
\hline 8 & $1005.2 \times$ HNR 61.1 & $0 \%+/-0.0 \%$ \\
\hline 9 & $1005.2 \times$ HNR 62.1 & $0 \%+/-0.0 \%$ \\
\hline 10 & $1005.2 \times$ HNR 63.1 & $0 \%+/-0.0 \%$ \\
\hline 11 & $1005.2 \times$ HNR 64.1 & $0 \%+/-0.0 \%$ \\
\hline 12 & $1005.2 \times$ T5 11.1 & $0 \%+/-0.0 \%$ \\
\hline 13 & $1005.2 \times \mathrm{T} 512.1$ & $0 \%+/-0.0 \%$ \\
\hline 14 & $1005.2 \times \mathrm{T} 513.1$ & $0 \%+/-0.0 \%$ \\
\hline 15 & $1005.2 \times \mathrm{T} 514.1$ & $0 \%+/-0.0 \%$ \\
\hline 16 & $1005.2 \times \mathrm{T} 515.1$ & $0 \%+/-0.0 \%$ \\
\hline 17 & $1005.2 \times$ T516.1 & $0.37 \%+/-0.6 \%$ \\
\hline 18 & $1005.2 \times \mathrm{T} 517.1$ & $0 \%+/-0.0 \%$ \\
\hline 19 & RAB $10.47 \times$ RNR 1.1 & $0 \%+/-0.0 \%$ \\
\hline 20 & RAB $10.47 \times$ RNR 2.3 & $24.57 \%+/-1.7 \%$ \\
\hline 21 & RAB $10.47 \times$ RNR 3.2 & $0 \%+/-0.0 \%$ \\
\hline 22 & RAB $10.47 \times$ RNR 4.1 & $45.87 \%+/-4.5 \%$ \\
\hline 23 & RAB $10.47 \times$ RNR 5.1 & $81.97 \%+/-1.7 \%$ \\
\hline 24 & RAB $10.47 \times$ HNR 57.1 & $0 \%+/-0.0 \%$ \\
\hline 25 & RAB $10.47 \times$ HNR 58.2 & $0 \%+/-0.0 \%$ \\
\hline 26 & RAB $10.47 \times$ HNR 61.1 & $26.43 \%+/-1.2 \%$ \\
\hline 27 & RAB $10.47 \times$ HNR 62.1 & $22.93 \%+/-1.9 \%$ \\
\hline 28 & RAB $10.47 \times$ HNR 63.1 & $19.30 \%+/-0.8 \%$ \\
\hline 29 & RAB $10.47 \times$ HNR 64.1 & $28.70 \%+/-3.1 \%$ \\
\hline 30 & RAB $10.47 \times$ T511.1 & $28.43+/-3.1 \%$ \\
\hline 31 & RAB $10.47 \times$ T512.1 & $2.20 \%+/-0.14 \%$ \\
\hline 32 & RAB $10.47 \times$ T513.1 & $0 \%+/-0.0 \%$ \\
\hline 33 & RAB $10.47 \times$ T514.1 & $0.43 \%+/-0.75 \%$ \\
\hline 34 & RAB $10.47 \times$ T515.1 & $0 \%+/-0.0 \%$ \\
\hline 35 & RAB $10.47 \times$ T516.1 & $0 \%+/-0.0 \%$ \\
\hline 36 & RAB $10.47 \times$ T517.1 & $5.20 \%+/-1.3 \%$ \\
\hline
\end{tabular}


A.

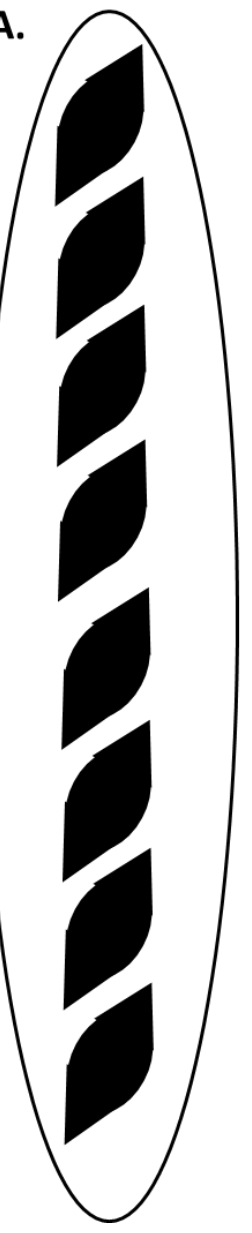

B.

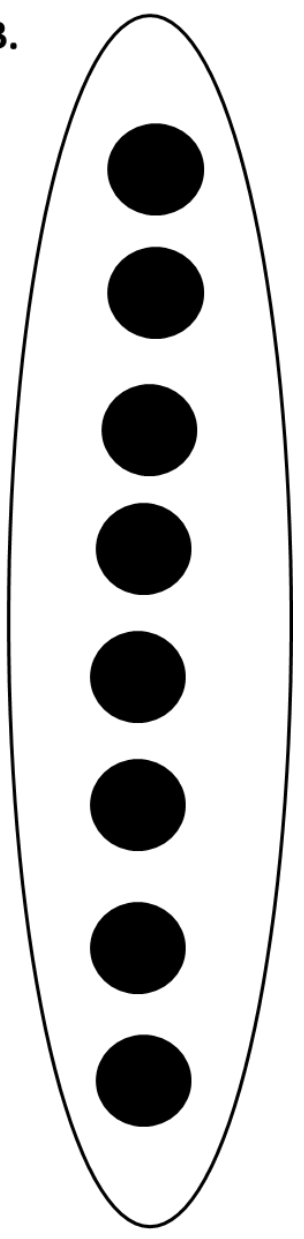

\section{Figure 4: Ascospore phenotypes}

Ascospore phenotypes can be used to determine MSUD efficiency. A.) When $r s p$ is paired during meiosis, spindle-shaped ascospores are produced. B.) When $r s p$ is unpaired during meiosis, MSUD silences the expression of $r s p$, resulting in round-shaped ascospores. 
A.

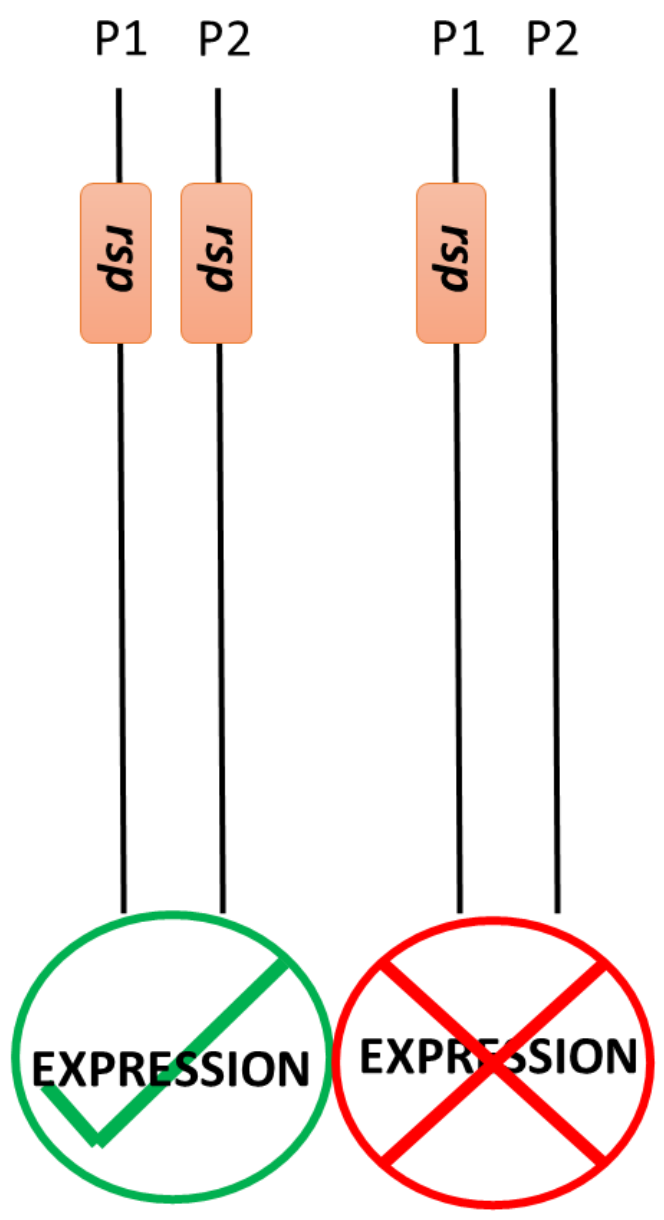

C. P1 P2
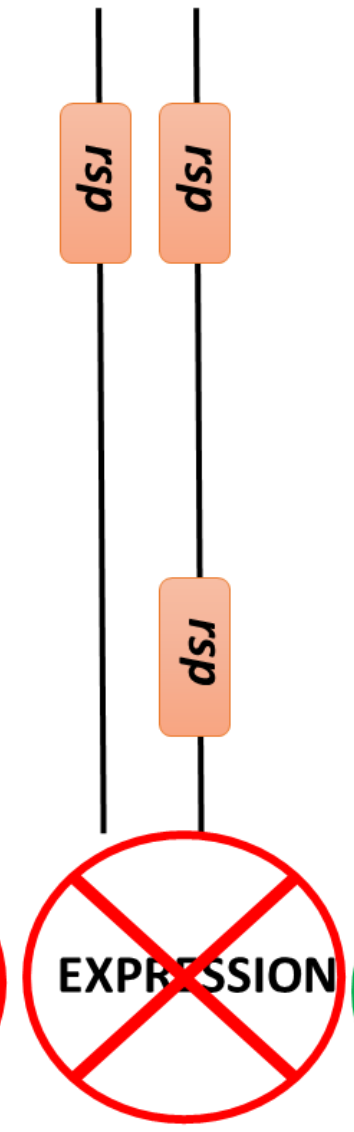

D.
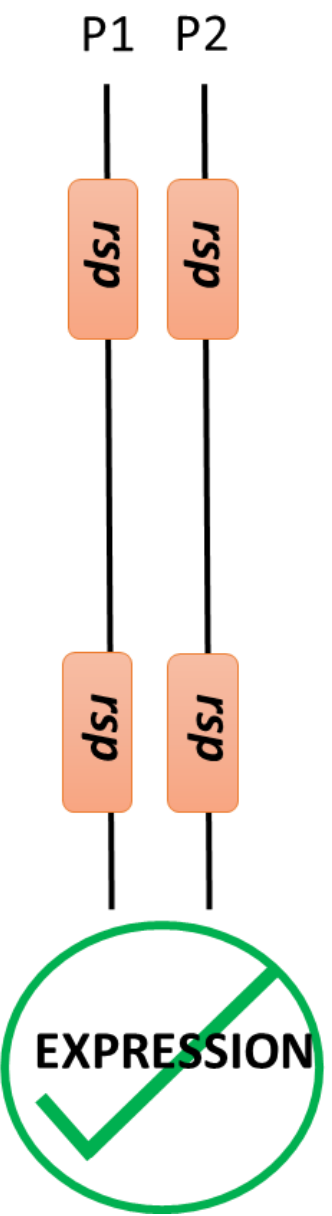

Figure 5: Conditions of gene silencing in MSUD

A.) When $r s p$ alleles are paired on homologous chromosomes of both parent strains (P1 and P2), there is no silencing and $r s p$ is expressed. B.) When $r s p$ alleles are unpaired on their homologous chromosomes, expression of $r s p$ is silenced. C.) Paired $r s p$ alleles on homologous chromosomes are silenced in the presence of an unpaired, ectopic copy of $r s p$. Expression of $r s p$ is silenced in cases where the ectopic copy is located on the same chromosome as well as cases in which the ectopic copy is located on a different chromosome than its paired alleles. D.) Pairing of an ectopic copy of $r s p$ restores expression of $r s p$. 
A.

B.

C.

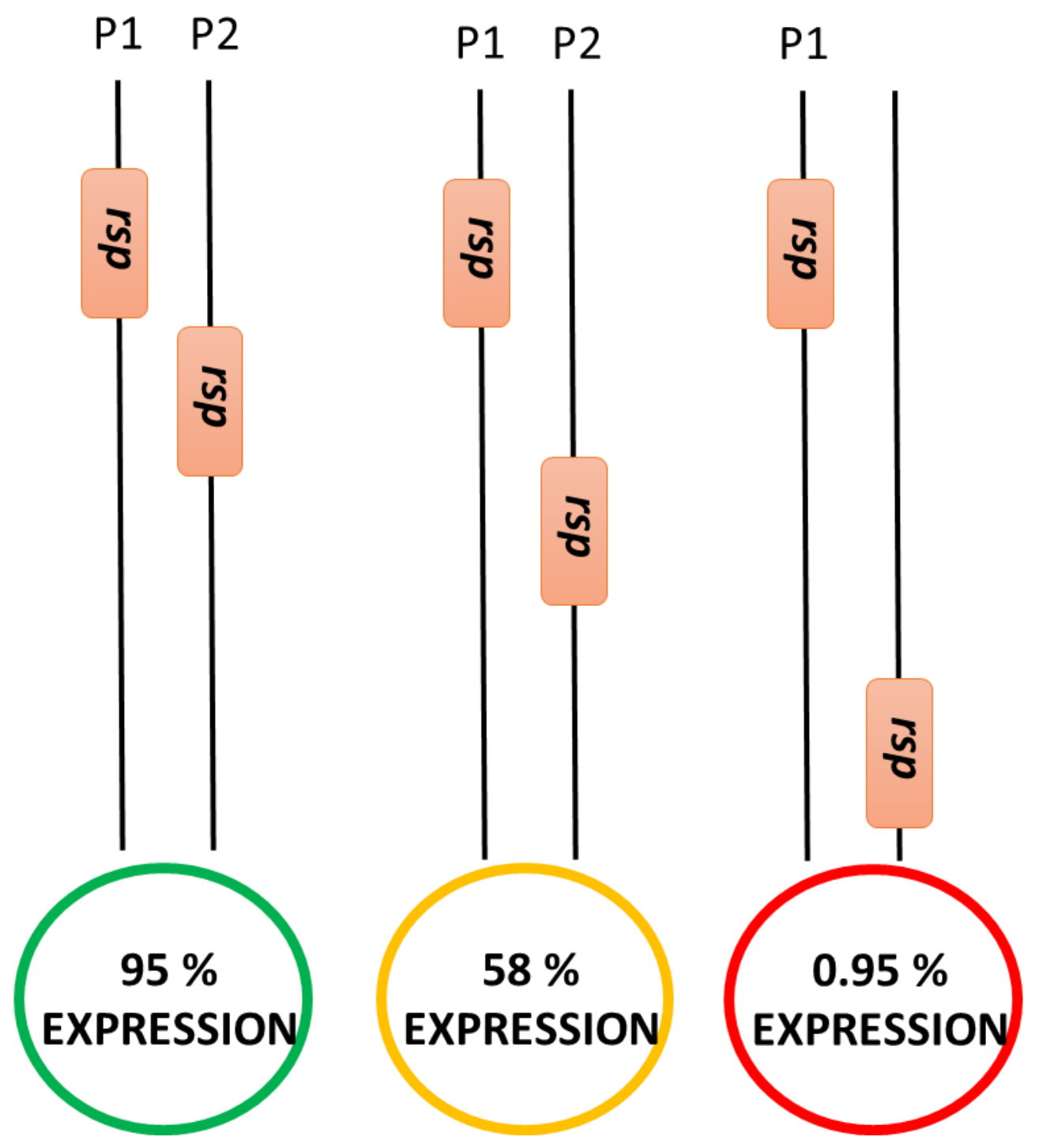

Figure 6: As unpaired distance increases, unDNA detection increases.

A.) When $r s p$ alleles are located $4.1 \mathrm{~kb}$ apart on homologous chromosomes MSUD fails to detect the alleles as unpaired in $95 \%$ of ascospore phenotypes. B.) Increasing the unpaired distance to $18 \mathrm{~kb}$ results detection of unDNA in $42 \%$ of ascospore phenotypes. C.) A distance of $1.2 \mathrm{Mbp}$ results in a fully functional MSUD silencing response, with $99.05 \%$ of ascospore phenotypes experiencing silencing of $r s p$. 

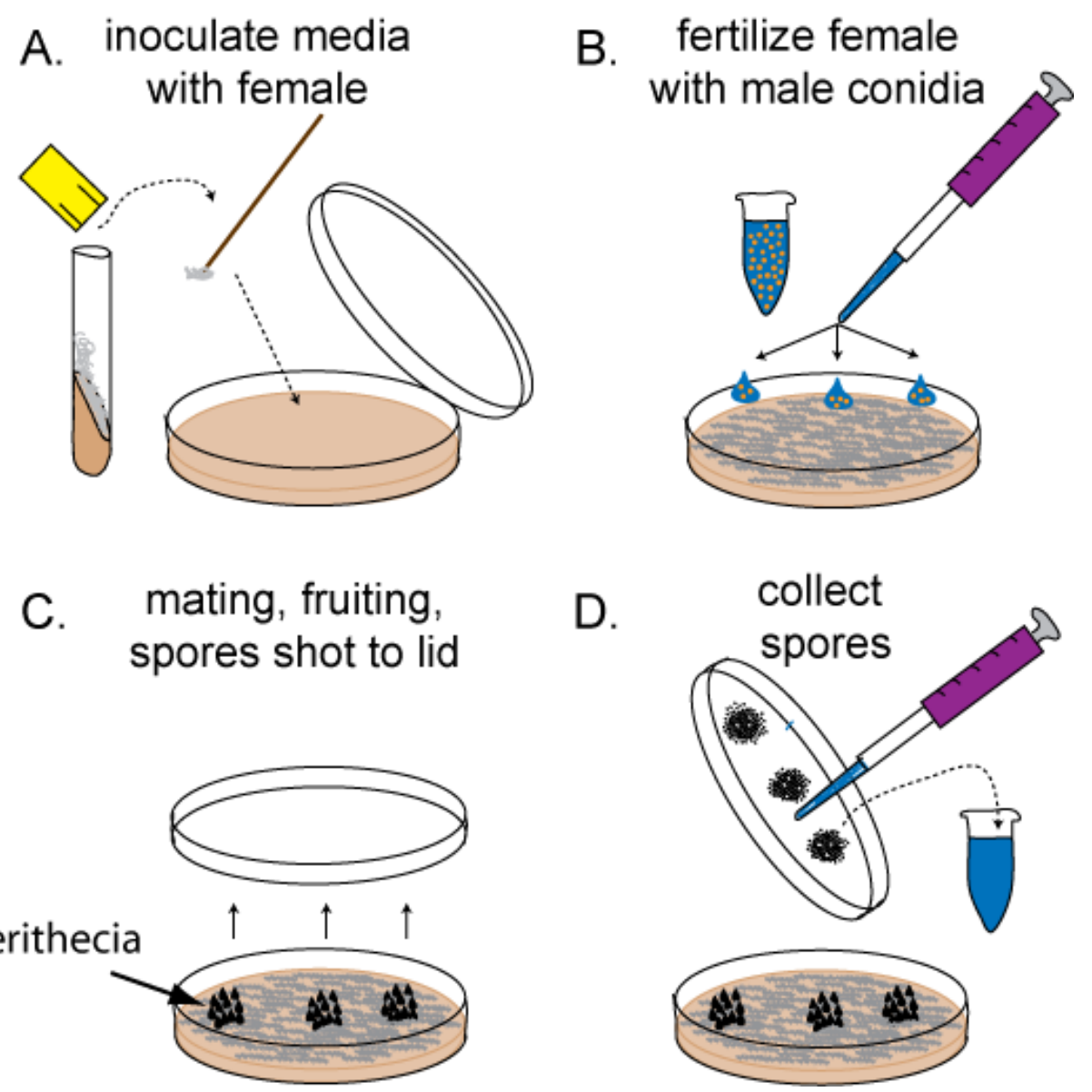

\section{Figure 7: Unidirectional crossing method}

A.) Six days prior to fertilization, female strains are inoculated to $60 \mathrm{~mm} \mathrm{SCM} \mathrm{crossing} \mathrm{plates}$ and are grown at room temperature. B.) Six days post-female inoculation, a conidial suspension of the male strain is diluted to 1000 conidial cells $/ \mu \mathrm{L}$. The female strain is fertilized with $33 \mathrm{uL}$ of diluted conidial suspension on three locations. C.) 21 days post-fertilization, perithecia will shoot ascospores to the lid of the SCM crossing plate. D.) Three washes using $330 \mathrm{uL}$ of sterile $\mathrm{H} 2 \mathrm{O}$ are used to collect the ascospores from the lid. Following collection, $10 \mathrm{uL}$ of this ascospore suspension is used to calculate the phenotype ratio of ascospores. 
A.
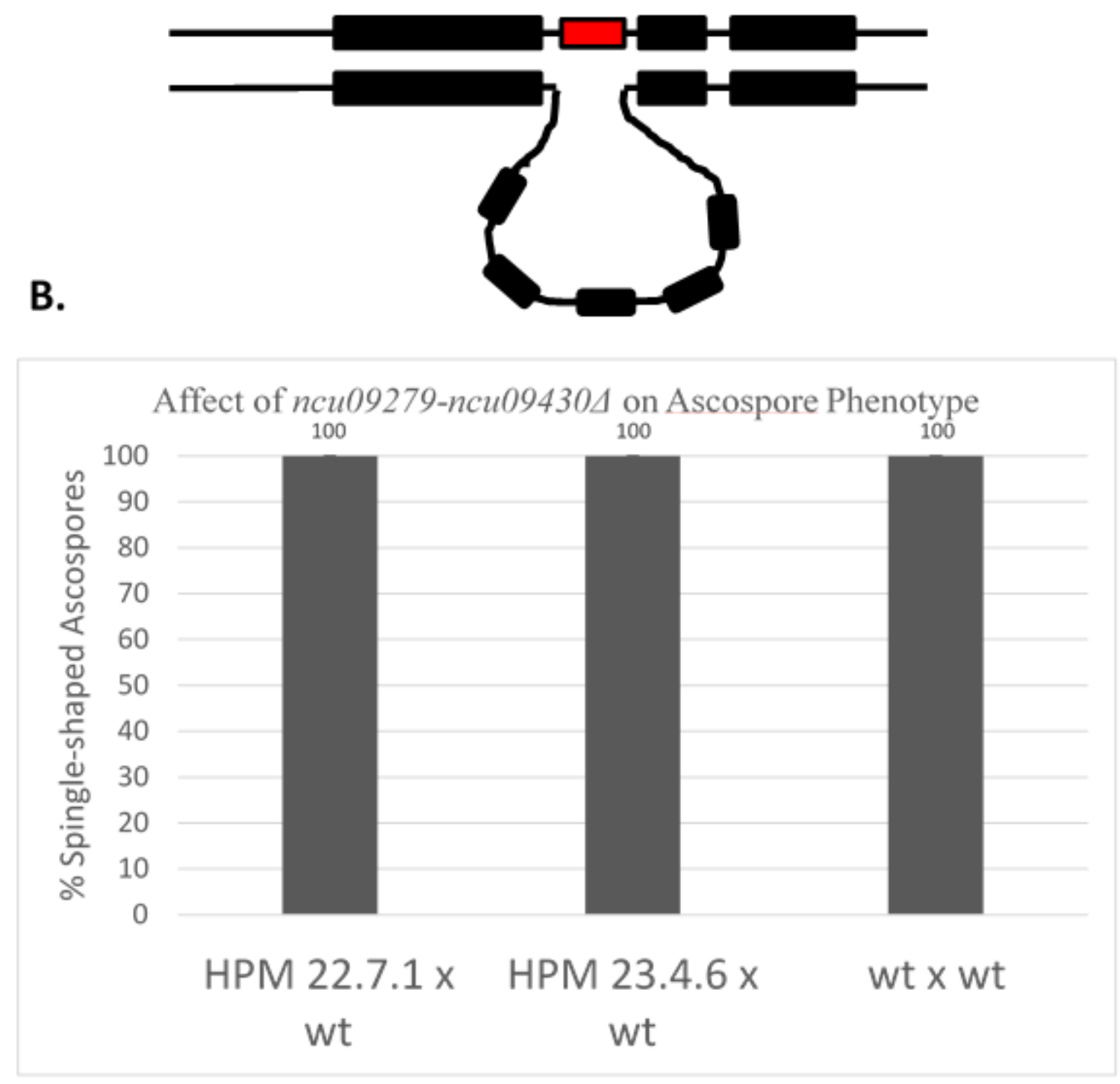

Figure 8: Deletion of hypothetical genes ncu09279-ncu094304 does not affect ascospore phenotype.

Red box denotes the hygromycin-resistance marker. Black boxes represent alleles. A.) Deletion of the $45 \mathrm{~kb}$ region including genes ncu09279-ncu09430 by insertion of a $h p h$ hygromycinresistance marker (red) results in the unpairing of these genes during meiosis. B.) Deletion of ncu09279-ncu09430 does not affect the production of spindle-shaped ascospores when crossed to a $w t$ strain. 


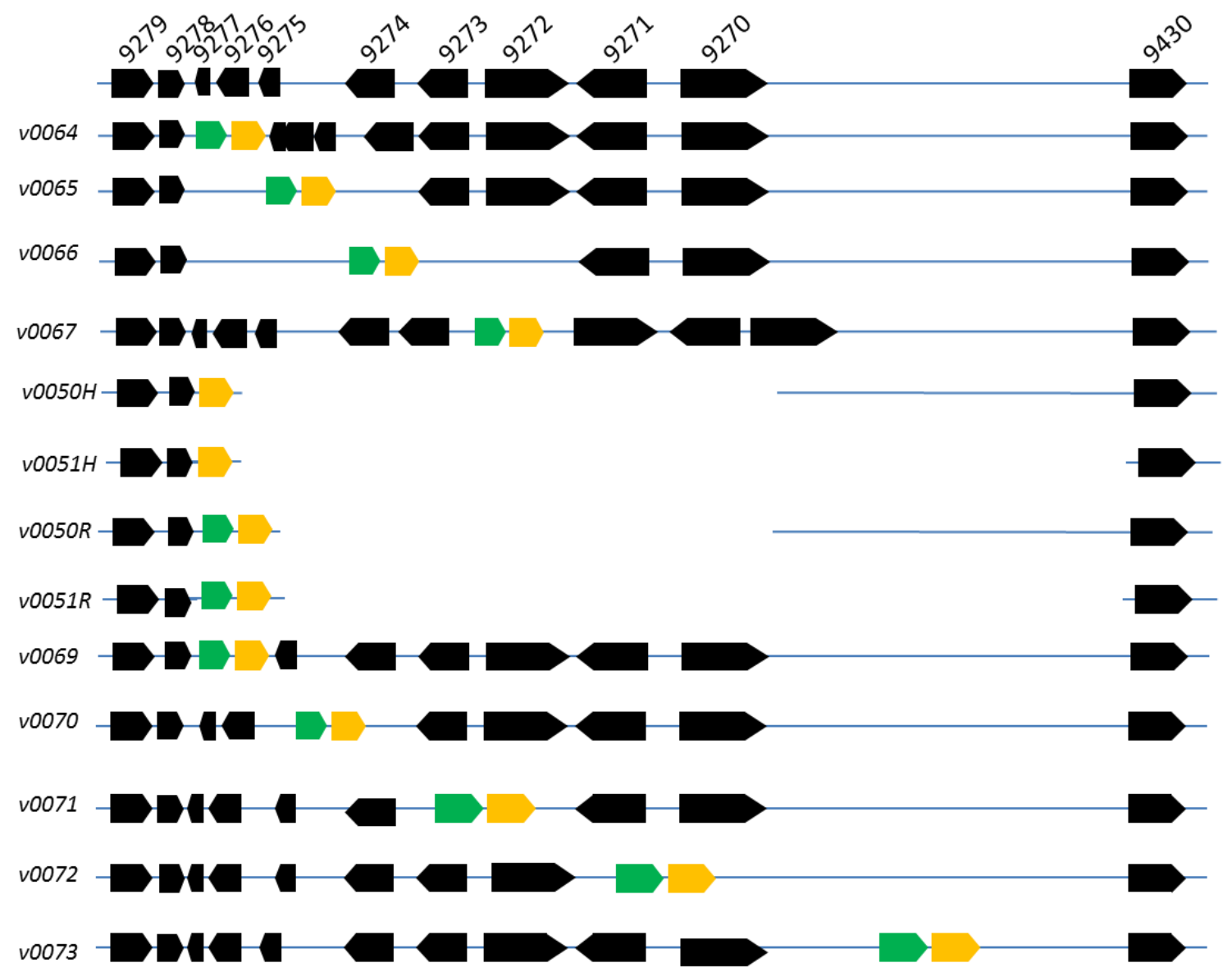

Figure 9: v50R-v73 deletion vector insertion sites.

Black boxes represent hypothetical genes. Green arrows represent $r s p$ gene insertion. Yellow arrows represent the hygromycin-resistance marker. 


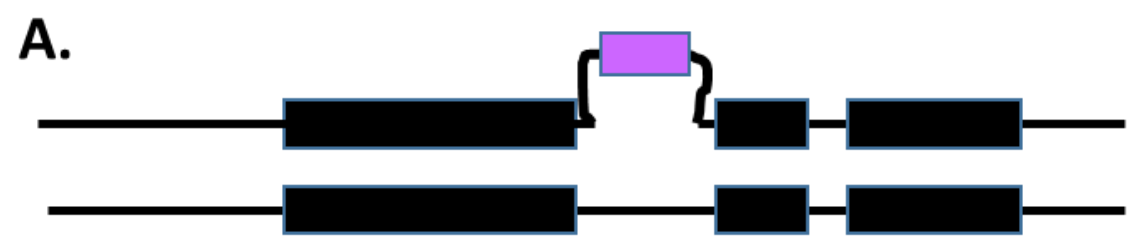

B.

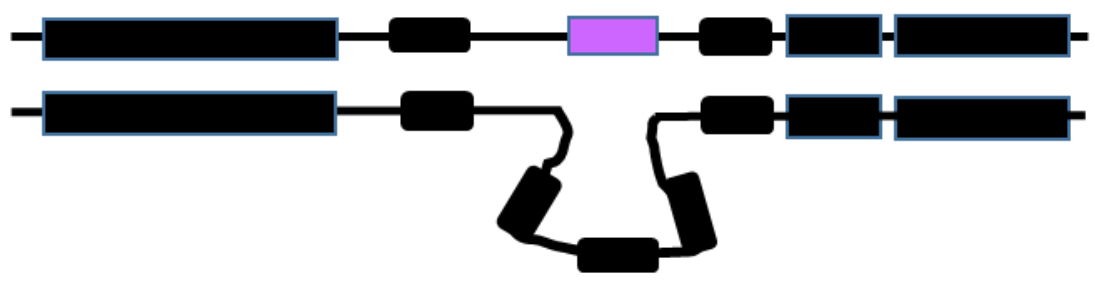

C.

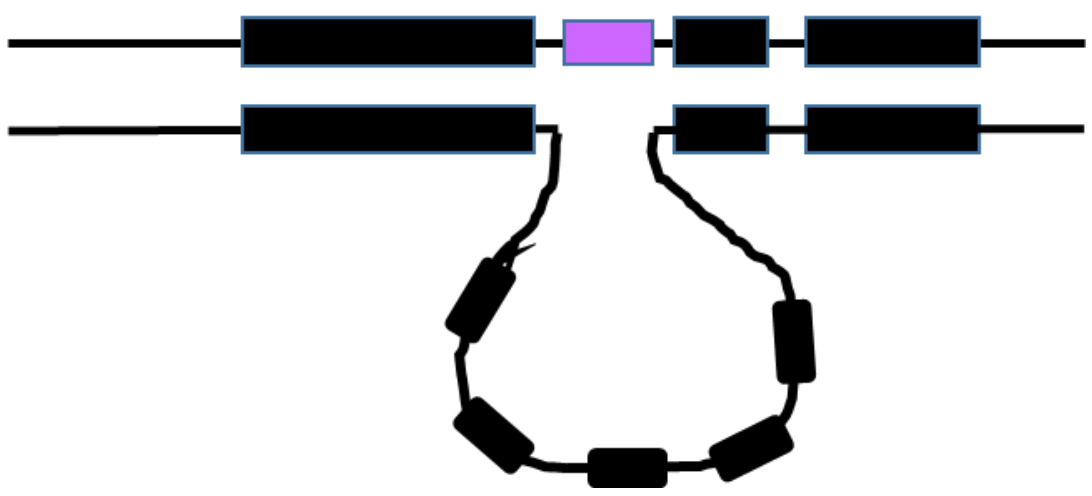

Figure 10: Deletion of large regions of DNA to insert a genetic marker results in large unpaired structures.

A.) Deletion of 200bp of DNA to insert the $r^{e f}$ marker (purple box) results in a small amount of unpaired DNA. B.) Increasing the amount of DNA deleted to insert the $r^{e f}$ marker forms complex structures of unpaired DNA. C.) Deletion of 45kb of DNA forms a larger region of unpaired DNA. 


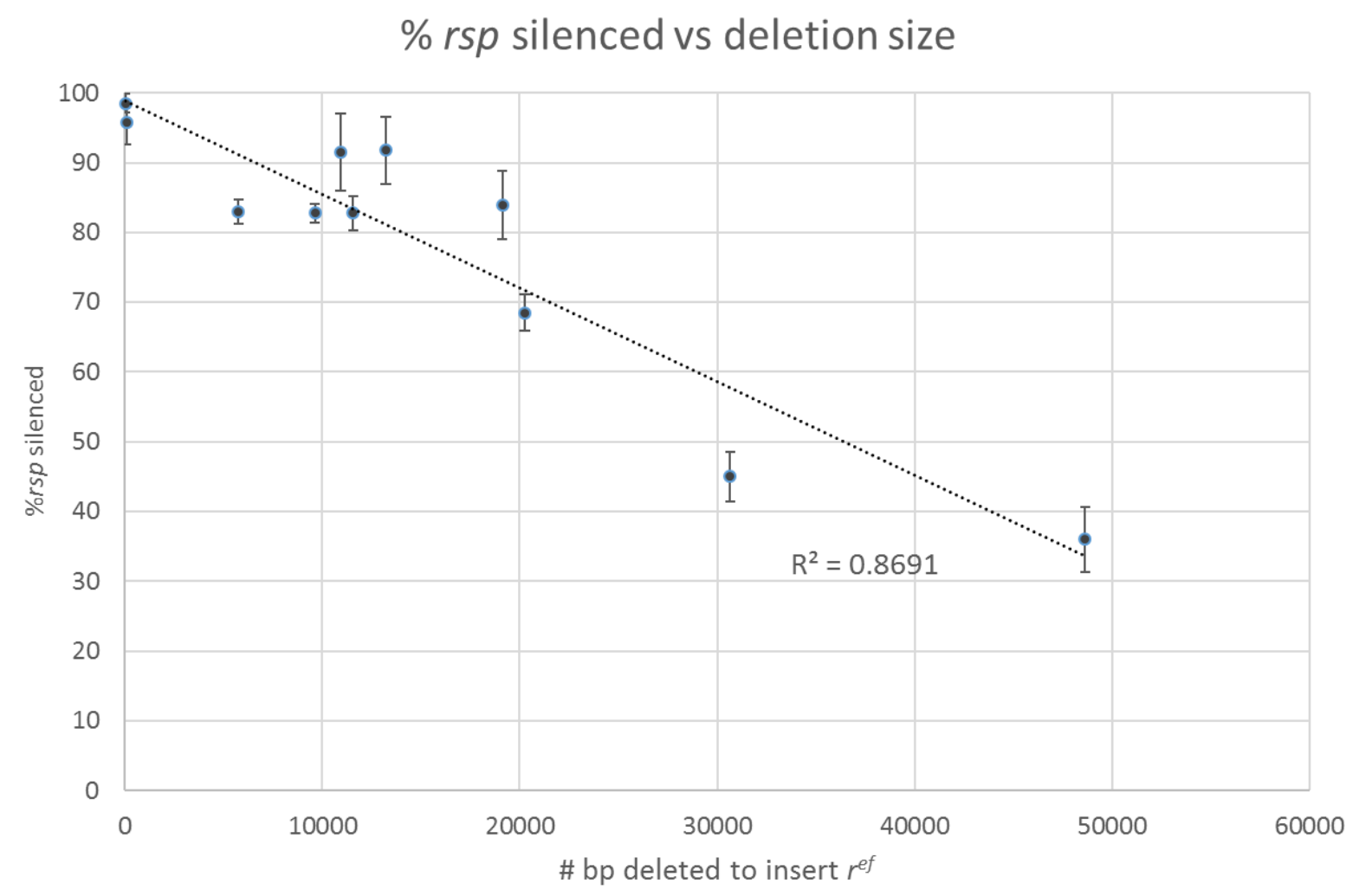

Figure 11: MSUD efficiency decreases as unpaired distance increases.

Deleting a small amount (20-100bp) of DNA to insert the $r^{e f}$ marker results in efficient unDNA detection. Deletion of a large amount $(45 \mathrm{~kb})$ of DNA to insert the $r^{e f}$ marker interferes with MSUD's ability to detect unDNA efficiently. 
A.

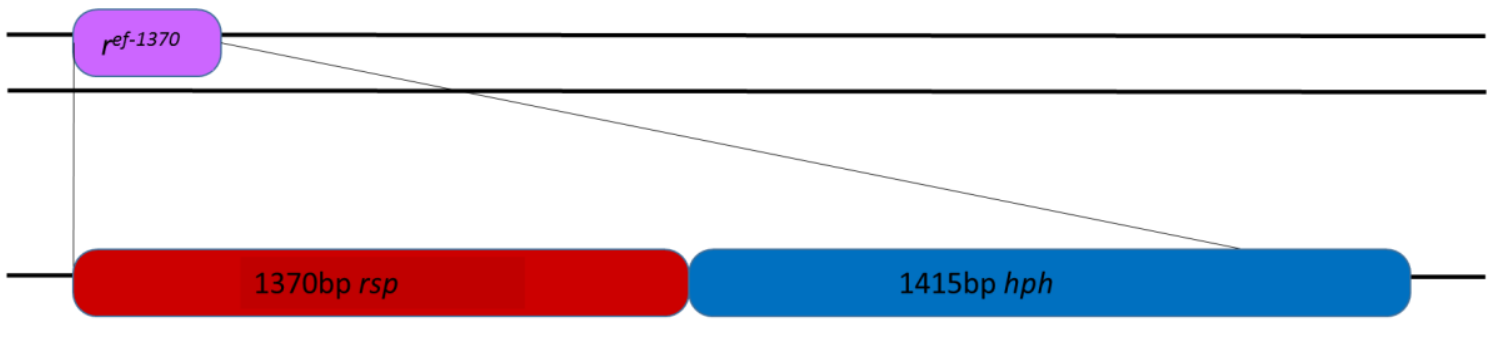

B.

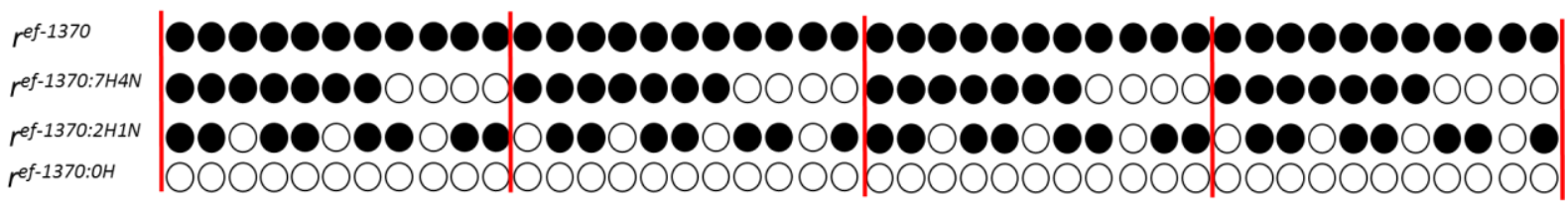

Figure 12: $r^{e f-1370}$ marker construct and interspersed homology to microhomology fragments.

A.) The $r^{e f-1370}$ marker is constructed by fusion of a 1370-bp fragment of the $r s p$ gene with the $h p h$ hygromycin-resistance gene. B.) Patterns of interspersed homology to the $r^{e f-1370}$ marker are represented by black and white dots. Each dot represents a single nucleotide at that position. A black dot represents a homologous base-pair at that position. A white dot represents a nonhomologous base-pair at that position. 

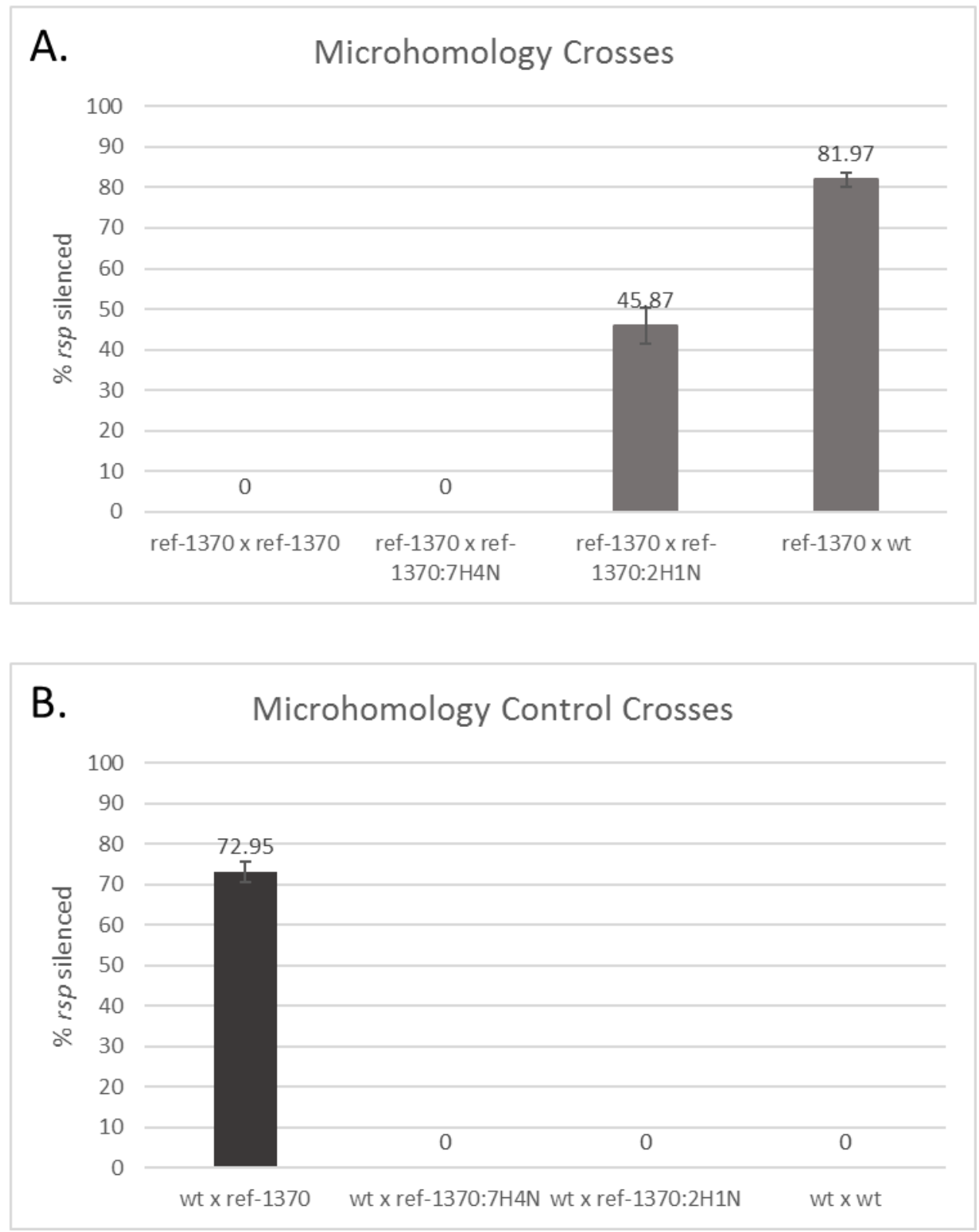

Figure 13: Interspersed homology patterns affect the detection of unDNA.

A.) Paired crosses between $r^{e f-1370} \mathrm{x} r^{e f-1370}$ result in no silencing of $r s p$ due to the markers being paired on homologous chromosomes. Crosses of $r^{e f-1370} \times r^{e f-1370: 7 H 4 N}$ do not result in silencing of $r s p$. An unpaired $r^{e f-1370}$ marker in the cross $r^{e f-1370} \mathrm{x} w t$ shows silencing of $r s p$ in $81.97 \%$ of ascospore phenotypes. The cross $r^{e f-1370} \mathrm{x} r^{e f-1370: 2 H 1 N}$ shows silencing occurring in $45.87 \%$ of ascospore phenotypes. 

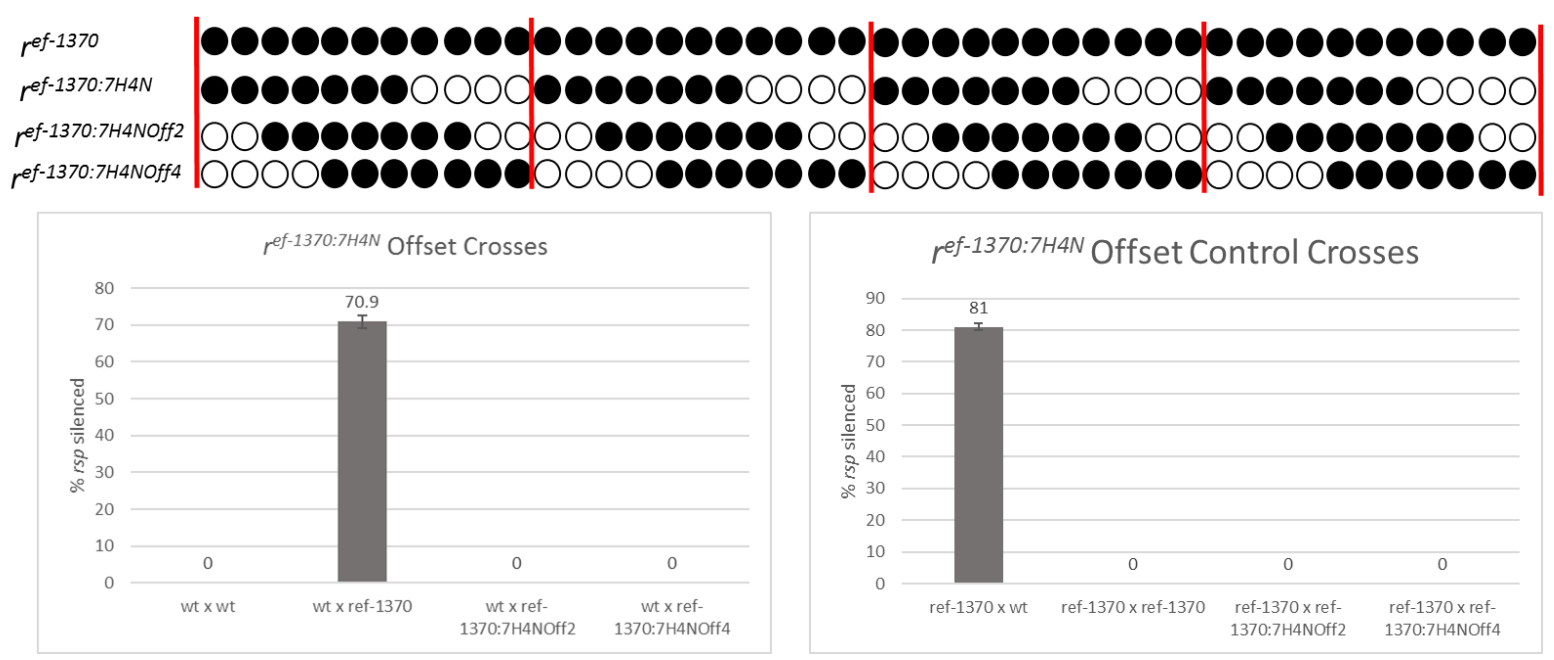

Figure 14: The $\mathbf{r}^{e f-1370: 7 H 4 N}$ pattern of interspersed homology is not detected as unpaired.

A.) Pattern of homology in $\mathrm{r}^{e f-1370: 7 H 4 N}$ offset markers in relation to the $\mathrm{r}^{e f-1370}$ marker. B.) Offset markers do not show silencing of $r s p$ when crossed to $\mathrm{r}^{e f-1370 .}$ 

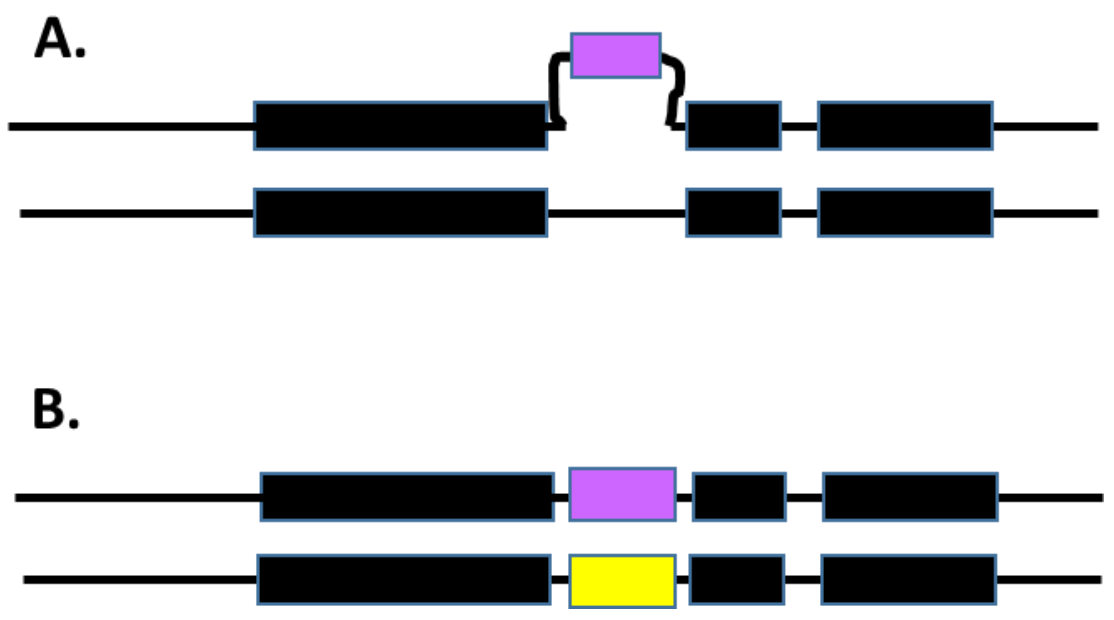

Figure 15: Spacer fragments paired with the $r^{e f-1370}$ marker balance homologous chromosomes.

A.) Insertion of the $r^{e f-1370}$ marker (purple) at the his-3 locus produces unbalanced homologous chromosomes. B.) Spacer fragments (yellow) containing zero sequence homology at any position to the $r^{e f-1370}$ marker place a physical piece of DNA across from the genetic marker. 

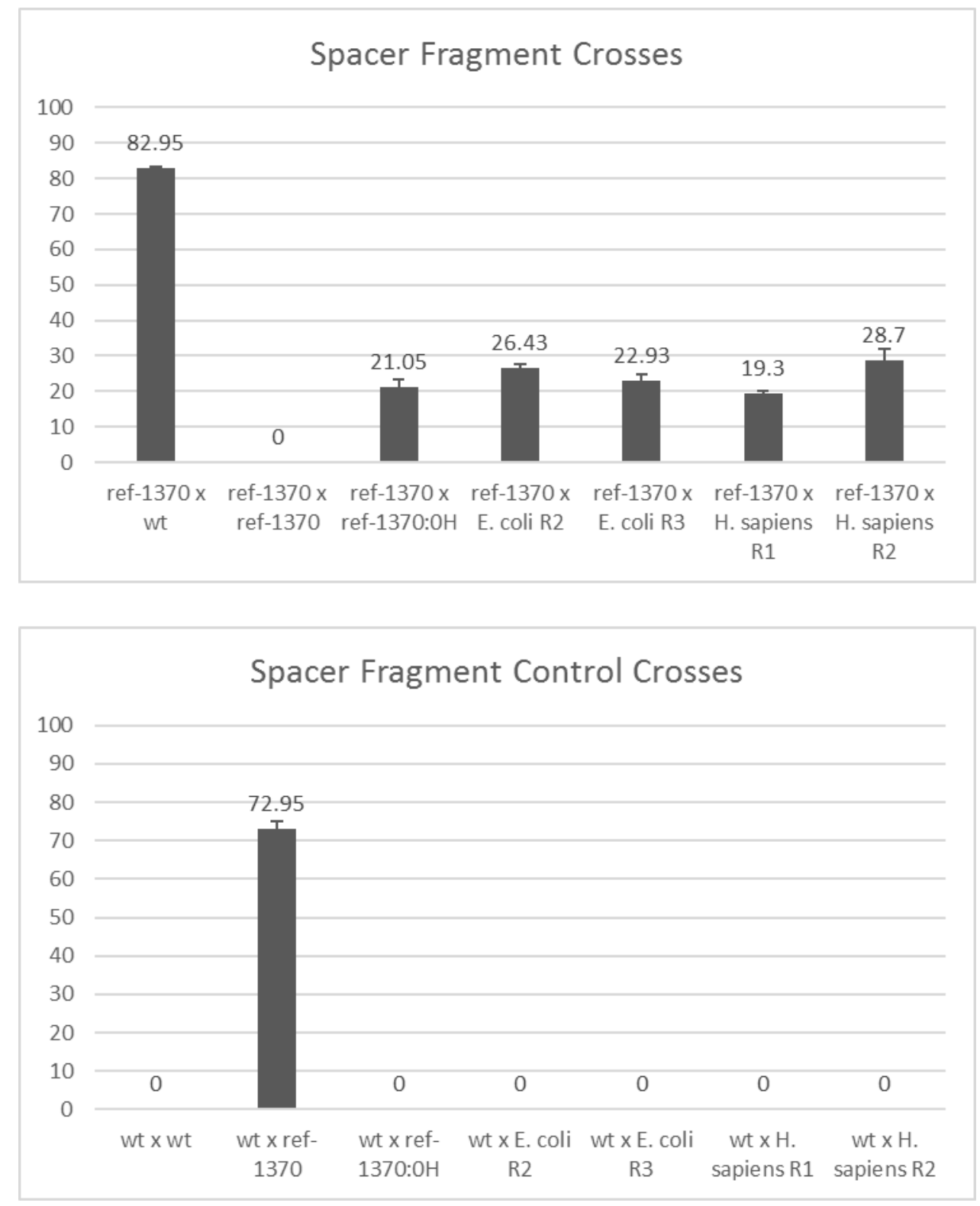

Figure 16: Placing a non-homologous segment of DNA across from a genetic marker reduces unDNA detection efficiency.

When the $r^{e f-1370}$ marker is unpaired in a cross of $r^{e f-1370} \mathrm{x} w t, r^{e f-1370}$ is detected as unpaired in $82.95 \%$ of ascospore phenotypes. Insertion of a non-homologous spacer fragment at the same location on a homologous chromosome reduces unDNA detection efficiency to approximately $25 \%$ of ascospore phenotypes. 

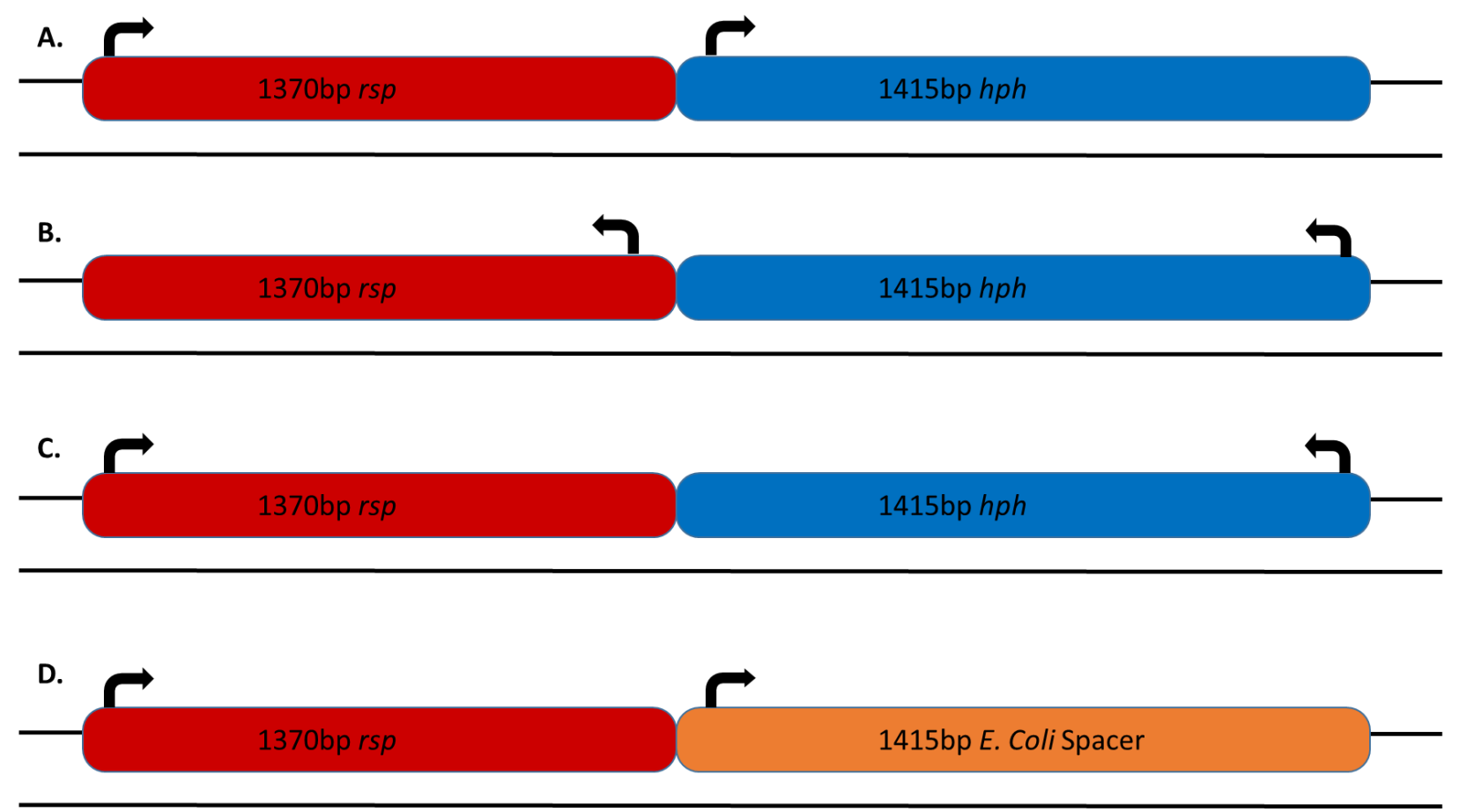

\section{Figure 17: $r^{e f-1370}$ Inversion spacer constructs}

A.) $r^{e f-1370}$ original construct as depicted in Figure 12A. Arrows indicate orientation in relation to the rest of the construct. B.) $r^{e f-1370}$ inv $:$ hphinv vector construct. Inversion of the $1370 \mathrm{bp}$ fragment of $r s p$ renders it unpaired with the $r^{e f-1370}$ at a sequence position level in addition to the $h p h$ inversion, which unpairs this marker with the $h p h$ marker of $r^{e f-1370}$ at a sequence position level. C.) $r^{e f-1370}:$ :hphinv vector construct. Inverting the $h p h$ selectable marker unpairs this marker with the $h p h$ marker of $r^{e f-1370}$ at a sequence position level. D.) $r^{e f-1370}: \because E C S$ vector construct. Replacing the $h p h$ marker with a $1415 \mathrm{bp}$ fragment of the E. coli genome leaves the $r s p$ fragment paired while unpairing the $h p h$ marker. 


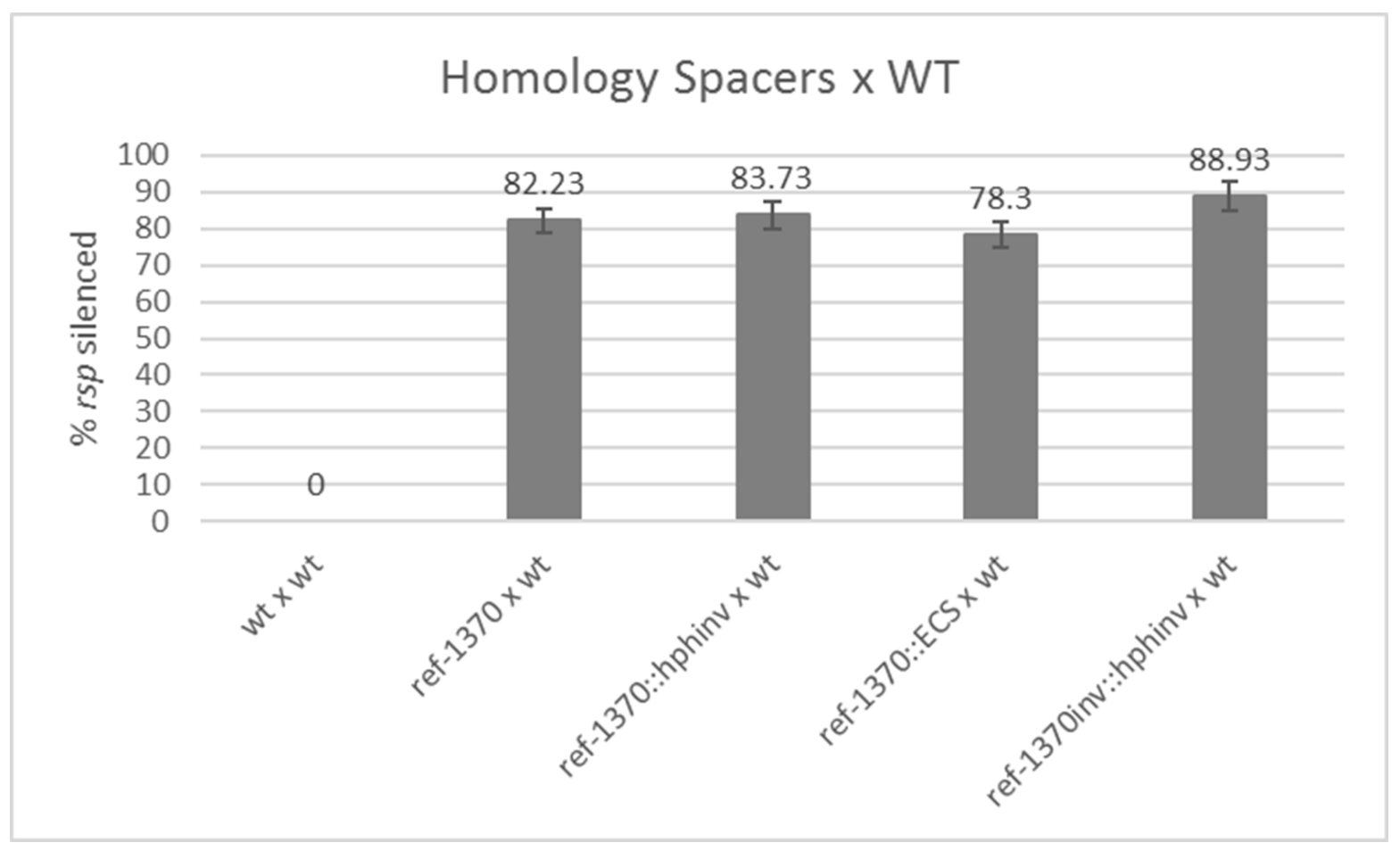

Figure 18: Unpairing the $h p h$ marker does not affect $r s p$ silencing in $w t$ crosses.

When the Homology Spacer vectors are crossed to $w t$ strains, similar levels of silencing are observed compared to the $r^{e f-1370}$ vector. 


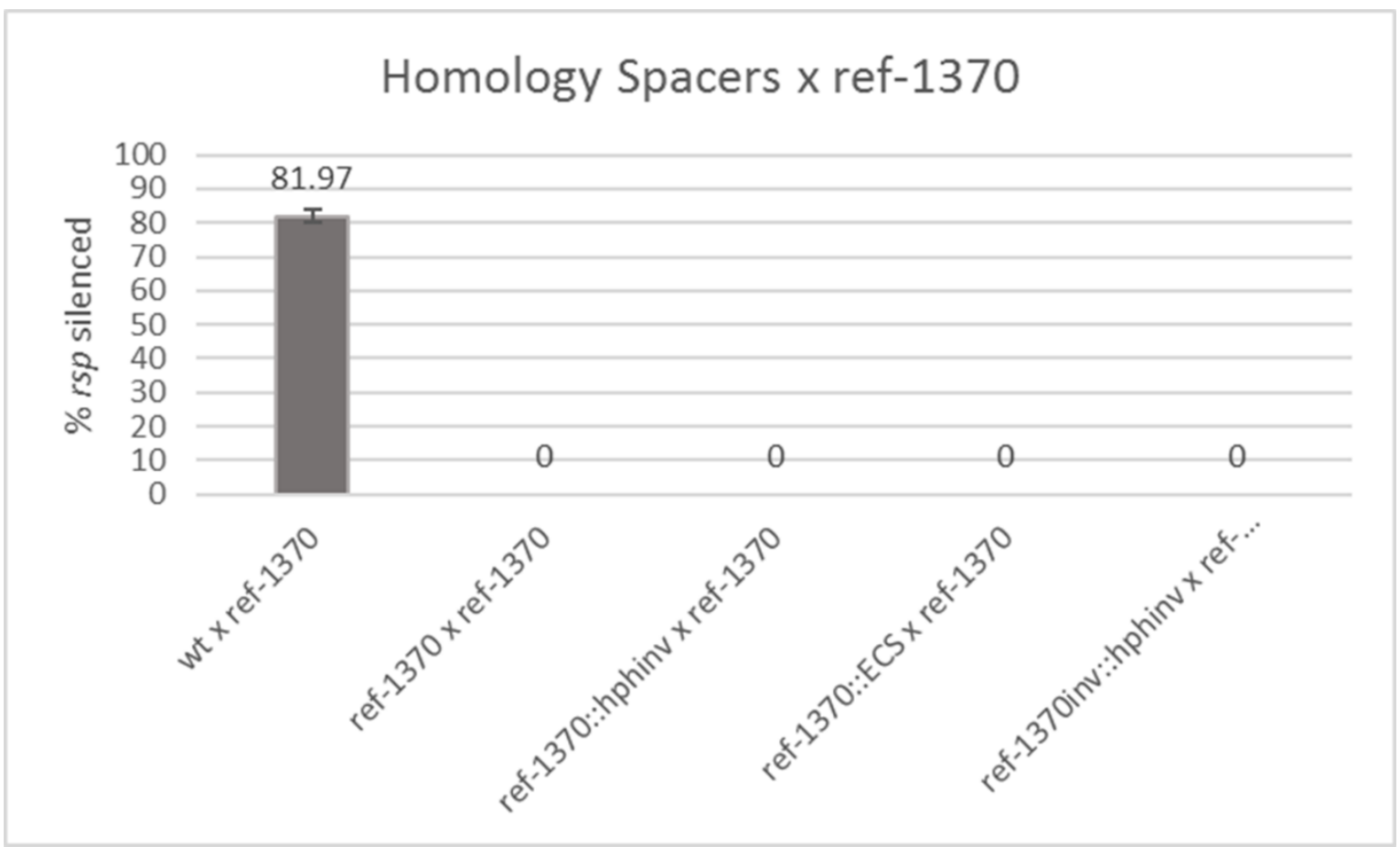

Figure 19: Unpairing the $h p h$ marker does not affect $r s p$ silencing in $r^{e f-1370}$ crosses.

When the Homology Spacer vectors are crossed to $r^{e f-1370}$ strains, similar levels of silencing are observed compared to the $r^{e f-1370}$ vector. 


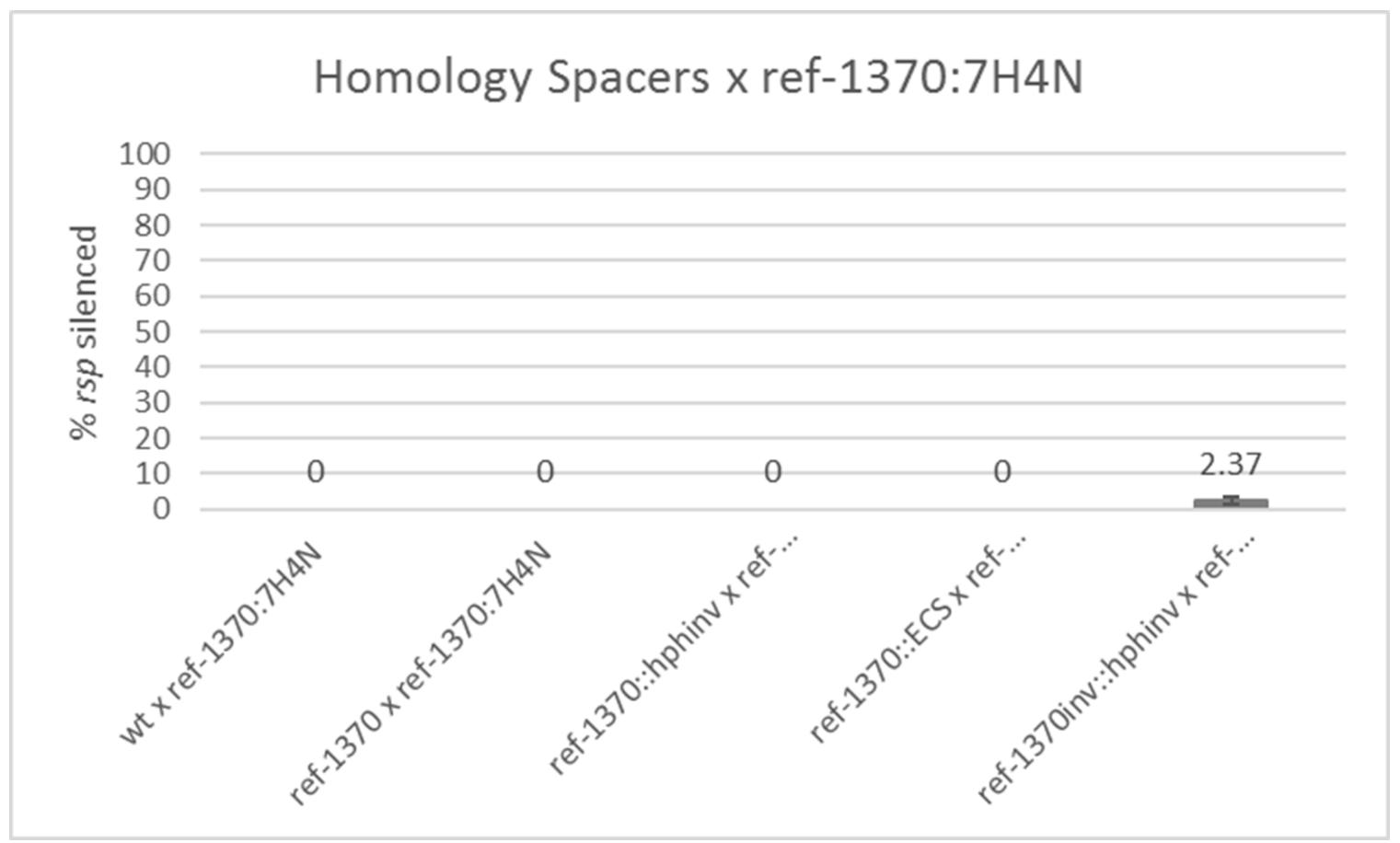

Figure 20: The 7H4N pattern of interspersed homology is not recognized as unpaired.

When the Homology Spacer vectors are crossed to $r^{e f-1370: 7 H 4 N}$ strains, similar levels of silencing are observed compared to the $r^{e f-1370}$ vector even though $r s p$ silencing efficiency is increased in these Spacer vectors. 


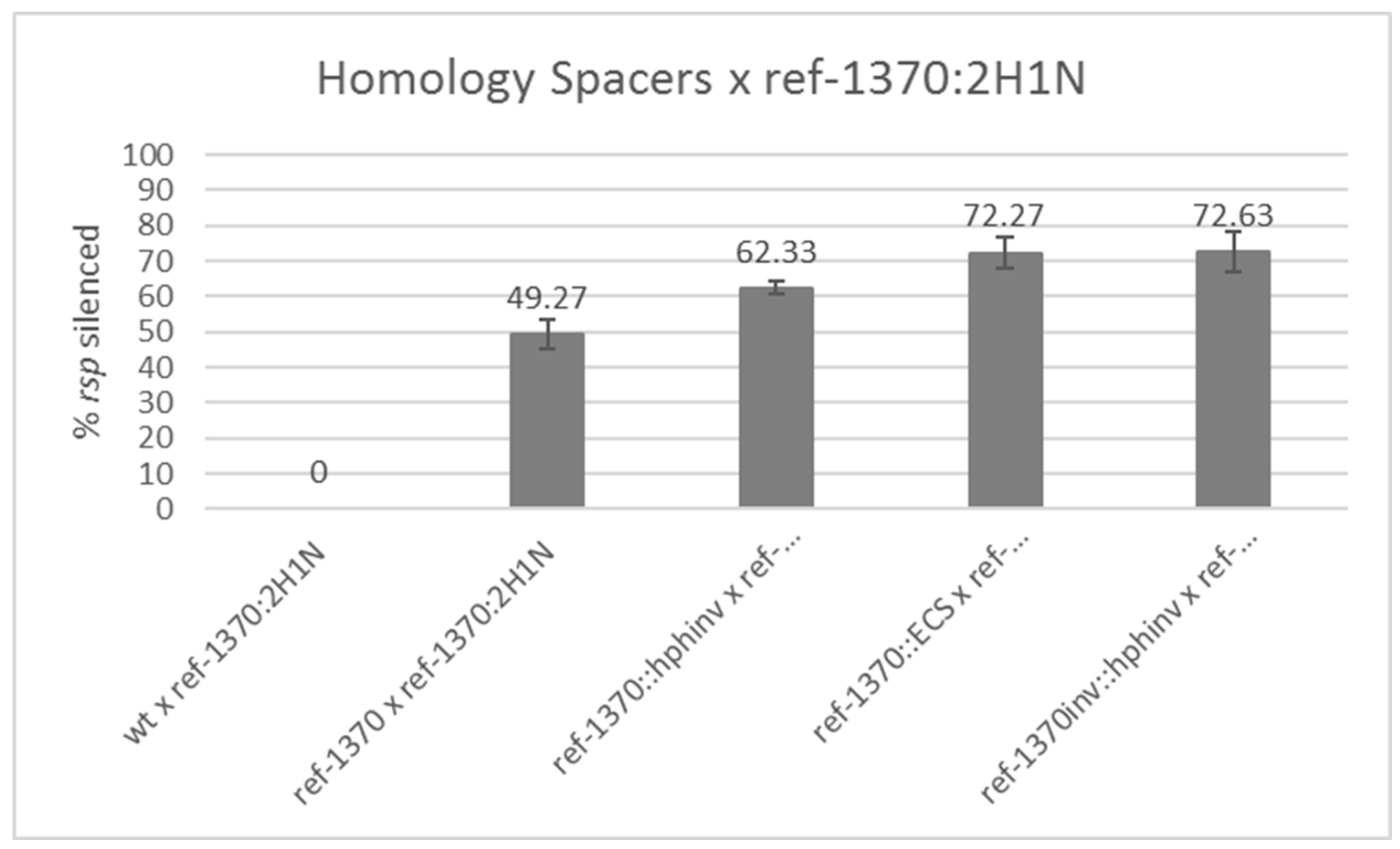

Figure 21: Unpairing the $h p h$ marker increases silencing efficiency in $2 \mathrm{H} 1 \mathrm{~N}$ crosses.

When the Homology Spacer vectors are crossed to $r^{e f-1370: 2 H 1 N}$ strains, significantly higher levels of silencing are observed compared to the $r^{e f-1370}$ vector. 


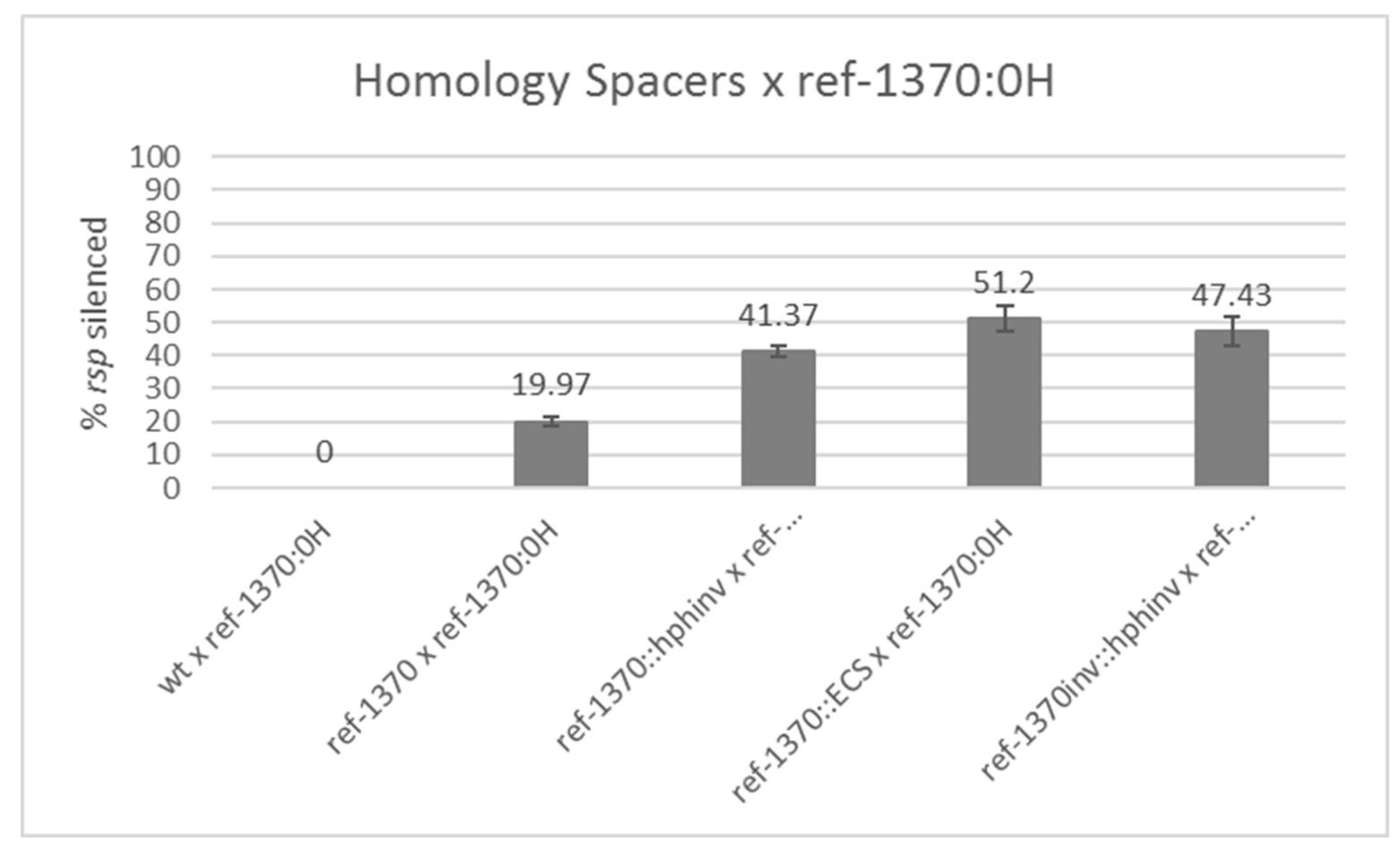

Figure 22: Unpairing the $h p h$ marker increases silencing efficiency in $0 \mathrm{H}$ crosses.

When the Homology Spacer vectors are crossed to $r^{e f-1370: 0 H}$ strains, significantly higher levels of silencing are observed compared to the $r^{e f-1370}$ vector. 

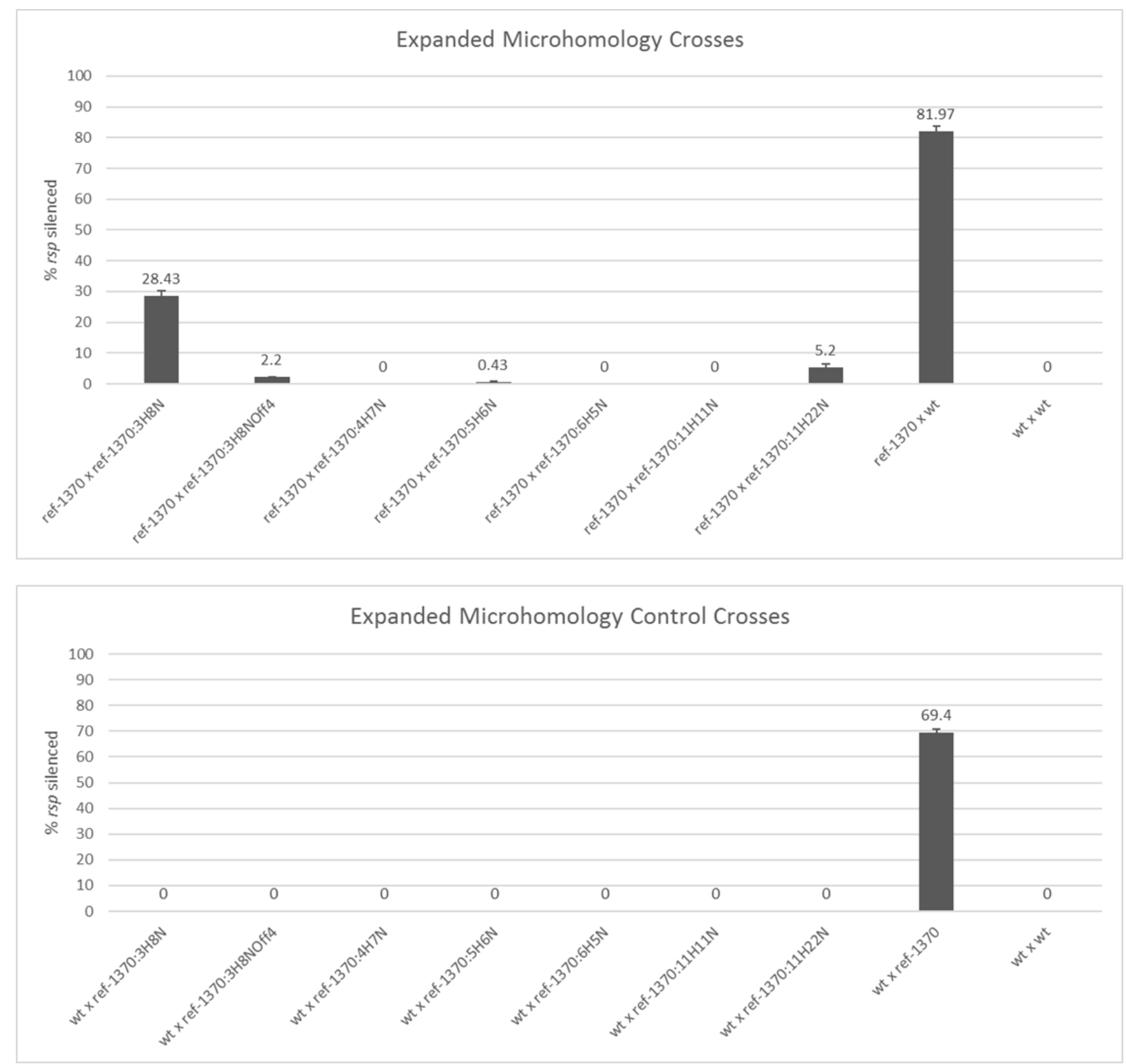

Figure 23: Many patterns of interspersed homology do not trigger silencing

A low level of silencing is shown across all homology patterns examined in this experiment. The $r^{e f-1370: 3 H 8 N}$ fragment shows similar levels of silencing to non-homologous spacer crosses (Figure 16). 

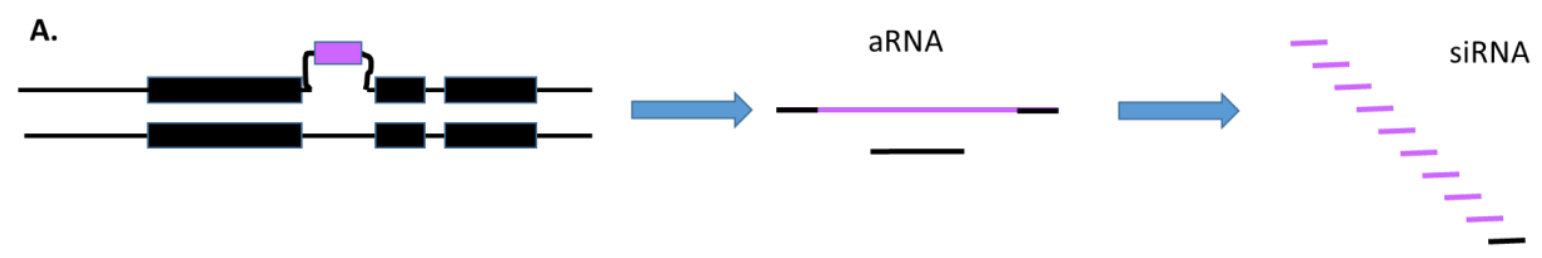

B.
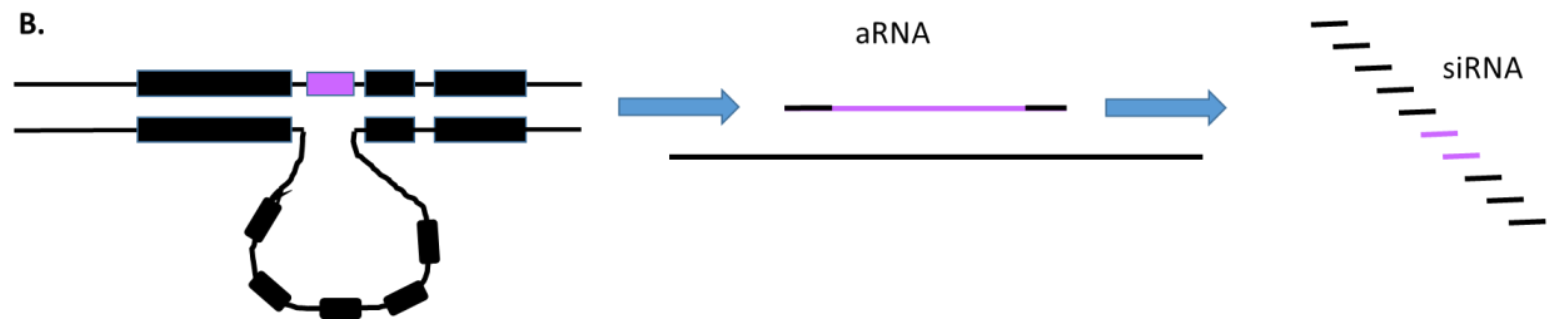

Figure 24: Complex unDNA may dilute siRNA homology

A.) When $r s p$ (purple) is unpaired, the majority of the aRNA sequence will be able to silence $r s p$ mRNAs. B.) Increasing the amount of unpaired DNA (black) surrounding $r s p$ may dilute the percentage of sequence able to silence $r s p$. Purple siRNA molecules represent siRNAs that are able to silence $r s p$. Black siRNA molecules represent siRNAs that do not share sequence homology to $r s p$ mRNAs. 
A.

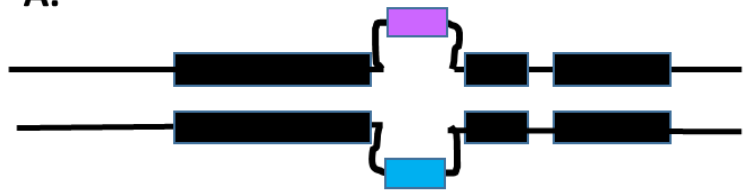

B.

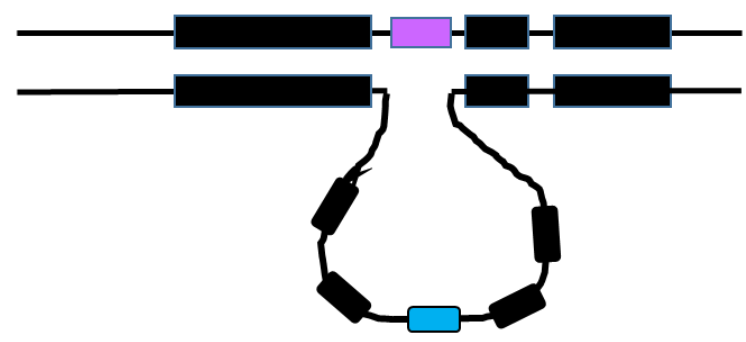

C.

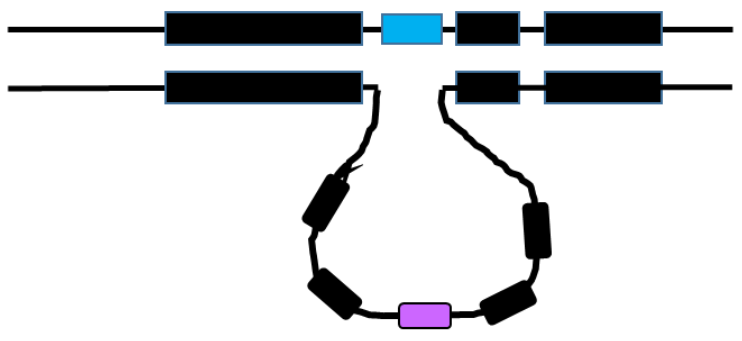

D.

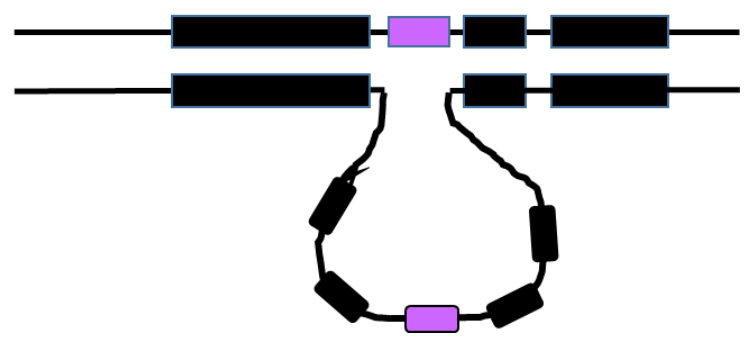

Figure 25: Further experimental conditions

Figure 25 depicts future experimental crosses involving the $r s p$ marker (purple) and the asm-1 marker (blue). 


\section{References}

Bishop DK, Park D, Xu L \& Kleckner N (1992) DMC1: A meiosis-specific yeast homolog of E. coli recA required for recombination, synaptonemal complex formation, and cell cycle progression. Cell 69: 439-456

Cogoni C \& Macino G (1997) Isolation of quelling-defective (qde) mutants impaired in posttranscriptional transgene-induced gene silencing in Neurospora crassa. Proc. Natl. Acad. Sci. U.S.A. 94: 10233-10238

Decker LM, Xiao H, Boone EC, Vierling MM, Shanker BS, Kingston SL, Boone SF, Haynes JB \& Shiu PKT (2017) The Nuclear Cap-Binding Complex Mediates Meiotic Silencing by Unpaired DNA. G3 (Bethesda) 7: 1149-1155

Ding D-Q, Haraguchi T \& Hiraoka Y (2010) From meiosis to postmeiotic events: Alignment and recognition of homologous chromosomes in meiosis. FEBS Journal 277: 565-570

Gladyshev E \& Kleckner N (2016) Recombination-Independent Recognition of DNA Homology for Repeat-Induced Point Mutation (RIP) Is Modulated by the Underlying Nucleotide Sequence. PLOS Genetics 12: e1006015

Gladyshev E \& Kleckner N (2017) DNA sequence homology induces cytosine-to-thymine mutation by a heterochromatin-related pathway in Neurospora. Nat Genet 49: 887-894

Hammond TM, Xiao H, Boone EC, Decker LM, Lee SA, Perdue TD, Pukkila PJ \& Shiu PKT (2013) Novel proteins required for meiotic silencing by unpaired DNA and siRNA generation in Neurospora crassa. Genetics 194: 91-100

Hammond TM, Xiao H, Boone EC, Perdue TD, Pukkila PJ \& Shiu PKT (2011) SAD-3, a Putative Helicase Required for Meiotic Silencing by Unpaired DNA, Interacts with Other Components of the Silencing Machinery. G3 (Bethesda) 1: 369-376

Lisby M, Rothstein R \& Mortensen UH (2001) Rad52 forms DNA repair and recombination centers during S phase. PNAS 98: 8276-8282

Samarajeewa DA, Manitchotpisit P, Henderson M, Xiao H, Rehard DG, Edwards KA, Shiu PKT \& Hammond TM (2017) An RNA Recognition Motif-Containing Protein Functions in Meiotic Silencing by Unpaired DNA. G3 (Bethesda) 7: 2871-2882

Samarajeewa DA, Sauls PA, Sharp KJ, Smith ZJ, Xiao H, Groskreutz KM, Malone TL, Boone EC, Edwards KA, Shiu PKT, Larson ED \& Hammond TM (2014) Efficient detection of unpaired DNA requires a member of the rad54-like family of homologous recombination proteins. Genetics 198: 895-904

Shiu PK, Raju NB, Zickler D \& Metzenberg RL (2001) Meiotic silencing by unpaired DNA. Cell 107: 905-916 
Shiu PKT, Zickler D, Raju NB, Ruprich-Robert G \& Metzenberg RL (2006) SAD-2 is required for meiotic silencing by unpaired DNA and perinuclear localization of SAD-1 RNAdirected RNA polymerase. Proc. Natl. Acad. Sci. U.S.A. 103: 2243-2248

Stacey NJ, Kuromori T, Azumi Y, Roberts G, Breuer C, Wada T, Maxwell A, Roberts K \& Sugimoto-Shirasu K (2006) Arabidopsis SPO11-2 functions with SPO11-1 in meiotic recombination. The Plant Journal 48: 206-216

Stahl F (1996) Meiotic Recombination in Yeast: Coronation of the Double-Strand-Break Repair Model. Cell 87: 965-968

Vogel, H.J. (1956) A Convenient Growth Medium for Neurospora crassa. Microbial Genetics Bulletin, 13, 42-47. - References - Scientific Research Publish Available at: http://www.scirp.org/(S(i43dyn45teexjx455qlt3d2q))/reference/ReferencesPapers.aspx?R eferenceID=1379446 [Accessed August 30, 2017]

Westergaard M \& Mitchell HK (1947) Neurospora V. A Synthetic Medium Favoring Sexual Reproduction. American Journal of Botany 34: 573-577

Yu J-H, Hamari Z, Han K-H, Seo J-A, Reyes-Domínguez Y \& Scazzocchio C (2004) Doublejoint PCR: a PCR-based molecular tool for gene manipulations in filamentous fungi. Fungal Genet. Biol. 41: 973-981

Zickler D (2006) From early homologue recognition to synaptonemal complex formation. Chromosoma 115: $158-174$ 
APPENDIX: PRIMERS USED IN THIS STUDY

\begin{tabular}{|c|c|c|}
\hline Primer & Sequence & Function \\
\hline $\begin{array}{l}\text { Hph- } \\
\text { cen-f }\end{array}$ & $\begin{array}{l}\text { AACTGATATTGAAGGAGCATTTTTTG } \\
\text { G }\end{array}$ & DJ center fragment \\
\hline $\begin{array}{l}\text { Hph- } \\
\text { cen-r }\end{array}$ & AACTGGTTCCCGGTCGGCAT & DJ center fragment \\
\hline $\begin{array}{l}\text { ref- } \\
082914 \\
\text { A }\end{array}$ & ACATCGGCAGTCGCACTATCACC & v0050H construction \\
\hline $\begin{array}{l}\text { ref- } \\
51115 \mathrm{G}\end{array}$ & $\begin{array}{l}\text { AAAAAATGCTCCTTCAATATCAGTTC } \\
\text { CCTCCGTCCСТCACTCATCCT }\end{array}$ & v0050H construction \\
\hline $\begin{array}{l}\text { ref- } \\
51115 \mathrm{H}\end{array}$ & $\begin{array}{l}\text { GAGTAGATGCCGACCGGGAACCAGTT } \\
\text { CGCGACGAAGAGAGATGATTGGA }\end{array}$ & v0050H construction \\
\hline $\begin{array}{l}\text { ref- } \\
082914 \\
\text { D }\end{array}$ & TTTGGGATCAGTTGAATGCTAGGG & v0050H construction \\
\hline $\begin{array}{l}\text { ref- } \\
082914 \\
\text { E }\end{array}$ & CCAGTCTCCAAACCCAAАCССТТC & v0050H construction \\
\hline $\begin{array}{l}\text { ref- } \\
082914 \\
\text { F }\end{array}$ & GGGCACGAAATACCCCAACCTTAC & v0050H construction \\
\hline $\begin{array}{l}\text { ref- } \\
082914 \\
\text { A }\end{array}$ & ACATCGGCAGTCGCACTATCACC & v0051H construction \\
\hline $\begin{array}{l}\text { ref- } \\
051115 \\
\text { I }\end{array}$ & $\begin{array}{l}\text { AAAAAATGCTCCTTCAATATCAGTTC } \\
\text { CCTCCGTCCСТCАСТCATCCT }\end{array}$ & v0051H construction \\
\hline $\begin{array}{l}\text { ref- } \\
051115 \\
\text { J }\end{array}$ & $\begin{array}{l}\text { GAGTAGATGCCGACCGGGAACCAGTT } \\
\text { GAAGAGACACAGCTTGGGCGTCA }\end{array}$ & v0051H construction \\
\hline $\begin{array}{l}\text { ref- } \\
082914 \\
\text { H }\end{array}$ & AGAAGACGGTGGTGGGGAGGAAG & $\begin{array}{l}\text { v0051H construction } \\
\text { (Table Continues) }\end{array}$ \\
\hline
\end{tabular}




\begin{tabular}{|c|c|c|}
\hline Primer & Sequence & Function \\
\hline $\begin{array}{l}\text { ref- } \\
082914 \\
\text { E }\end{array}$ & CCAGTCTCCAAACCCAAACCCTTC & v0051H construction \\
\hline $\begin{array}{l}\text { ref- } \\
082914 \\
\text { I }\end{array}$ & AGTGGCGGGGGAGGAGTAGTCG & v0051H construction \\
\hline $\begin{array}{l}\text { ref- } \\
082914 \\
\text { A }\end{array}$ & ACATCGGCAGTCGCACTATCACC & v0050R construction \\
\hline $\begin{array}{l}\text { ref- } \\
082914 \\
\text { B }\end{array}$ & $\begin{array}{l}\text { AGAGAAGCTCTGCTGCTGCGTTCTGT } \\
\text { CCTCCCTCCGTCCCTCACTCATCCT }\end{array}$ & v0050R construction \\
\hline $\begin{array}{l}\text { ref- } \\
082914 \\
\text { C }\end{array}$ & $\begin{array}{l}\text { TAACGGGTTTCAGGGGTTTCGTTCGC } \\
\text { TGTCGCGACGAAGAGAGATGATTGGA }\end{array}$ & v0050R construction \\
\hline $\begin{array}{l}\text { ref- } \\
082914 \\
\text { D }\end{array}$ & TTTGGGATCAGTTGAATGCTAGGG & v0050R construction \\
\hline $\begin{array}{l}\text { ref- } \\
082914 \\
\text { E }\end{array}$ & CCAGTCTCCAAACCCAAACCCTTC & v0050R construction \\
\hline $\begin{array}{l}\text { ref- } \\
082914 \\
\text { F }\end{array}$ & GGGCACGAAATACCCCAACCTTAC & v0050R construction \\
\hline $\begin{array}{l}\text { ref- } \\
082914 \\
\text { A }\end{array}$ & ACATCGGCAGTCGCACTATCACC & v0051R construction \\
\hline $\begin{array}{l}\text { ref- } \\
082914 \\
\text { B }\end{array}$ & $\begin{array}{l}\text { AGAGAAGCTCTGCTGCTGCGTTCTGT } \\
\text { CCTCCCTCCGTCCCTCACTCATCCT }\end{array}$ & v0051R construction \\
\hline $\begin{array}{l}\text { ref- } \\
082914 \\
\text { G }\end{array}$ & $\begin{array}{l}\text { TAACGGGTTTCAGGGGTTTCGTTCGC } \\
\text { TGTGAAGAGACACAGCTTGGGCGTCA }\end{array}$ & $\begin{array}{l}\text { v0051R construction } \\
\qquad \text { (Table Continues) }\end{array}$ \\
\hline
\end{tabular}




\begin{tabular}{|c|c|c|}
\hline Primer & Sequence & Function \\
\hline $\begin{array}{l}\text { ref- } \\
082914 \\
\mathrm{H}\end{array}$ & AGAAGACGGTGGTGGGGAGGAAG & v0051R construction \\
\hline $\begin{array}{l}\text { ref- } \\
082914 \\
\text { E }\end{array}$ & CCAGTCTCCAAACCCAAACCCТTC & v0051R construction \\
\hline $\begin{array}{l}\text { ref- } \\
082914 \\
\text { I }\end{array}$ & AGTGGCGGGGGAGGAGTAGTCG & v0051R construction \\
\hline $\begin{array}{l}\text { ref- } \\
082914 \\
\text { A }\end{array}$ & ACATCGGCAGTCGCACTATCACC & v0064 construction \\
\hline $\begin{array}{l}\text { ref- } \\
082914 \\
\text { B }\end{array}$ & $\begin{array}{l}\text { AGAGAAGCTCTGCTGCTGCGTTCTGT } \\
\text { ССТCССТCCGTCCСТCACTCATCCT }\end{array}$ & v0064 construction \\
\hline $\begin{array}{l}\text { ref- } \\
051015 \\
\text { V }\end{array}$ & $\begin{array}{l}\text { TAACGGGTTTCAGGGGTTTCGTTCGC } \\
\text { TGTCCCATCAAATTGAAACTTTCCTGC } \\
\mathrm{T}\end{array}$ & v0064 construction \\
\hline $\begin{array}{l}\text { ref- } \\
051015 \\
\text { W }\end{array}$ & TTGAGCGCGACCATCCTTCTTC & v0064 construction \\
\hline $\begin{array}{l}\text { ref- } \\
082914 \\
\text { E }\end{array}$ & CCAGTCTCCAAACCCAAACССТTC & v0064 construction \\
\hline $\begin{array}{l}\text { ref- } \\
051015 \\
X\end{array}$ & CGGTCGTCTGCGGCTTCCT & v0064 construction \\
\hline $\begin{array}{l}\text { ref- } \\
082914 \\
\text { A }\end{array}$ & ACATCGGCAGTCGCACTATCACC & v0065 construction \\
\hline $\begin{array}{l}\text { ref- } \\
082914 \\
\text { B }\end{array}$ & $\begin{array}{l}\text { AGAGAAGCTCTGCTGCTGCGTTCTGT } \\
\text { CCTCCCTCCGTCCСТCACTCATCCT }\end{array}$ & $\begin{array}{l}\text { v0065 construction } \\
\qquad \text { (Table Continues) }\end{array}$ \\
\hline
\end{tabular}




\begin{tabular}{|c|c|c|}
\hline Primer & Sequence & Function \\
\hline $\begin{array}{l}\text { ref- } \\
051015 \\
\text { F }\end{array}$ & $\begin{array}{l}\text { TAACGGGTTTCAGGGGTTTCGTTCGC } \\
\text { TGTTCGGATGGATGGAGGGAGAGATG }\end{array}$ & v0065 construction \\
\hline $\begin{array}{l}\text { ref- } \\
051015 \\
\text { G }\end{array}$ & AGAGGGGCCTGTTGCTGGACTTT & v0065 construction \\
\hline $\begin{array}{l}\text { ref- } \\
082914 \\
\text { E }\end{array}$ & CCAGTCTCCAAACCCAAACCCTTC & v0065 construction \\
\hline $\begin{array}{l}\text { ref- } \\
051015 \\
\text { I }\end{array}$ & TGGAGGGTTCTTGGTGAGGGATT & v0065 construction \\
\hline $\begin{array}{l}\text { ref- } \\
082914 \\
\text { A }\end{array}$ & ACATCGGCAGTCGCACTATCACC & v0066 construction \\
\hline $\begin{array}{l}\text { ref- } \\
082914 \\
\text { B }\end{array}$ & $\begin{array}{l}\text { AGAGAAGCTCTGCTGCTGCGTTCTGT } \\
\text { CCTCCCTCCGTCCCTCACTCATCCT }\end{array}$ & v0066 construction \\
\hline $\begin{array}{l}\text { ref- } \\
051015 \\
\text { L }\end{array}$ & $\begin{array}{l}\text { TAACGGGTTTCAGGGGTTTCGTTCGC } \\
\text { TGTGTGGAAGGTGCAATGGGGTGTC }\end{array}$ & v0066 construction \\
\hline $\begin{array}{l}\text { ref- } \\
051015 \\
M\end{array}$ & GTCGATTTTGGCGTGCAAGGAG & v0066 construction \\
\hline $\begin{array}{l}\text { ref- } \\
082914 \\
\text { E }\end{array}$ & CCAGTCTCCAAACCCAAACCCTTC & v0066 construction \\
\hline $\begin{array}{l}\text { ref- } \\
051015 \\
O\end{array}$ & GCGTCACAAGCAGCACGATCAC & v0066 construction \\
\hline $\begin{array}{l}\text { ref- } \\
051115 \\
\text { A }\end{array}$ & TCCGGGTCAAAGGACTTATCGTTC & $\begin{array}{l}\text { v0067 construction } \\
\qquad \text { (Table Continues) }\end{array}$ \\
\hline
\end{tabular}




\begin{tabular}{|c|c|c|}
\hline Primer & Sequence & Function \\
\hline $\begin{array}{l}\text { ref- } \\
051115 \\
\text { B }\end{array}$ & $\begin{array}{l}\text { AGAGAAGCTCTGCTGCTGCGTTCTGT } \\
\text { CCTGGTGGCAATAGGCATGGGATGT }\end{array}$ & v0067 construction \\
\hline $\begin{array}{l}\text { ref- } \\
051115 \\
\text { C }\end{array}$ & $\begin{array}{l}\text { TAACGGGTTTCAGGGGTTTCGTTCGC } \\
\text { TGTGTCAGTGCCCACCTTCCTGTCT }\end{array}$ & v0067 construction \\
\hline $\begin{array}{l}\text { ref- } \\
051115 \\
\text { D }\end{array}$ & TGGTGTGTGATGTCGTTGTGGTG & v0067 construction \\
\hline $\begin{array}{l}\text { ref- } \\
051115 \\
\mathrm{E}\end{array}$ & TGCAAATCAATAATCACGCCATCTT & v0067 construction \\
\hline $\begin{array}{l}\text { ref- } \\
051115 \\
\text { F }\end{array}$ & GAGTCCGCCATTCGGCTTTACAC & v0067 construction \\
\hline $\begin{array}{l}\text { ref- } \\
082914 \\
\text { A }\end{array}$ & ACATCGGCAGTCGCACTATCACC & v0069 construction \\
\hline $\begin{array}{l}\text { ref- } \\
082914 \\
\text { B }\end{array}$ & $\begin{array}{l}\text { AGAGAAGCTCTGCTGCTGCGTTCTGT } \\
\text { CCTCCCTCCGTCCCTCACTCATCCT }\end{array}$ & v0069 construction \\
\hline $\begin{array}{l}\text { ref- } \\
051015 \\
\text { A }\end{array}$ & $\begin{array}{l}\text { TAACGGGTTTCAGGGGTTTCGTTCGC } \\
\text { TGTGAGTTGCGGGTTGGAAGAAGGAA }\end{array}$ & v0069 construction \\
\hline $\begin{array}{l}\text { ref- } \\
051015 \\
\text { B }\end{array}$ & CTCTTGCTGGCTTGGCGATGTC & v0069 construction \\
\hline $\begin{array}{l}\text { ref- } \\
082914 \\
\text { E }\end{array}$ & CCAGTCTCCAAACCCAAACCCTTC & v0069 construction \\
\hline $\begin{array}{l}\text { ref- } \\
051015 \\
\text { C }\end{array}$ & TGCTACTTCCATCCTTCCGAGCA & $\begin{array}{l}\text { v0069 construction } \\
\qquad \text { (Table Continues) }\end{array}$ \\
\hline
\end{tabular}




\begin{tabular}{|c|c|c|}
\hline Primer & Sequence & Function \\
\hline $\begin{array}{l}\text { ref- } \\
051015 \\
\text { D }\end{array}$ & TCGATGGCATTACGGCAAAGAGA & v0070 construction \\
\hline $\begin{array}{l}\text { ref- } \\
051015 \\
\text { E }\end{array}$ & $\begin{array}{l}\text { AGAGAAGCTCTGCTGCTGCGTTCTGT } \\
\text { CCTTCGTTTTCCTCCCTTGACCACCA }\end{array}$ & v0070 construction \\
\hline $\begin{array}{l}\text { ref- } \\
051015 \\
\text { F }\end{array}$ & $\begin{array}{l}\text { TAACGGGTTTCAGGGGTTTCGTTCGC } \\
\text { TGTTCGGATGGATGGAGGGAGAGATG }\end{array}$ & v0070 construction \\
\hline $\begin{array}{l}\text { ref- } \\
051015 \\
\text { G }\end{array}$ & AGAGGGGCCTGTTGCTGGACTTT & v0070 construction \\
\hline $\begin{array}{l}\text { ref- } \\
051015 \\
\mathrm{H}\end{array}$ & TGTCTACAGGGGATGGTGGCAGT & v0070 construction \\
\hline $\begin{array}{l}\text { ref- } \\
051015 \\
\text { I }\end{array}$ & TGGAGGGTTCTTGGTGAGGGATT & v0070 construction \\
\hline $\begin{array}{l}\text { ref- } \\
051015 \\
\text { J }\end{array}$ & TGGTGGAGAGGAACCAGGATGTG & v0071 construction \\
\hline $\begin{array}{l}\text { ref- } \\
051015 \\
\mathrm{~K}\end{array}$ & $\begin{array}{l}\text { AGAGAAGCTCTGCTGCTGCGTTCTGT } \\
\text { CCTCTGTCTCAGCGCGTCAAGGGTTA }\end{array}$ & v0071 construction \\
\hline $\begin{array}{l}\text { ref- } \\
051015 \\
\text { L }\end{array}$ & $\begin{array}{l}\text { TAACGGGTTTCAGGGGTTTCGTTCGC } \\
\text { TGTGTGGAAGGTGCAATGGGGTGTC }\end{array}$ & v0071 construction \\
\hline $\begin{array}{l}\text { ref- } \\
051015 \\
\text { M }\end{array}$ & GTCGATTTTGGCGTGCAAGGAG & v0071 construction \\
\hline $\begin{array}{l}\text { ref- } \\
051015 \\
\mathrm{~N}\end{array}$ & GGCGAGGTGGAAAGGGTTAGCA & $\begin{array}{l}\text { v0071 construction } \\
\qquad \text { (Table Continues) }\end{array}$ \\
\hline
\end{tabular}




\begin{tabular}{|c|c|c|}
\hline Primer & Sequence & Function \\
\hline $\begin{array}{l}\text { ref- } \\
051015 \\
O\end{array}$ & GCGTCACAAGCAGCACGATCAC & v0071 construction \\
\hline $\begin{array}{l}\text { ref- } \\
051015 \\
P\end{array}$ & CCATTACCGAACCCCACGATCC & v0072 construction \\
\hline $\begin{array}{l}\text { ref- } \\
051015 \\
Q\end{array}$ & $\begin{array}{l}\text { AGAGAAGCTCTGCTGCTGCGTTCTGT } \\
\text { CCTCCCATTAGAAGACCGCCCCAAG }\end{array}$ & v0072 construction \\
\hline $\begin{array}{l}\text { ref- } \\
082914 \\
\text { C }\end{array}$ & $\begin{array}{l}\text { TAACGGGTTTCAGGGGTTTCGTTCGC } \\
\text { TGTCGCGACGAAGAGAGATGATTGGA }\end{array}$ & v0072 construction \\
\hline $\begin{array}{l}\text { ref- } \\
082914 \\
\text { D }\end{array}$ & TTTGGGATCAGTTGAATGCTAGGG & v0072 construction \\
\hline $\begin{array}{l}\text { ref- } \\
051015 \\
\text { R }\end{array}$ & TTCAACAAGGACGCCAGGACAA & v0072 construction \\
\hline $\begin{array}{l}\text { ref- } \\
082914 \\
\text { F }\end{array}$ & GGGCACGAAATACCCCAACCTTAC & v0072 construction \\
\hline $\begin{array}{l}\text { ref- } \\
051015 \\
\text { S }\end{array}$ & CCCCGAAGGTGTTGACGTTCCT & v0073 construction \\
\hline $\begin{array}{l}\text { ref- } \\
051015 \\
T\end{array}$ & $\begin{array}{l}\text { AGAGAAGCTCTGCTGCTGCGTTCTGT } \\
\text { CCTTTTGCATTCGCTGTCACATCAGC }\end{array}$ & v0073 construction \\
\hline $\begin{array}{l}\text { ref- } \\
082914 \\
\text { G }\end{array}$ & $\begin{array}{l}\text { TAACGGGTTTCAGGGGTTTCGTTCGC } \\
\text { TGTGAAGAGACACAGCTTGGGCGTCA }\end{array}$ & v0073 construction \\
\hline $\begin{array}{l}\text { ref- } \\
082914 \\
\text { H }\end{array}$ & AGAAGACGGTGGTGGGGAGGAAG & $\begin{array}{l}\text { v0073 construction } \\
\qquad \text { (Table Continues) }\end{array}$ \\
\hline
\end{tabular}




\begin{tabular}{|l|l|l|}
\hline Primer & Sequence & Function \\
\hline $\begin{array}{l}\text { ref- } \\
\text { U }\end{array}$ & GGCCGCGTTACCAAGAGGATCA & v0073 construction \\
\hline $\begin{array}{l}\text { ref- } \\
082914\end{array}$ & AGTGGCGGGGGAGGAGTAGTCG & v0073 construction \\
I & & \\
\hline his3- & GAGGGAGTGTGGGAAATGGTGTC & His-3 Insertion Screen \\
102113 & & \\
F & & \\
\hline his3- & GTTGGTTAGGTGGGAAACGCTTGT & His-3 Insertion Screen \\
102113 & & \\
R & & \\
\hline
\end{tabular}

